NBL -267

Distribution Category UC-4

UNITED STATES ATOMIC ENERGY COMMISSION

\title{
ANNUAL PROGRESS REPORT FOR THE PERIOD JULY 1972 THROUGH JUNE 1973
}

AEC Research and Development Report

NEW BRUNSWICK LABORATORY

Carleton D. Bingham, Director

NOTICE

This report was prepared as an account of work sponsored by the United States Government. Neithe the United States nor the United States Atomic Energy Commission, nor any of their employees, nor any of their contractors, subcontractors, or their employees, makes any warranty, express or implied, or assumes any legal liability or responsibility for the accuracy, completeness or usefulness of any information, apparatus, product or process disclosed or represents that its use would not infringe privately owned rights.
This document is PUBLICLY RELEASABLR CF. Authorizing Qfficial Date: $8 \longdiv { 7 0 8 }$

September 1973 


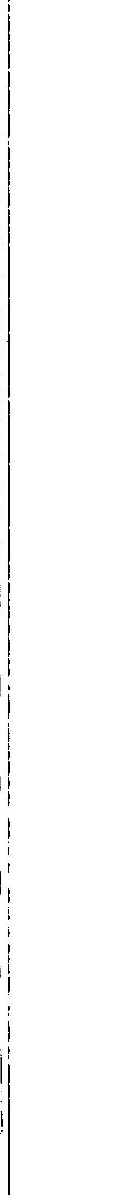


TABLE OF CONTENTS

Page No.

ABSTRACTS . . . . . . . . . . . . . . . . . . . . . . . . 1

THE EFFECT OF IMPURITIES ON THE NEW BRUNSWICK LABORATORY TITRIMETRIC METHOD OF DETERMINING URANIUM. II. PLATINUM METALS, CHLORIDE AND BROMIDE

J. M. Scarborough and L. Z. Bodnar . . . . . . . . . . 6

THE EFFECT OF IMPURITIES ON THE NEW BRUNSWICK LABORATORY TITRIMETRIC METHOD OF DETERMINING URANIUM. III. FLUORIDE

L. Z. Bodnar and J. M. Scarborough . . . . . . . . . . 13

THE EFFECT OF IMPURITIES ON THE NEW BRUNSWICK LABORATORY TITRIMETRIC METHOD OF DETERMINING URANIUM. IV. HYDROGEN PEROXIDE

J. M. Scarborough . . . . . . . . . . . . . . . . . .17

ELIMINATION OF SOME INTERFERENCES IN THE NEW BRUNSWICK LABORATORY TITRIMETRIC URAN IUM METHOD BY MEANS OF A COPPER COLUMN

L. Z. Bodnar, J. M. Scarborough and M. W. Lerner. . . 19

APPLICATION OF THE RADIOMETER TITRATOR MODEL TTT2

TO THE NEW BRUNSWICK LABORATORY TITRIMETRIC METHOD

OF DETERMINING URANIUM

L. Z. Bodnar and J. M. Scarborough . . . . . . . . . . 22

EVALUATION OF AN AUTOMATIC URANIUM ANALYZER BASED UPON CONSTANT CURRENT COULOMETRY - A PROGRESS REPORT

C. G. Goldbeck, M. W. Lerner and G. E. Peoples . . . . 29

DETERMINATION OF URANIUM IN URANIUM-THORIUM SOLUTIONS BY CONTROLLED-POTENTIAL COULOMETRY AT A MERCURY POOL ELECTRODE

K. Lewis . . . . . . . . . . . . . . . . . . . . . . 32

CONTROLLED-POTENTIAL COULOMETRIC DETERMINATION OF URANIUM WITH A PLATINUM ELECTRODE AFTER REDUCTION WITH IRON(II) IN PHOSPHORIC ACID

K. Lewis and M. W. Lerner . . . . . . . . . . . . . . 35

X-RAY SPECTROGRAPHIC DETERM INATION OF URANIUM IN LOW-GRADE SAMPLES BY A LITHIUM TETRABORATE FUSION TECHNIQUE - A PROGRESS REPORT

A. J. Busch and C. G. Goldbeck . . . . . . . . . . . . 36

NON-DESTRUCTIVE ANALYSIS OF LOW-GRADE URANIUM SAMPLES BY A PASSIVE GAMMA-RAY TECHN IQUE

R. C. Hagenauer, C. L. Zyskowski and L. C. Nelson, Jr. 40 
Page No.

DETERMINATION OF URANIUM-235 BY A DELAYED NEUTRON

COUNTING TECHNIQUE

R. C. Hagenauer, C. L. Zyskowski and L. C. Nelson, Jr.

PREPARATION OF TEST MATERIALS FOR AN INTERLABORATORY

CALIFORNIUM-252 ACTIVATION ANALYSIS EVALUATION PROGRAM

N. M. Trahey, J. M. Scarborough and L. Z. Bodnar. . . . 56

ATOMIC ABSORPTION SPECTROPHOTOMETRIC DETERMINATION OF

MERCURY IN TEST MATERIALS FOR THE CALIFORNIUM-252

EVALUATION PROGRAM

R. L. Graff . . . . . . . . . . . . . . . . . 67

DETERMINATION OF THORIUM IN URANIUM-THORIUM MIXTURES

J. M. Scarborough . . . . . . . . . . . . . . . . . . . 70

DISSOLUTION OF PYROCARBON- AND SILICON CARBIDE-COATED

URANIUM-THORIUM CARBIDE FUEL BEADS - CHLORINATION AND

FUSION DISSOLUTIONS

C. E. Hedrick . . . . . . . . . . . . . . . . . . . 75

SUMMARY OF AN INTERLABORATORY COMPARISON PROGRAM ON THE

ANALYSIS OF PYROCARBON- AND SILICON CARBIDE-COATED

URANIUM-THORIUM CARBIDE BEADS

C. D. Bingham and J. Whichard . . . . . . . . . . . . . 80

MASS SPECTROMETRIC ISOTOPE DILUTION DETERMINATION OF

URANIUM AND PLUTONIUM - VOLUMETRIC VS GRAVIMETRIC

TECHNIQUES FOR PREPARING THE ISOTOPE MIXTURES

A. W. Wenzel, P. C. Puleio, R. J. Greer, G. E. Peoples,

J. R. Weiss and C. E. Pietri . . . . . . . . . .

A FOCAL PROGRAMMING SYSTEM FOR AN ISOTOPE RATIO MASS

SPECTROMETER LABORATORY

L. C. Nelson, Jr. . . . . . . . . . . . . . . . . . . . 84

DETERMINATION OF SENSITIVITY FACTORS FOR THE SPARK

SOURCE MASS SPECTROMETER

E. L. Callis . . . . . . . . . . . . . . . . . . . . . 86

SPARK SOURCE MASS SPECTROGRAPHIC DETERMINATION OF

IMPURITIES IN URANIUM HEXAFLUORIDE - A PROGRESS REPORT

E. L. Callis . . . . . . . . . . . . . . . . 9 93

EVALUATION OF THE FABRY-PEROT INTERFERENCE SPECTROMETER

FOR URANIUM ISOTOPIC ANALYSIS - A STATUS REPORT

H. G. Yuster . . . . . . . . . . . . . . . . . 94

A CENTRAL ANNUNCIATOR PANEL FOR THE NEW - BRUNSWICK

LABORATORY - A PROGRESS REPORT

R. J. Hemmer . . . . . . . . . . . . . . . . . . . . . 96

AN AUTOMATED MINI ION-EXCHANGE AND COULOMETRY SYSTEM -

A PROGRESS REPORT

J. R. Weiss, A. W. Wenzel and C. E. Pietri . . . . . . 101 
CALCULATION OF HYDROGEN GENERATION FROM PLUTONIUMINDUCED RADIOLYSIS OF NITRIC, SULFURIC AND PERCHLORIC ACIDS

J. R. Weiss and C. E. Pietri. . . . . . . . . . 105

A GENERAL ANALYTICAL EVALUATION (GAE) PROGRAM FOR URANIUM HEXAFLUORIDE

C. D. Bingham . . . . . . . . . . . . . . . . . . . . 107

A TENTATIVE METHOD FOR THE SPECTROCHEMICAL DETERMINATION OF MERCURY AND ARSENIC IN A SYNTHETIC ENVIRONMENTAL TEST MATER IAL

H. G. Yuster . . . . . . . . . . . . . . . . . . . . . 109

BACKGROUND CORRECTION IN EMISSION SPECTROSCOPY

H. G. Yuster . . . . . . . . . . . . . . . . . . . . . 112 
$$
1
$$

$L$

-



r
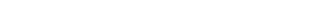


\section{DISCLAIMER}

This report was prepared as an account of work sponsored by an agency of the United States Government. Neither the United States Government nor any agency Thereof, nor any of their employees, makes any warranty, express or implied, or assumes any legal liability or responsibility for the accuracy, completeness, or usefulness of any information, apparatus, product, or process disclosed, or represents that its use would not infringe privately owned rights. Reference herein to any specific commercial product, process, or service by trade name, trademark, manufacturer, or otherwise does not necessarily constitute or imply its endorsement, recommendation, or favoring by the United States Government or any agency thereof. The views and opinions of authors expressed herein do not necessarily state or reflect those of the United States Government or any agency thereof. 


\section{DISCLAIMER}

Portions of this document may be illegible in electronic image products. Images are produced from the best available original document. 


\section{ABSTRACTS}

The Effect of Impurities on the New Brunswick Laboratory Titrimetric Method of Determining Uranium. II. Platinum Metals, Chloride and Bromide

Most platinum metals, chloride and bromide in certain concentrations interfere with the NBL titrimetric method for uranium. The elimination of the interferences is discussed.

The Effect of Impurities on the New Brunswick Laboratory Titrimetric Method of Determining Uranium. III: Fluoride

Fluoride above certain concentrations has been shown to interfere with the NBL titrimetric method for uranium. The interference can be eliminated by an evaporation step or by complexing prior to the determination of uranium.

The Effect of Impurities on the New Brunswick Laboratory Titrimetric Method of Determining Uranium. IV. Hydrogen Peroxide

The interference of hydrogen peroxide in the NBL titrimetric method of determining uranium has been shown to be due to the depletion of the ferrous ion reductant in the procedure.

Elimination of Some Interferences in the New Brunswick Laboratory Titrimetric Uranium Method by Means of a Copper Column

The interference of mercury, platinum and palladium in the NBL titrimetric method for uranium can be eliminated by a copper column technique.

Application of the Radiometer Titrator Model TTT2 to the New Brunswick Laboratory Titrimetric Method of Determining Uranium

The Radiometer Titrator TTT2, a commercially available instrument that automatically titrates a solution to a preselected potential or $\mathrm{pH}$, was evaluated for its applicability to the NBL method of determining uranium.

Evaluation of an Automatic Uranium Analyzer Based Upon Constant Current Coulometry - A Progress Report

Evaluation of the automatic uranium analyzer based upon the constant-current generation of vanadium(V) has revealed several modifications that were needed to improve the reliability of results. An unknown factor responsible for slightly negative errors still exists. 
Determination of Uranium in Uranium-Thorium Solutions by ControlledPotential Coulometry at a Mercury pool Electrode

Uranium in uranium dioxide-thorium dioxide mixtures was determined by controlled-potential coulometry at a mercury pool electrode. The proposed procedure is described.

Controlled-Potential Coulometric Determination of Uranium with a platinum Electrode After Reduction with Iron(II) in Phosphoric Acid

After reduction to uranium(IV) by the Davies and Gray procedure, uranium can be determined by controlled-potential coulometry with a platinum electrode by allowing it to react with iron(III) prior to the coulometry. Determinations of 5 to $10 \mathrm{mg}$ of uranium show a relative standard deviation of within $0.1 \%$.

X-Ray Spectrographic Determination of Uranium in Low-Grade Samples by a Lithium Tetraborate Fusion Technique - A Progress Report

$X$-ray spectrography has been applied to the determination of uranium in low-grade residue samples. The tentative method proposed involves the use of a lithium tetraborate fusion. The experimental details and some comparative results are presented.

Non-Destructive Analysis of Low-Grade Uranium Samples by a Passive Gamma-Ray Technique

Non-Destructive analys is of low-grade uranium samples has been carried out by gamma-ray spectrometry. Correction for selfabsorption was made by a ytterbium-169 technique. The results obtained for a number of analytical samples were compared to the chemical results.

Determination of Uranium-235 by a Delayed Neutron Counting Technique

Determination of uranium-235 in uranium dioxide-thorium dioxide mixtures and pyrocarbon- and silicon carbide-coated uranium-thorium carbide fuel beads has been carried out by bombarding with thermal neutrons and counting the delayed neutrons arising from fission of the uranium-235. The precision and accuracy of some results are given.

Preparation of Test Materials for an Interlaboratory Californium252 Activation Analysis Evaluation Program

To evaluate the general applicability of californium-252 as a neutron source for activation analysis, an interlaboratory program was designed by Savannah River Operations involving the analysis of two materials: a $2 \mathrm{~N}$ nitric acid solution; and a $70 \%$ silica, $20 \%$ iron oxide, $10 \%$ calcium carbonate mixture, both containing 13 elements at various levels. Details of the preparation and characterization of these test materials, carried out by NBL, are described. 
Atomic Absorption Spectrophotometric Determination of Mercury in Test Materials for the Californium-252 Evaluation program

Difficulty in the atomic absorption spectrophotometric determination of mercury in the test materials for the californium252 evaluation program was traced to the presence of mercury(I) in the solutions for analysis.

Determination of Thorium in Uranium-Thorium Mixtures

Thorium in uranium-thorium mixtures is determined by a direct EDTA titration. The results are compared to those obtained by the conventional gravimetric procedure.

Dissolution of Pyrocarbon- and Silicon Carbide-Coated UraniumThorium Carbide Fuel Beads - Chlorination and Fusion Dissolutions

Studies on the dissolution of pyrocarbon- and silicon carbidecoated uranium-thorium carbide nuclear fuel beads by fusion techniques were continued. Also studied was a high-temperature chlorination technique. A proposed chlorination procedure is described.

Summary of an Interlaboratory Comparison Program on the Analysis of Pyrocarbon- and Silicon Carbide-Coated Uranium-Thorium Carbide Beads

NBL conducted an interlaboratory comparison program on the analysis of pyrocarbon- and silicon carbide-coated uranium-thorium carbide nuclear fuel beads. Samples of the beads from a single production lot, and synthetic uranium dioxide-thorium dioxide mixtures were analyzed for uranium by 3 laboratories by nondestructive assay techniques, and for uranium and thorium by 7 laboratories by destructive chemical procedures. The evaluation will be given in a separate report.

Mass Spectrometric Isotope Dilution Determination of Uranium and plutonium - Volumetric vs Gravimetric Techniques for Preparing the Isotope Mixtures

The precisions of mass spectrometric isotope dilution assays of uranium and plutonium using volumetric and gravimetric preparation of the sample-tracer mixtures were compared. The preparations made by volume additions gave results essentially as precise as those made by weighing.

A FOCAL Programming System for an Isotope Ratio Mass Spectrometer Laboratory

The addition of three external FOCAL functions to enable the use of an analog to digital converter, a real time clock and a relay buffer-driver has permitted the use of the FOCAL programming system to operate the mass spectrometer installation that was formerly operated under a fixed assembly language system. The function routines, their operation and application are described. 
Determination of Sensitivity Factors for the Spark Source Mass Spectrometer

Relative sensitivity factors for 70 elements in a graphite matrix were determined for a spark source mass spectrometer with electrical detection. A log-ratio scanning technique was used which yielded an average relative standard deviation of $\pm 29 \%$ for an individual determination. By means of these factors, $\mathrm{U}_{3} \mathrm{O}_{8}$ and a synthetic mineral spiked with impurities were analyzed.

Spark Source Mass Spectrographic Determination of Impurities in Uranium Hexafluoride - A Progress Report

Progress on the development of a technique for the determination of volatile impurities in uranium hexafluoride by spark source mass spectrometry is described.

Evaluation of the Fabry-Perot Interference Spectrometer for Uranium Isotopic Analysis - A Status Report

Modifications are being made in a procedure previously described for the determination of uranium isotopic abundance by means of the Fabry-Perot interference spectrometer. These changes should speed up the analysis and may improve the precision of the results.

A Central Annunciator Panel for the New Brunswick Laboratory - A Progress Report

The various NBL alarm systems have been consolidated into one master panel in the main building with a repeater panel in the other building. The various alarms are given one of three priorities indicated by the color of the lighted display and by a distinct audio signal. The system has been in partial operation for several months.

An Automated Mini Ion-Exchange and Coulometry system - A Progress Report

To provide greater productivity two related automated systems for the determination of plutonium are under development: the ion-exchange separation of plutonium from interferences by mini-columns; the controlled-potential coulometric determination of the separated plutonium. The projects are described, their advantages are enumerated, and the status of the fabrication is outlined.

Calculation of Hydrogen Generation from plutonium-Induced Radiolysis of Nitric, Sulfuric and Perchloric Acids

Modifications were made to an existing equation so that the hydrogen produced by radiolysis in aqueous acidic solutions of plutonium can be calculated. The calculations show that storage of plutonium in high concentrations of $\mathrm{HNO}_{3}$ produces a smaller quantity of hydrogen than storage in $\mathrm{H}_{2} \mathrm{SO}_{4}$ or $\mathrm{HClO}_{4}$ solution. The explosion hazard thus is minimized in $\mathrm{HNO}_{3}$ solution. 
A General Ana 1ytical Evaluation (GAE) Program for Uranium Hexafluoride

A new GAE program for uranium hexafluoride has been started. Phase I involving the determination of uranium content and isotopic abundance began June 1,1973 with 20 laboratories including 11 foreign laboratories participating.

A Tentative Method for the Spectrochemical Determination of Mercury and Arsenic in a Synthetic Environmental Test Material

Existing $\mathrm{U}_{3} \mathrm{O}_{8}$ standards were used to determine mercury and arsenic in a synthetic $70 \%$ silica, $20 \%$ ferric oxide, $10 \%$ calcium carbonate matrix material containing impurities at various levels for a californium-252 evaluation program. Standards with this matrix alone were difficult to prepare. The results by the proposed procedure are compared to the quantities originally added and to the results obtained by spectrophotometric determinations.

Background Correction in Emission Spectroscopy

A simple equation is presented for correcting line intensity for background effects. 


\begin{abstract}
THE EFFECT OF IMPURITIES ON THE NEW BRUNSWICK LABORATORY TITRIMETRIC METHOD OF DETERMINING URANIUM. II . PLATINUM METALS, CHLORIDE AND BROMIDE
\end{abstract}

J. M. Scarborough and L. Z. Bodnar

Previous reports ${ }^{1-3}$ have discussed the interference of elements such as manganese, vanadium and mercury on the New Brunswick Laboratory (NBL) titrimetric method of determining uranium. Since these reports were issued, a systematic study of the effect of all possible impurities was undertaken, and the non-interference of copper, titanium, cobalt, nickel, cerium and samarium was demonstrated. 4 In the present work, this comprehensive. study has been continued with the platinum metals, chloride and bromide.

\title{
EXPERIMENTAL
}

Reagents and Apparatus

The reagents and apparatus for the uranium determination are identical to those described in reference (1) with the exception that: (1) $100 \mathrm{mg}$ of solid vanadyl sulfate dihydrate is used in place of the $10 \mathrm{ml}$ of $0.05 \mathrm{M}$ vanadyl solution in the dilution step before titration; (2) a small amount, $1 \mathrm{ml}$, of $0.03 \mathrm{~N}$ potassium dichromate is added to the $\mathrm{H}_{3} \mathrm{PO}_{4}$ before it is used $5 \frac{7}{;}$ (3) water is used as the diluent instead of 1 M $\mathrm{H}_{2} \mathrm{SO}_{4}$.

Uranium Standard Solution, prepared from NBL dingot uranium.

Ruthenium Standard Solution, $10 \mathrm{mg} \mathrm{Ru} / \mathrm{ml}$. Dissolve $2.1 \mathrm{~g}$ of $\mathrm{RuCl}_{3}$ in $5 \mathrm{ml} \mathrm{HCl}$ and dilute the solution to $100 \mathrm{ml}$.

Rhodium Standard Solution, $8.0 \mathrm{mg} / \mathrm{ml}$. Dissolve $1.0 \mathrm{~g}$ of $\mathrm{RhCl}_{3} \cdot 3 \cdot \mathrm{H}_{2} \mathrm{O}$ in water and dilute to $50 \mathrm{ml}$.

Palladium Standard Solution, $10 \mathrm{mg} / \mathrm{ml}$. Dissolve $1.7 \mathrm{~g}$ of $\mathrm{PdCl}_{2}$ in $30 \mathrm{ml}$ of aqua regia; evaporate the solution to dryness, dissolve the residue in a small amount of $9 \underline{\mathrm{M}} \mathrm{H}_{2} \mathrm{SO}_{4}$ and dilute the solution to $100 \mathrm{ml}$ with water.

Osmium Standard Solution, $10 \mathrm{mg} / \mathrm{ml}$. Dissolve $0.85 \mathrm{~g}$ of $\mathrm{OsCl}_{3} \cdot 1.5 \mathrm{H}_{2} \mathrm{O}$ in a few milliliters of dilute $\mathrm{HCl}$, and dilute the solution to $50 \mathrm{ml}$ with water.

Ir idium Standard Solution, $10 \mathrm{mg} / \mathrm{ml}$. Dissolve $0.92 \mathrm{~g}$ of $\mathrm{IrCl}_{3} \cdot 3 \cdot \mathrm{H}_{2} \mathrm{O}$ in $6 \mathrm{ml}$ of $\mathrm{HCl}$, and dilute the solution to $50 \mathrm{ml}$ with water. 
Platinum Standard Solution, (1) $1.0 \mathrm{mg} / \mathrm{ml}$. Dissolve $0.25 \mathrm{~g}$ of $\mathrm{K}_{2} \mathrm{PtCl}_{6}$ in water containing a few drops of $\mathrm{HCl}$ and dilute the solution to $100 \mathrm{ml}$ with water.

(2) $10 \mathrm{mg} / \mathrm{ml}$. Dissolve $0.50 \mathrm{~g}$ of platinum metal in aqua regia. Evaporate the solution to dryness; add $20 \mathrm{ml} \mathrm{HNO}_{3}$ and evaporate to dryness; add $5 \mathrm{ml} \mathrm{H}_{2} \mathrm{SO}_{4}$ and a small amount of water and fume nearly to dryness; add $5 \mathrm{ml} \mathrm{H} \mathrm{H}_{2} \mathrm{SO}_{4}$ and a small amount of water together with $15 \mathrm{ml}$ of $\mathrm{H}_{3} \mathrm{PO}_{4}$, heat until the solution is clear, and dilute to $50 \mathrm{ml}$ with water.

Chloride Standard Solution, $2.0 \mathrm{mg} / \mathrm{ml}$. Dissolve $0.33 \mathrm{~g}$ of $\mathrm{NaCl}$ in water and dilute the solution to $100 \mathrm{ml}$ with water. For tests with higher concentration of chloride, use $\mathrm{HCl}$.

Bromide Standard Solution, $4.0 \mathrm{mg} / \mathrm{ml}$. Dissolve $0.52 \mathrm{~g}$ of $\mathrm{NaBr}$ in water and dilute the solution to $100 \mathrm{ml}$ with water.

\section{Procedure}

Transfer to a 400-ml beaker a weighed aliquot of a uranium standard solution containing about $100 \mathrm{mg}$ of uranium. In the case of the platinum group, add the appropriate quantity of standard solution of the individual platinum metal plus 2 to $5 \mathrm{ml}$ of $9 \mathrm{M}$ $\mathrm{H}_{2} \mathrm{SO}_{4}$, and heat the solution to strong fumes of $\mathrm{SO}_{3}$ to remove any chloride ion. Cool the solution and dilute to $15 \mathrm{ml}$ with water before determining the uranium. In the halogen tests, add the appropriate quantity of halogen standard solution to the weighed aliquot of standard uranium solution and adjust the combined volume by dilution to $15 \mathrm{ml}$ prior to the uranium determination. After 1 to 3 tests as indicated above, routinely determine the uranium in a weighed aliquot of the uranium standard solution containing no impurity to be assured of the proper functioning of the electrode system.

\section{RESULTS AND DISCUSSION}

\section{Interference Effects}

The data presented in Table I demonstrate the type and magnitude of the effects given by the platinum group elements. All the data obtained in the study are not shown; data sufficient to indicate the general effects are presented.

From Table I it can be seen that ruthenium, palladium, osmium, iridium and platinum cause serious positive errors in the determination of uranium by the NBL titrimetric method. Rhodium alone among the platinum metals does not cause any significant error.

Additional studies with platinum proved to be interesting. In another series of tests, not included in Table I, different results were obtained when a platinum solution prepared as described under platinum Standard Solution (2) was used. When this platinum solution was tested, the uranium results were consistently low. In a typical experiment, $10 \mathrm{mg}$ of platinum produced about a $-0.5 \%$ error. This anamolous behavior requires further investigation. 
TABLE I

EFFECT OF PLATINUM METALS ON NBL TITRIMETRIC METHOD

\begin{tabular}{|c|c|c|c|c|}
\hline Impurity & $\begin{array}{l}\text { Amount of } \\
\text { Impurity } \\
\text { Added, mg }\end{array}$ & $\begin{array}{c}\mathrm{U} \text { Added, } \\
\mathrm{mg}\end{array}$ & $\begin{array}{c}\mathrm{U} \text { Found, } \\
\mathrm{mg}\end{array}$ & Difference, \\
\hline $\mathrm{Ru}$ & $\begin{array}{l}10 \\
50\end{array}$ & $\begin{array}{l}116.91 \\
116.67\end{array}$ & $\begin{array}{l}117.40 \\
121.90\end{array}$ & $\begin{array}{l}+0.42 \\
+\quad 4.5\end{array}$ \\
\hline $\mathrm{Rh}$ & $\begin{array}{r}8 \\
8 \\
16 \\
40 \\
80\end{array}$ & $\begin{array}{l}103.22 \\
103.99 \\
103.97 \\
104.29 \\
103.63\end{array}$ & $\begin{array}{l}103.36 \\
104.06 \\
104.00 \\
104.35 \\
103.77\end{array}$ & $\begin{array}{l}+0.14 \\
+0.07 \\
+0.03 \\
+0.06 \\
+0.14^{a}\end{array}$ \\
\hline $\mathrm{Pd}$ & $\begin{array}{r}3 \\
5 \\
30\end{array}$ & $\begin{array}{r}101.09 \\
100.51 \\
97.24\end{array}$ & $\begin{array}{r}101.27 \\
101.57 \\
99.02\end{array}$ & $\begin{array}{l}+0.18 \\
+1.0 \\
+1.8\end{array}$ \\
\hline Os & $\begin{array}{r}5 \\
10 \\
50\end{array}$ & $\begin{array}{l}103.89 \\
102.89 \\
103.13\end{array}$ & $\begin{array}{l}104.06 \\
103.45 \\
105.35\end{array}$ & $\begin{array}{l}+0.16 \\
+0.54 \\
+2.1\end{array}$ \\
\hline Ir & $\begin{array}{r}5 \\
10 \\
20\end{array}$ & $\begin{array}{l}102.90 \\
102.96 \\
103.75\end{array}$ & $\begin{array}{l}102.97 \\
103.12 \\
104.08\end{array}$ & $\begin{array}{l}+0.07 \\
+0.16 \\
+0.32\end{array}$ \\
\hline Pt & $\begin{array}{r}1 \\
2 \\
3 \\
5 \\
10 \\
15\end{array}$ & $\begin{array}{l}103.85 \\
103.50 \\
103.20 \\
104.15 \\
103.05 \\
109.61\end{array}$ & $\begin{array}{l}104.00 \\
104.02 \\
103.81 \\
105.67 \\
104.35 \\
111.21\end{array}$ & $\begin{array}{l}+0.14 \\
+0.50 \\
+0.59 \\
+1.5 \\
+1.3 \\
+1.5\end{array}$ \\
\hline
\end{tabular}

a. Sluggish end point.

The effects of chloride and bromide are shown by the data in Table II. Chloride causes positive errors apparently not strictly related to the stoichiometric quantity present. In addition, chloride seriously affects the behavior of the platinum electrode. Bromide can cause either positive or negative errors depending upon the amount present. This fact suggests that there are two interfering processes occurring. One milligram or less of bromide can be tolerated.

\section{Interference Mechanism}

The mechanism of the positive interference of platinum was briefly studied. Positive errors as reported in Table I can be caused by either a dramatic shift in the end-point potential or by the presence of a reducible species capable of being oxidized by dichromate in the final diluted solution to be titrated.

Titrations in which the second-derivative technique was used to establish the exact end point showed that the presence of 
platinum did not change the end-point potential of about $590 \mathrm{mV}$, and that the errors obtained by titration to the actual inflection point were of the same magnitude as those observed by titrating to a fixed potential of $590 \mathrm{mV}$. Thus, it can be concluded that the error can be attributed to the presence of a titratable species in the solution titrated rather than a shift in end-point potential.

TABLE I I

EFFECT OF CHLORIDE AND BROMIDE ON NBL TITRIMETRIC METHOD

\begin{tabular}{|c|c|c|c|c|}
\hline Impurity & $\begin{array}{l}\text { Amount of } \\
\text { Impurity } \\
\text { Added, mg }\end{array}$ & $\begin{array}{c}\text { U Added, } \\
\mathrm{mg}\end{array}$ & $\begin{array}{c}\mathrm{U} \text { Found, } \\
\mathrm{mg}\end{array}$ & Difference, \% \\
\hline \multirow{6}{*}{$\mathrm{Cl}$} & 1 & 99.37 & 99.55 & +0.18 \\
\hline & 5 & 98.40 & 98.60 & +0.20 \\
\hline & 15 & 96.61 & 96.96 & +0.36 \\
\hline & 425 & 91.30 & 91.71 & +0.45 \\
\hline & 850 & 97.58 & 98.57 & +1.0 \\
\hline & 850 & 98.16 & 100.18 & +2.0 \\
\hline \multirow[t]{13}{*}{$\mathrm{Br}$} & 1 & 108.91 & 108.82 & -0.08 \\
\hline & 1 & 108.49 & 108.40 & -0.08 \\
\hline & 1 & 106.69 & 106.70 & -0.01 \\
\hline & 2 & 108.62 & 108.44 & -0.17 \\
\hline & 3 & 107.46 & 107.21 & -0.23 \\
\hline & 4 & 108.01 & 108.00 & -0.01 \\
\hline & 4 & 109.49 & 109.43 & -0.06 \\
\hline & 5 & 108.60 & 108.86 & +0.24 \\
\hline & 5 & 108.61 & 108.76 & +0.14 \\
\hline & 10 & 110.43 & 110.72 & +0.26 \\
\hline & 10 & 105.11 & 105.44 & +0.31 \\
\hline & 25 & 108.98 & 111.20 & +2.0 \\
\hline & 25 & 108.52 & 110.91 & +2.2 \\
\hline
\end{tabular}

A series of tests was carried out with solutions containing platinum and either no uranium or varying ratios of platinum to uranium, Table III. When platinum only, from 1 to $15 \mathrm{mg}$, is carried through the procedure, no significant blank, which would appear as uranium in a typical titration, is observed. The potential measured just prior to the start of the titration in every case was between 560 and $590 \mathrm{mV}$, and less than 1 drop of $0.03 \mathrm{~N}$ dichromate was sufficient to increase the potential to $640 \mathrm{mV}$. However, in the presence of uranium, $5 \mathrm{mg}$ of platinum causes significant positive errors. If, for example, platinum(II) is the source of the interference, it is interesting that uranium must be present in order for sufficient platinum(II) to be formed and survive the oxidation step of the procedure. 
TABLE I I I

EFFECT OF PLATINUM IN THE PRESENCE AND ABSENCE OF URANIUM

\begin{tabular}{|c|c|c|c|}
\hline $\begin{array}{l}\text { Pt Added, } \\
\text { mg } \\
\end{array}$ & $\begin{array}{c}\mathrm{U} \text { Added, } \\
\mathrm{mg}\end{array}$ & $\begin{array}{c}\text { U Found, } \\
\mathrm{mg}\end{array}$ & $\begin{array}{c}\text { Difference, } \\
\mathrm{mg}\end{array}$ \\
\hline 1 & 0 & $<0.06$ & $+<0.06$ \\
\hline 5 & 0 & $<0.06$ & $t<0.06$ \\
\hline 10 & 0 & $<0.06$ & $t<0.06$ \\
\hline 15 & 0 & $<0.06$ & $+<0.06$ \\
\hline 0 & 11.47 & 11.49 & +0.02 \\
\hline 5 & 11.66 & 12.33 & +0.67 \\
\hline 0 & 21.37 & 21.41 & +0.04 \\
\hline 5 & 22.00 & 22.57 & +0.57 \\
\hline 0 & 32.84 & 32.86 & +0.02 \\
\hline 5 & 32.58 & 33.58 & +1.0 \\
\hline 0 & 108.55 & 108.51 & -0.04 \\
\hline 5 & 108.37 & 109.46 & +1.1 \\
\hline
\end{tabular}

A spectrophotometric procedure was developed to identify platinum(II) at various stages in the titrimetric procedure. Platinum(II) in acid solution forms an extractable dithizonate; platinum(IV) does not. A brief study with this technique revealed that:

1. No platinum(II) is present in the platinum solution (No. 1) used to spike the uranium standards;

2. Platinum(IV) is not reduced to platinum(II) in the reduction step of the procedure in the absence of uranium; this fact confirms the data in Table III.

3. A large fraction of the platinum(IV) is reduced to platinum(II) in the reduction step in the presence of uranium;

4. A large fraction of the platinum(II) produced by reduction of platinum(IV) is not oxidized by the $\mathrm{HNO}_{3}$-molybdate in the iron(II) oxidation step; it is oxidized by the dichromate titrant. In an additional study, the oxidation times for the oxidation step were increased from $3.0 \mathrm{~min}$ to $12 \mathrm{~min}$. The platinum(II) was still not oxidized by the $\mathrm{HNO}_{3}$-molybdate. Therefore, it is reasonable to conclude that the high results 1 isted in Table I are caused by the presence of platinum(II) in the solution being titrated. Additional future tests will be carried out similarly with the platinum standard solution 2 .

Although no tests were made to identify the oxidation states of the other platinum metals at various stages in the procedure, it is probable that these elements interfere in a manner similar to that of platinum. For example, in the case of palladium, it has been observed that finely divided metal is formed in the re- 
duction step of the procedure. This metallic palladium survives the $\mathrm{HNO}_{3}$-molybdate oxidation but is readily oxidized and dissolved by the dichromate, thereby producing high results for the uranium.

The mechanism of the chloride interference has not been studied to date in detail. With chloride present, the induction period (the time the solution is colored a deep brown-black) in the catalytic oxidation step is increased from about $30 \mathrm{sec}$ to about $21 / 2$ min depending on its concentration. This long induction period may indicate an interference in the oxidation step of the procedure. However, it is also possible that the main interference of chloride arises from its effect on the proper functioning of the platinum electrode, since, after exposure to chloride, the electrode must be flamed at high temperature before it can be used again. Titrations carried out by the second-derivative technique gave errors similar to those obtained with the fixed end-point procedure indicating that the presence of chloride does not affect the end-point potential.

Similarly, bromide has a serious deleterious effect on the platinum electrode behavior. After exposure to bromide in high concentrations, e.g. 10 to $25 \mathrm{mg}$ in the final solution for titration, the platinum electrode must be cleaned with molten sodium carbonate and/or molten sodium bisulfate followed by cleaning in hot $\mathrm{HNO}_{3}$. The electrode is finally ignited in a flame at high temperature and conditioned for several hours in the titration medium or ferrous sulfate solution before it can be used again. Positive errors may be due to oxidation of bromide to bromine or bromate in the final solution by the dichromate titrant. Negative errors could be caused by the formation of bromine, which can oxidize uranium(IV), in other steps in the preparation. For example, free bromine can be detected by odor just as soon as the phosphoric acid, which contains a small amount of dichromate to oxidize reducible species in the acid, is added in the procedure, and the odor persists during the entire procedure. Again, no shift in the end-point potential is observed in titrating solutions containing bromide. Additional studies with chloride and bromide are planned.

\section{Elimination of Interferences}

The platinum group metals are customarily removed from uranium sample solutions by precipitation with hydrogen sulfide in acid solution. In some cases, a double precipitation is necessary. In attempts to eliminate this gassing procedure other techniques were studied.

It was found that ruthenium and osmium can be eliminated satisfactorily by volatilization of their oxides from fuming $\mathrm{HClO}_{4}$. Sample solutions are first evaporated to dryness to remove any excess $\mathrm{HNO}_{3}$. Then, for samples containing less than $50 \mathrm{mg}$ of the elements, $5 \mathrm{ml}$ of $\mathrm{HClO}_{4}$ and a few milliliters of water are added and the solution is heated to fumes of $\mathrm{HClO}_{4}$ until the intensely colored solution changes to a pale yellow. Larger amounts can be removed by adding more $\mathrm{HClO}_{4}$ and fuming longer. Samples treated in this way show no interference from these elements. 
The removal of palladium and platinum can be accomplished smoothly by the copper column procedure ${ }^{6}$ developed at NBL. In this procedure, the solution is converted to a sulfuric acid solution and then is passed through a small column of granular copper. Palladium and platinum remain on the column as metal, and uranium is eluted without loss.

At the present time, iridium must be removed by gassing with hydrogen sulfide. Rhodium, in moderate amounts, i.e. up to $80 \mathrm{mg}$ in a 100-mg uranium sample, need not be removed.

Chloride and bromide are easily removed by adding 1 to $3 \mathrm{ml}$ of sulfuric acid and evaporating the solution to strong fumes of $\mathrm{SO}_{3}$.

\section{REFERENCES}

1. Eberle, A. R., Lerner, M. W., Goldbeck, C. G., Rodden, C. J., NBL-252 Part I (July 1970).

2. Wenzel, A. W., Simmons, H. N. and Pietri, C. E., NBL-258 (June 1971), p. 33 .

3. Eberle, A. R. and Lerner, M. W., NBL-262 (March 1972), p. 21.

4. Scarborough, J. M., NBL-265 (October 1972), p. 26 .

5. Eberle, A. R. and Lerner, M. W., NBL-258 (June 1971), p. 14.

6. Bodnar, L. Z., Scarborough, J. M. and Lerner, M. W., NBL-267 (September 1973), p. 19 . 


\begin{abstract}
IHE EFFECT OF IMPURITIES ON THE NEW BRUNSWICK LABORATORY TITRIMETRIC METHOD OF DETERMIN ING URANIUM. II I. FLUORIDE
\end{abstract}

\author{
L. Z. Bodnar and J. M. Scarborough
}

A previous report ${ }^{1}$ on the New Brunswick Laboratory (NBL) titrimetric method of determining uranium has stated that fluoride does not interfere. This conclusion was based upon the results obtained with solutions of uranium-zirconium mixtures to which fluoride was added to keep the zirconium in solution. However, subsequent studies have shown that under certain conditions fluoride does in fact interfere. This report describes the interference of fluoride, a probable mechanism by which low results are obtained, and the elimination of the interference.

\title{
EXPER IMENTAL
}

\section{Reagents, Apparatus and Procedure}

The reagents, apparatus and procedure are identical to those described in reference (1) with the following exceptions:

(1) $100 \mathrm{mg}$ of solid vanadyl sulfate dihydrate is used instead of the $10 \mathrm{ml}$ of $0.05 \mathrm{M}$ vanadyl solution; ${ }^{2}$ (2) a small amount, $1 \mathrm{ml}$, of $0.03 \mathrm{~N}$ potassium dichromate is added to the phosphoric acid before it is used to oxidize reducible material present; ${ }^{3}$ (3) water is used as the diluent instead of $1 \mathrm{M} \mathrm{H}_{2} \mathrm{SO}_{4}$.

\section{RESULTS AND DISCUSSION}

Effect of Fluoride. As a point of reference, a series of standard uranium solutions in 400-m 1 beakers was evaporated to dryness to remove most of the $\mathrm{HNO}_{3}$ present. Then $10 \mathrm{ml}$ of water and various quantities of fluoride as $H F$ were added to each beaker. Determination of the uranium in each beaker gave the results shown in Table I. These data indicate that up to $400 \mathrm{mg}$ of HF can be tolerated in the absence of free acid; larger amounts cause negative errors in excess of $0.1 \%$.

The test was repeated with uranium aliquots containing $2 \mathrm{ml}$ $\mathrm{HNO}_{3}$, Table II. In this situation, slightly larger amounts of fluoride can be tolerated.

Similar tests were then carried out with standard uranium solutions containing zirconium (and $\mathrm{HNO}_{3}$ ), the type of mixture commonly met in actual analytical samples, Table III. These data explain the earlier conclusion about the non-interference of fluoride. In the presence of $1.0 \mathrm{~g}$ of zirconium, which is a good complexing agent for fluoride, much larger quantities, up to about $1.5 \mathrm{~g}$, of fluoride can be tolerated. 
TABLE I

EFFECT OF FLUORIDE IN THE ABSENCE OF NITRIC ACID

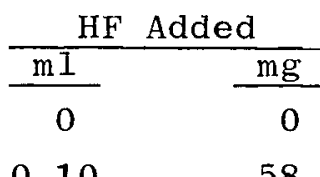

Relative Error, \%

$0.10 \quad 58$

(115 mg U Titrated)

0.00

$0.20 \quad 116$

$-0.01,0.00$

0.50

289

$-0.01$

0.75

434

$-0.05$

1.00

578

$-0.09$

2.00

1160

$-0.14$

3.00

1730

$-0.39$

4.00

2320

$-0.59$

$-0.63$

TABLE I I

EFFECT OF FLUORIDE IN THE PRESENCE OF NITRIC ACID

$\begin{array}{cr}\text { HF } & \text { Added } \\ \frac{\mathrm{ml}}{0} & \frac{\mathrm{mg}}{0}\end{array}$

$0.10 \quad 58$

0.25

0.50

145

289

0.75

1.00

2.00
Relative Error, \%

(115 mg_U Titrated)

$+0.02$

$-0.01$

$+0.01$

$+0.02$

0.0

$+0.02$

$-0.22$

TABLE I I I

EFFECT OF FLUORIDE IN THE PRESENCE OF ZIRCONIUM

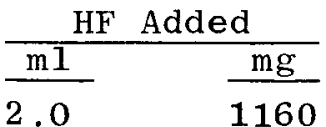

$2.0 \quad 1160$

$2.5 \quad 1450$

$3.0 \quad 1730$

$4.0 \quad 2310$

6.0

3470
Relative Error, \%

$(1.0 \mathrm{~g} \mathrm{Zr}$ and $55 \mathrm{mg} \mathrm{U}$ Taken)

$-0.01$

$-0.01$

$-0.09$

$-0.27$

$-0.76$

$-3.5$ 
Thus, small amounts of fluoride, less than $400 \mathrm{mg}$ as HF, can be generally tolerated in the NBL titrimetric method. The amount present can be increased to about $600 \mathrm{mg}$ as $\mathrm{HF}$ if $\mathrm{HNO}_{3}$ is present. Above these quantities, serious errors can result unless the fluoride is complexed.

Mechanism of the Interference

It was established that $1.5 \mathrm{~g}$ of boric acid, a good complexing agent for fluoride, added before the analysis to a standard uranium solution containing $2 \mathrm{ml}(1156 \mathrm{mg})$ of $\mathrm{HF}$ effectively eliminates the interference. Accordingly, a series of tests was carried out in which boric acid was added to uranium solutions containing fluoride at various steps in the NBL procedure. These data, Table IV, indicate that the interference occurs prior to the dilution step. Therefore, it seems likely that the uranium(IV), normally stable in the oxidation step, is being oxidized in part along with the excess iron(II) when fluoride is present.

TABLE IV

EFFECT OF BORIC ACID ADDED AT VARIOUS STEṔS IN THE PROCEDURE

\begin{tabular}{|c|c|c|c|}
\hline \multicolumn{2}{|c|}{ HF Added } & & Relative Err \\
\hline $\mathrm{ml}$ & $\underline{\mathrm{mg}}$ & $\mathrm{H}_{3} \mathrm{BO}_{3}$ Added, $\mathrm{g}$ & $(115 \mathrm{mg}$ U Tit \\
\hline 0 & 0 & 0 & 0.0 \\
\hline 4 & 2310 & 0 & -0.51 \\
\hline 4 & 2310 & 1.5 at start & -0.04 \\
\hline 4 & 2310 & 1.5 at reduction & -0.02 \\
\hline 4 & 2310 & 1.5 at reduction & -0.04 \\
\hline 4 & 2310 & 1.5 at dilution & -0.55 \\
\hline
\end{tabular}

To test this supposition, the relative errors obtained by increasing the oxidation period (normally 3.0 minutes after the disappearance of the brown-black color) in the presence and absence of fluoride in the solution were determined, Table $V$. The results indeed tend to indicate that the errors caused by free fluoride are caused by premature oxidation of some uranium(IV) in the oxidation step.

One final point was checked to eliminate the possibility that fluoride interferes at least partially by shifting the end-point potential. Titrations were carried out by the second-derivative technique when fluoride was present in the solution. No significant shift in the end-point potential was observed.

Removal of Fluoride Interference

Normally, fluoride in the sample solution can be removed by a $\mathrm{H}_{2} \mathrm{SO}_{4}$ - or $\mathrm{HClO}_{4}$-fuming step. In some cases, however, precipitates may be formed upon fuming. In these cases, boric acid can be added to the sample solution aliquot to complex the fluoride. Table VI compares the results obtained by analyzing actual sample solutions containing excess fluoride after fuming or after adding boric acid. 
TABLE V

STABILITY OF URANIUM (IV) IN THE PRESENCE OF FLUORIDE

\begin{tabular}{|c|c|c|c|}
\hline$\frac{\mathrm{HF}}{\mathrm{m} 1}$ & $\frac{\text { Added }}{\underline{\mathrm{mg}}}$ & $\begin{array}{l}\text { Duration of } \\
\text { Oxidation Step, min. }\end{array}$ & $\begin{array}{c}\text { Relative Error, } \% \\
\text { (90-150 mg U Titrated) }\end{array}$ \\
\hline 0 & 0 & 3 (usual time) & 0.00 \\
\hline 0 & 0 & 10 & 0.00 \\
\hline 0 & 0 & 20 & -0.10 \\
\hline 0 & 0 & 60 & -0.49 \\
\hline 4 & 2310 & 3 (usual time) & -0.39 \\
\hline 4 & 2310 & 10 & -1.13 \\
\hline 4 & 2310 & 20 & -1.49 \\
\hline 4 & 2310 & 60 & -3.09 \\
\hline
\end{tabular}

TABLE VI

COMPARISON OF METHODS FOR ELIMINATION OF FLUORIDE INTERFERENCE

Sample, a

NBL No.

Uranium Determined, $\mathrm{mg} / \mathrm{g}$

CS 1638

Fuming

$1.5 \mathrm{~g} \mathrm{H}_{3} \mathrm{BO}_{3}$ Added

Untreated

9.077

9.086

8.999

CS 1639

5.939

5.923

5.701

CS 1640

11.866

11.882

11.640

CS 1642

8.791

8.789

8.599

CS 1643

6.922

6.927

6.660

CS 1644

8.426

8.430

8.150

a. Solution obtained from actual U-Zr samples containing small amounts of fluoride from sample preparation; $4 \mathrm{ml} \mathrm{HF}$ added to each aliquot used before the determination.

\section{REFERENCES}

1. Eberle, A. R., Lerner, M. W., Goldbeck, C. G. and Rodden, C. J., NBL-252 part I (July 1970).

2. Eberle, A. R. and Lerner, M. W., NBL-258 (June 1971), p. 22.

3. Eberle, A. R. and Lerner, M. W., NBL-258 (June 1971), p. 14. 


\section{THE EFFECT OF IMPURITIES ON THE NEW BRUNSWICK LABORATORY TITR IMETRIC METHOD OF DETERMINING URANIUM. \\ IV. HYDROGEN PEROXIDE}

\section{J. M. Scarborough}

Occasionally hydrogen peroxide may be used in the dissolution of certain uranium-zirconium alloys ${ }^{1}$ or otherwise may be present in sample solutions. Although hydrogen peroxide is usually removed by evaporation or fuming steps, it is of interest to establish limits on the amount of hydrogen peroxide which can be tolerated in the New Brunswick Laboratory (NBL) titrimetric method of determining uranium.

Peroxides interfere by depleting the amount of ferrous iron added to reduce uranium(VI) to uranium(IV).

\section{EXPER IMENTAL}

Reagents, Apparatus and procedure

In addition to the use of reagent-grade hydrogen peroxide, the reagents, apparatus and procedure are identical to those appearing in reference (1) with the following exceptions: the substitution of $100 \mathrm{mg}$ of solid vanadyl sulfate for the $0.05 \mathrm{M}$ vanadyl solution as proposed in reference (2); the pretreatment of the $\mathrm{H}_{3} \mathrm{PO}_{4}$ with $1 \mathrm{ml}$ of $0.03 \mathrm{M}$ dichromate as recommended in reference $(3)$; the use of water instead of $1 \mathrm{M}_{2} \mathrm{SO}_{4}$ for the diluent.

\section{RESULTS AND DISCUSSION}

The data obtained from the titration of known amounts of uranium mixed with known amounts of hydrogen peroxide are shown in Table I.

As expected, the results of the study indicated that hydrogen peroxide does not interfere with the NBL titrimetric method if the number of milliequivalents of iron(II) exceeds by an appreciable amount the total milliequivalents of hydrogen peroxide and uranium(VI).

It should be noted that insufficient iron(II) is indicated by the absence of the dark brown coloration which follows the addition of the $\mathrm{HNO}_{3}$-molybdate oxidizer solution. When this condition is reached, the data show that serious interference from hydrogen peroxide occurs. Normally, failure to observe the dark coloration during the oxidation step is sufficient reason to discard a sample and to determine the cause of the failure. Thus, it is unlikely that a sample containing excessive amounts of peroxide would be titrated unknowingly. 
TABLE I

EFFECT OF HYDROGEN PEROXIDE ON THE NBL TITRIMETRIC METHOD FOR THE DETERMINAT ION OF URANIUM

\begin{tabular}{|c|c|c|c|c|c|}
\hline \multicolumn{3}{|c|}{ Milliequivalents Added } & \multicolumn{2}{|c|}{ Uranium, mg } & \multirow{2}{*}{$\begin{array}{c}\text { Difference } \\
\mathrm{mg}\end{array}$} \\
\hline $\mathrm{H}_{2} \mathrm{O}_{2}$ & $\mathrm{U}(\mathrm{VI})$ & Fe (II) & Added & Found & \\
\hline 0 & 0.8 & 5 & 100.82 & 100.80 & -0.02 \\
\hline 0.018 & 1.0 & 5 & 115.84 & 115.81 & -0.03 \\
\hline 0.09 & 1.0 & 5 & 115.43 & 115.40 & -0.03 \\
\hline 0.18 & 1.0 & 5 & 117.36 & 117.30 & -0.06 \\
\hline 1.8 & 1.0 & 5 & 116.94 & $116.97^{\mathrm{a}}$ & +0.03 \\
\hline 2.7 & 1.0 & 5 & 116.54 & $\mathrm{~b}, \mathrm{c}$ & -- \\
\hline 3.2 & 1.0 & 5 & 116.48 & $113.51^{\mathrm{b}}$ & -2.6 \\
\hline 3.2 & 0.8 & 10 & 97.64 & 97.59 & -0.05 \\
\hline 3.6 & 1.0 & 5 & 115.40 & $\mathrm{~b}, \mathrm{c}$ & -- \\
\hline 3.6 & 0.8 & 10 & 97.66 & 97.72 & +0.05 \\
\hline 5.4 & 1.0 & 5 & 117.07 & $c, d$ & -- \\
\hline 9.0 & 1.0 & 5 & 115.75 & $\mathrm{c}, \mathrm{e}$ & -- \\
\hline
\end{tabular}

a. Very light brown color on addition of $\mathrm{HNO}_{3}$-Mo oxidizer

b. No color on addition of oxidizer.

c. Titration not performed.

d. Color at reduction indicated a small amount of U(VI) rema ins.

e. Color at reduction indicates most of $U(V I)$ remains.

\section{REFERENCES}

1. Eberle, A. R., Lerner, M. W., Goldbeck, C. G. and Rodden, C. J., NBL-252 Part I (July 1970), p. 6.

2. Eberle, A. R. and Lerner, M. W. NBL-258 (June 1971), p. 22.

3. Ioid., p. 14. 
ELIMINATION OF SOME INTERFERENCES IN THE NEW BRUNSWICK LABORATORY TITRIMETRIC URANIUM METHOD BY MEANS OF A COPPER COLUMN

\author{
L. Z. Bodnar, J. M. Scarborough and M. W. Lerner
}

Mercury, platinum and palladium have been shown to interfere with the New Brunswick Laboratory (NBL) titrimetric method of determining uranium.1,2 These elements can be removed by precipitation with hydrogen sulfide; mercury can also be separated by reduction with stannous chloride. ${ }^{1}$ A new method, involving the use of a copper column to reduce these elements to the metallic state, has been developed. This technique accomplishes both the reduction and separation in one step. Thus, it is faster, simpler and less subject to error than the previous procedures described.

\title{
EXPER IMENTAL
}

\section{Reagents and Apparatus}

Copper column. The reduction column is prepared by filling a Bio-Rad disposable polyethylene column, $0.7 \mathrm{~cm}$ ID by $4 \mathrm{~cm}$ high, with reservoir, to a depth of about $3.0 \mathrm{~cm}$ with electrolytic copper granules of about 50 mesh. The column is washed with a few milliliters of $10 \% \mathrm{H}_{2} \mathrm{SO}_{4}$ before it is used.

Mercury Solution, $16.4 \mathrm{mg} / \mathrm{ml}$, prepared by dissolving mercury metal in 1:1 $\mathrm{HNO}_{3}$ and diluting the solution to volume.

Platinum Solution, $1.0 \mathrm{mg} / \mathrm{ml}$ (solution No. 1), and $10 \mathrm{mg} / \mathrm{ml}$ (solution No. 2), prepared as in reference (2).

Palladium Solution, $10 \mathrm{mg} / \mathrm{ml}$, prepared by dissolving $\mathrm{PdCl}_{2}$ in aqua regia, evaporating the solution to dryness, dissolving the residue in $9 \mathrm{M} \mathrm{H}_{2} \mathrm{SO}_{4}$, and diluting the resulting solution to volume.

The reagents, apparatus and procedure for the NBL titrimetric method are as described in reference (3) except that: $100 \mathrm{mg}$ of solid vanadyl sulfate is used in place of the $0.05 \mathrm{M}$ vanadyl solution in the dilution step; ${ }^{4} 1 \mathrm{ml}$ of $0.03 \mathrm{M}$ dichromate is added to the $\mathrm{H}_{3} \mathrm{PO}_{4}$ before it is used; ${ }^{5}$ and water ${ }^{-}$is used as the diluent instead of $1 \underline{M} \mathrm{H}_{2} \mathrm{SO}_{4}$.

\section{procedure}

Add 5 to $7 \mathrm{ml}$ of $9 \mathrm{M} \mathrm{H}_{2} \mathrm{SO}_{4}$ to a weighed sample solution aliquot and evaporate the mixture to light fumes of $\mathrm{SO}_{3}$. Cool the solution and dilute to about $25 \mathrm{ml}$. Add the solution to the copper column. When the column flow stops, wash the beaker and column once with a 10-ml portion of $10 \% \mathrm{H}_{2} \mathrm{SO}_{4}$ and twice more with 10-m1 portions of $2 \%$ $\mathrm{H}_{2} \mathrm{SO}_{4}$. Finally, wash with $10 \mathrm{ml}$ of water. Evaporate the combined effluents on a steam bath to a small volume and dilute to $15 \mathrm{ml}$. 
(The final solution should contain less than $5 \mathrm{ml}$ of $\mathrm{H}_{2} \mathrm{SO}_{4}$.) Determine the uranium in the usual manner. Use $\mathrm{HClO}_{4}$ in place of the $\mathrm{H}_{2} \mathrm{SO}_{4}$ if so desired.

Removal of Mercury

\section{RESULTS AND DISCUSSION}

Two series of 7 uranium standard solutions each containing aluminum and mercury were prepared as given in the procedure with either $\mathrm{H}_{2} \mathrm{SO}_{4}$ or $\mathrm{HClO}_{4}$ being used. The results of the uranium determinations are shown in Tabie $i$.

\section{TABLE I}

REMOVAL OF MERCURY ${ }^{\mathbf{a}}$ ON A COPPER COLUMN PRIOR TO URANIUM - DETERM INATION

Relative Difference from Prepared Value of Uranium, $\%$

\begin{tabular}{|c|c|c|c|}
\hline \multicolumn{2}{|c|}{$\underline{\mathrm{H}_{2} \mathrm{SO}_{4} \text { Medium }}$} & \multicolumn{2}{|c|}{$\mathrm{HClO}_{4}$ Medium } \\
\hline-0.10 & -0.04 & +0.16 & +0.03 \\
\hline-0.04 & +0.08 & -0.01 & -0.03 \\
\hline+0.08 & +0.01 & +0.07 & +0.07 \\
\hline+0.02 & & +0.05 & \\
\hline
\end{tabular}

a. Solutions contained 61 to $91 \mathrm{mg}$ of uranium, about $300 \mathrm{mg}$ of aluminum and $75 \mathrm{mg}$ of mercury.

To evaluate the limitation of the amount of mercury that the column will remove, another series of solutions containing uranium, aluminum and increasing amounts of mercury was treated and analyzed, Table II. It is apparent that the column technique will separate at least $240 \mathrm{mg}$ of mercury, a quantity far greater than is normally present in actual sample aliquots.

TABLE I I

COLUMN CAPACITY FOR REMOVAL OF MERCURY

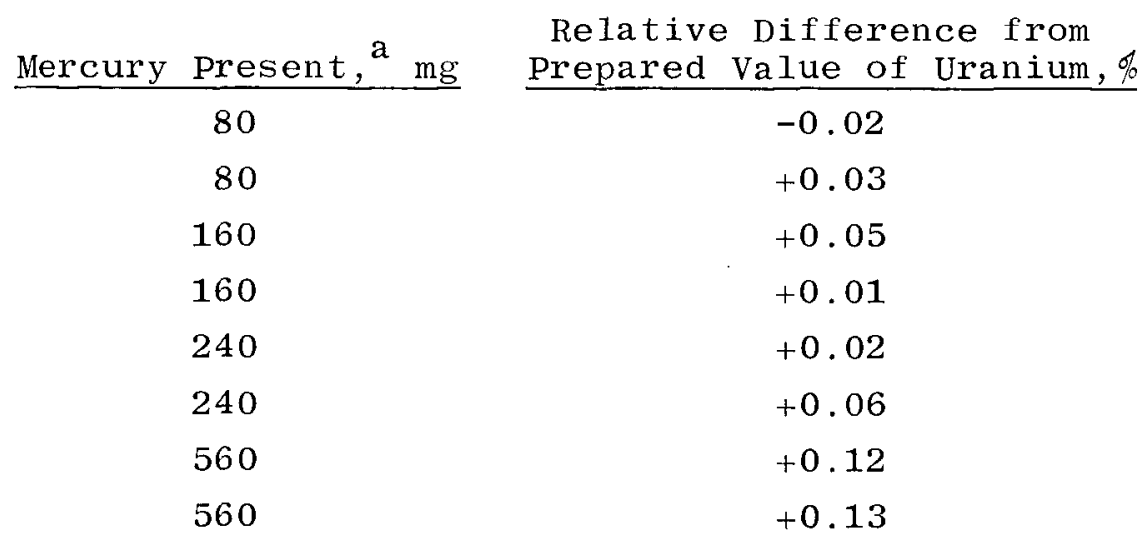

a. Solutions to be analyzed contained 61 to $102 \mathrm{mg}$ uranium plus $5 \mathrm{~g} \mathrm{Al}\left(\mathrm{NO}_{3}\right)_{3} \cdot 9 \mathrm{H}_{2} \mathrm{O}$ in $10 \% \mathrm{HNO}_{3}$ in addition to the mercury. The $\mathrm{H}_{2} \mathrm{SO}_{4}$-fuming preparation was used. 
Table III presents results obtained both by the stannous chloride separation technique and proposed procedure on actual uranium-thorium dissolver solutions containing 15 to $20 \mathrm{mg}$ of mercury per aliquot.

TABLE I I I

ANALYSIS OF URANIUM-THORIUM DISSOLVER SOLUTIONS CONTAINING MERCURY BY STANNOUS CHLORIDE AND COPPER COLUMN TECHNIQUES

\begin{tabular}{ccc} 
Sample No. & Concentration of Uranium in Sample, $\mathrm{mg} / \mathrm{g}$ \\
\cline { 2 - 3 } 1 & $\frac{\text { Stannous Chloride }}{1.33,1.34}$ & $\frac{\text { Copper Column }}{1.34,1.34}$ \\
2 & $1.42,1.44$ & $1.42,1.42$ \\
3 & $1.36,1.38$ & $1.38,1.37$ \\
4 & $1.22,1.25$ & $1.23,1.23$ \\
5 & $1.35,1.35$ & $1.36,1.36$ \\
6 & $1.57,1.59$ & $1.60,1.60$ \\
7 & $1.59,1.60$ & $1.62,1.62$ \\
8 & $1.68,1.68$ & $1.72,1.71$ \\
9 & $1.48,1.47$ & $1.51,1.51$
\end{tabular}

$\underline{\text { Removal of Platinum and Palladium }}$

Preliminary results with solutions containing platinum or palladium treated by the proposed procedure indicate that up to $10 \mathrm{mg}$ of each can be removed from a solution containing $100 \mathrm{mg}$ of uranium. One modification that appeared to be necessary in the column preparation was the addition of a $1-\mathrm{cm}$ depth of filter pulp below the copper granules. This layer of filter pulp aids in the removal of finely divided platinum or palladium metal that is not held by the copper column. These studies are continuing.

\section{REFERENCES}

1. Eberle, A. R. and Lerner, M. W., NBL-258 (June 1971), p. 26.

2. Scarborough, J. M. and Bodnar, L. Z., NBL-267 (September 1973), p. 6 .

3. Eberle, A. R., Lerner, M. W., Goldbeck, C. G. and Rodden, C.J., NBL-252 Part I (July 1970).

4. Eberle, A. R. and Lerner, M. W., NBL-258 (July 1971), p. 22.

5. Ibid., p. 14 . 


\section{APPLICATION OF THE RADIOMETER TITRATOR MODEL TTT2 \\ TO THE NEW BRUNSWICK LABORATORY TITRIMETRIC METHOD OF DETERMINING URANIUM}

\section{Z. Bodnar and J. M. Scarborough}

The Radiometer Titrator TTT2 is an instrument that automatically titrates a solution to either a preselected potential or $\mathrm{pH}$. Accurate approach to the end point is controlled by means of a "proportional band", an adjustable span of potentials or $\mathrm{pH}$ values prior to the end point within which the titrant delivery rate is controlled by the Titrator. Under Titrator control, the titration proceeds by incremental addition, each new increment being smaller and each interval between increments being longer. Thus, the end point is approached gradually after an initial period of rapid titrant addition.

This instrument is potentially useful in applying the New Brunswick Laboratory (NBL) titrimetric method ${ }^{1}$ of determining uranium both in the manual and automatic mode. The goals of this study were to assess the basic reliability of the Titrator in titrating uranium solutions according to the NBL method, and to learn of any modifications needed to improve its performance.

\section{EXPER IMENTAL}

\section{Reagents and Apparatus}

The reagents for the titrimetric procedure are identical to those given in reference (1) with the following exceptions:

(1) $100 \mathrm{mg}$ of solid vanadyl sulfate dihydrate is used in place of the $10 \mathrm{ml}$ of $0.05 \mathrm{M}$ vanadyl solution in the diluent; (2) $1 \mathrm{ml}$ of $0.027 \mathrm{~N}$ dichromate is added to the $\mathrm{H}_{3} \mathrm{PO}_{4}$ before it is used; (3) water is used as the diluent instead of $1 \underline{M} \mathrm{H}_{2} \mathrm{SO}_{4}$.

Radiometer Titrator (London Company) Model TTT2, equipped with magnetic valve MNV-1, and 50-ml gravity buret with fine tip.

Balance, top-loading Mettler Model P162, with gravimetric titration accessory Model DP11.

\section{Procedure}

Prepare the solution to be titrated in the usual manner by reducing the uranium to uranium(IV) with ferrous ion in $\mathrm{H}_{3} \mathrm{PO}_{4}$, oxidizing the excess ferrous ion with $\mathrm{HNO}_{3}$ and molybdate catalyst, diluting with water, and adding solid vanadyl sulfate. Insert the platinum and calomel electrodes, position the solution so that the buret tip is under the surface, and activate the Titrator. 
To titrate 50 to $150 \mathrm{mg}$ of uranium, use the following instrumental settings:

$$
\begin{aligned}
\text { Range } & =\mathrm{mV} \times 1 \\
\text { Titration Selector } & =\text { downscale } \\
\text { End Point } & =580 \mathrm{mV} \\
\text { Proportional Band Width } & =200 \mathrm{mV} \\
\text { Delay of Shut off } & =15 \mathrm{sec} \\
\text { Buret Rate of Delivery } & =10 \mathrm{ml} / \mathrm{min}
\end{aligned}
$$

\section{RESULTS AND DISCUSSION}

\section{Instrumental settings}

The instrument settings 1 isted above were selected on the basis of the recommendations given by the manufacturer and a large number of exploratory titrations with standard uranium solutions. In the volumetric mode, the delivery rate of the buret is controlled by both the buret-tip opening and an adjustable set screw on the magnetic buret control. A rate of $10 \mathrm{ml} / \mathrm{min}$ was selected because the delivery of $50 \mathrm{ml}$, the buret capacity, would take somewhat under 6 min: about 4 min for continuous delivery and less than 2 min for the intermittant (proportional-band) delivery. This 6-min period is within the maximum time of 7 min that can be taken in a titration without the possibility of incurring a negative error. 1

The proportional-band width setting is adjusted to allow about $80 \%$ of the titrant to be added without interruption; the remaining $20 \%$ is then added under the control of the Titrator. With a $200-\mathrm{mV}$ proportional-band width and the cut-off potential at $580 \mathrm{mV}$, the Titrator will generally control the addition of titrant, when more than $50 \mathrm{mg}$ of uranium is present, after about $80 \%$ of the titrant has been added and the registered potential is $380 \mathrm{mV}$. However, in cases in which less than $50 \mathrm{mg}$ of uranium is present, control may begin much earlier because the electrode potential of the initial solution may be very close to $380 \mathrm{mV}$. A setting of $300 \mathrm{mV}$ for the band width would cause the titration to be under the Titrator control right from the beginning of the titration, even in the presence of large amounts of uranium, causing the titration to be unduly prolonged. With a 100-mv setting for the band width, the Titrator control would take over only a few tenths of a milliliter before the actual end point and overshooting would undoubtedly occur. There are no adjustment settings between these values.

When the preselected end-point potential is reached, a "delay of shut-off" circuit is activated which blocks the delivery of titrant for a preselected period. When the potential remains at or above the end-point potential for the preselected period of time, the "delay of shut-off" circuit turns of $f$ the instrument. The 15-sec delay time was chosen arbitrarily; the rapid estabishment of equilibrium near the end point makes this setting non-critical. Longer periods made no difference in the results. 
The end-point setting of $580 \mathrm{mV}$ was selected on the basis of the volumetric results with standards, Table $I$. With this cut-off potential, very little overshooting of the actual end point of 590 to $600 \mathrm{mV}$ occurs. Previous work ${ }^{1}$ has shown that this actual endpoint potential is reasonably independent of the composition of the sample solution provided the $\mathrm{H}_{3} \mathrm{PO}_{4}$ concentration remains constant. Thus, mixtures of uranium with aluminum, niobium, zirconium, thorium, stainless steel elements, and beryllium all have this identical end point. (Increasing the volume of $\mathrm{H}_{3} \mathrm{PO}_{4}$ in the procedure from 40 to $65 \mathrm{ml}$ as is used for uranium-plutonium sample solutions? to help keep the plutonium from precipitating does affect the end-point potential, increasing it to about $610 \mathrm{mV}$.)

TABLE I

EFFECT OF CUT-OFF POTENTIAL AND DICHROMATE CONCENTRATION ON TITRATION

\begin{tabular}{|c|c|c|c|c|c|}
\hline $\begin{array}{c}\text { Dichromate } \\
\text { Concen- } \\
\text { tration, N }\end{array}$ & $\begin{array}{c}\text { Uranium } \\
\text { Titrated, } \\
\text { mg } \\
\end{array}$ & $\begin{array}{c}\text { Cut-off } \\
\text { Potential, } \\
m V \\
\end{array}$ & $\begin{array}{c}\text { Average } \\
\text { Final } \\
\text { Potential, } \\
\mathrm{mV} \\
\end{array}$ & $\begin{array}{r}\text { Relative } \\
\text { Difference }\end{array}$ & $q^{a}$ \\
\hline 0.027 & 100 & 570 & 610 & $\begin{array}{l}-0.07, \quad-0.10, \\
+0.01, \quad-0.06 \\
-0.02, \quad-0.09\end{array}$ & $\begin{array}{l}+0.01 \\
-0.07 \\
-0.12\end{array}$ \\
\hline & 100 & 580 & 625 & $\begin{array}{l}+0.02,+0.03, \\
-0.07, \quad 0.00 \\
-0.02, \quad 0.00\end{array}$ & $\begin{array}{l}-0.03 \\
+0.03 \\
+0.08\end{array}$ \\
\hline & 100 & 590 & 635 & $\begin{array}{l}+0.09,+0.11, \\
+0.06,+0.03,\end{array}$ & $\begin{array}{l}-0.06 \\
+0.08\end{array}$ \\
\hline & 50 & 580 & 645 & $\begin{array}{l}-0.02,+0.08, \\
-0.01,+0.07,\end{array}$ & $\begin{array}{l}+0.08 \\
+0.01\end{array}$ \\
\hline \multirow[t]{4}{*}{0.010} & 50 & 580 & 605 & $\begin{array}{l}-0.29,-0.25 \\
-0.19\end{array}$ & -0.27 \\
\hline & 50 & 590 & 615 & $\begin{array}{l}-0.09,-0.11 \\
-0.01\end{array}$ & 0.00 \\
\hline & 50 & 600 & 625 & $\begin{array}{r}0.00, \quad-0.02, \\
-0.02,+0.02\end{array}$ & -0.06 \\
\hline & 50 & 610 & 640 & $\begin{array}{l}+0.14,+0.17 \\
+0.20,+0.17\end{array}$ & +0.22 \\
\hline
\end{tabular}

a. $\left(\frac{\text { Determined-Actua } 1}{\text { Actual }}\right) \cdot 100$.

With $0.01 \mathrm{~N}$ potassium dichromate in the titration of quantities of uranium below $50 \mathrm{mg}$, the optimum cut-off potential appears to be near $600 \mathrm{mV}$, Table I. Again there is little overshoot of the potential, but it is unfortunate that the end-point setting must be changed with the use of the more dilute dichromate. 
With $0.027 \mathrm{~N}$ dichromate and the $580 \mathrm{mV}$ cut-off potential, the reliability of the titration was studied with niobium, stainless steel elements, aluminum, thorium, zirconium, and fluoride (complexed with boric acid) added to about $100 \mathrm{mg}$ of uranium, Table II. All of the relative differences obtained between the determined value and the amount of uranium taken can be seen to be within $0.10 \%$ and most are within $0.05 \%$. The results of one group do not differ significantly from the others.

TABLE II

EFFECT OF IMPURITIES ON THE TITRATION ${ }^{\mathbf{a}}$

\begin{tabular}{|c|c|c|c|c|}
\hline Impurity & Quantity, mg & Relative & Difference, & \\
\hline 0 & 0 & $-0.07,+0.01$, & $-0.02,+0.03$ & \\
\hline $\mathrm{Nb}$ & 100 & $-0.02,+0.06$ & $-0.04,+0.03$ & -0.07 \\
\hline Stainless stee $l^{b}$ & 500 & $+0.05,-0.03$, & $-0.05,+0.03$ & \\
\hline$A I$ & 100 & $-0.01,-0.04$, & $+0.02,+0.02$ & \\
\hline Th & 750 & $-0.08,-0.02$, & $-0.03,+0.01$ & \\
\hline $\mathrm{Zr}$ & 100 & $-0.06,-0.07$ & $+0.03,-0.07$ & \\
\hline
\end{tabular}
a. $100 \mathrm{mg}$ uranium titrated
b. No. $304(18 \% \mathrm{Cr}, 8 \% \mathrm{Ni}, \sim 74 \% \mathrm{Fe})$

Table III lists the results obtained with the gravimetric titration apparatus. The same concentration of dichromate titrant, $0.027 \mathrm{~N}$, was used throughout to evaluate the levels of uranium that can be titrated without changing the end point cut-off potential. It can be seen that from about 40 to $350 \mathrm{mg}$ can be titrated with the same setting, $580 \mathrm{mV}$. Again it is unfortunate that for less than $40 \mathrm{mg}$ of uranium, the cut-off potential must be shifted to another value, $550 \mathrm{mV}$. The lower cut-off potential is necessary to prevent overshooting the end point when titrating with $0.027 \mathrm{~N}$ dichromate. This observation is in contrast to the case discussed earlier in which the cut-off potential was raised when titrating with $0.01 \mathrm{~N}$ dichromate.

The reliability of the Titrator was further assessed by the analysis by the volume technique of actual analytical samples containing a fairly constant quantity, 84 to $133 \mathrm{mg}$, of uranium, Table IV. These samples were also analyzed by a different analyst by the conventional NBL manual procedure. 
TABLE I I I

URANIUM ANALYSES WITH GRAVIMETRIC BURET AND CONSTANT DICHROMATE CONCENTRATION

\begin{tabular}{|c|c|c|c|c|}
\hline \multirow{2}{*}{ Cut-off } & \multirow[b]{2}{*}{ Potential, $\mathrm{mV}$} & \multicolumn{2}{|c|}{ Uranium, $\mathrm{mg}$} & \multirow{2}{*}{ Difference, \% } \\
\hline & & Added & Found & \\
\hline \multirow{17}{*}{\multicolumn{2}{|c|}{580}} & 349.473 & 349.242 & -0.07 \\
\hline & & 335.876 & 335.540 & -0.10 \\
\hline & & 226.693 & 226.483 & -0.09 \\
\hline & & 219.598 & 219.546 & -0.02 \\
\hline & & 122.967 & 122.955 & -0.01 \\
\hline & & 113.086 & 113.093 & +0.01 \\
\hline & & 98.048 & 98.038 & -0.01 \\
\hline & & 85.468 & 85.543 & +0.09 \\
\hline & & 82.187 & 82.151 & -0.04 \\
\hline & & 80.449 & 80.416 & -0.04 \\
\hline & & 79.898 & 79.961 & +0.08 \\
\hline & & 75.824 & 75.894 & +0.09 \\
\hline & & 75.432 & 75.410 & -0.03 \\
\hline & & 52.739 & 52.794 & +0.10 \\
\hline & & 53.719 & 53.761 & +0.08 \\
\hline & & 42.457 & 42.474 & +0.04 \\
\hline & & 42.630 & 42.693 & +0.15 \\
\hline & 580 & 24.420 & 24.501 & +0.33 \\
\hline & 570 & 21.604 & 21.735 & +0.61 \\
\hline & 560 & 21.390 & 21.426 & +0.17 \\
\hline \multirow{6}{*}{\multicolumn{2}{|c|}{550}} & 31.795 & 31.813 & +0.06 \\
\hline & & 31.835 & 31.823 & -0.04 \\
\hline & & 20.238 & 20.246 & +0.04 \\
\hline & & 21.405 & 21.403 & -0.01 \\
\hline & & 11.337 & 11.345 & +0.07 \\
\hline & & 10.591 & 10.603 & +0.11 \\
\hline
\end{tabular}




\section{COMPARISON OF RESULTS OBTA INED MANUALLY AND WITH TITRATOR}

\begin{tabular}{|c|c|c|c|c|c|c|}
\hline \multirow{3}{*}{$\begin{array}{l}\begin{array}{l}\text { NBL } \\
\text { Number }\end{array} \\
\text { EU-19410 }\end{array}$} & \multirow{3}{*}{$\begin{array}{l}\begin{array}{l}\text { Sample } \\
\text { Type }\end{array} \\
\text { uranyl } \\
\text { nitrate }\end{array}$} & \multirow{2}{*}{$\begin{array}{c}\text { Uranium } \\
\text { Titrated, } \\
\text { mg }\end{array}$} & \multicolumn{4}{|c|}{ Uranium, $g / g$} \\
\hline & & & \multicolumn{2}{|c|}{ Manua l } & \multicolumn{2}{|c|}{ Titrator } \\
\hline & & 84 & 0.2131 & 0.2131 & 0.2130 & 0.2131 \\
\hline EU-19411 & $\mathrm{UO}_{2}$ & 113 & 0.8710 & 0.8712 & 0.8712 & 0.8709 \\
\hline EU-19658 & $\mathrm{U}-\mathrm{Zr}$ scrap & 95 & 0.00971 & 0.00971 & 0.00970 , & 0.00970 \\
\hline EU-19666 & $\mathrm{U}-\mathrm{Al}$ & 133 & 0.01303 & 0.01302 & 0.01303 & 0.01303 \\
\hline $\mathrm{EU}-19667$ & U scrap & 114 & 0.01099 & 0.01098 & 0.01098 & 0.01097 \\
\hline EU-19668 & U scrap & 107 & 0.01730 & 0.01729 & 0.01730, & 0.01730 \\
\hline EU-19669 & U scrap & 130 & 0.01600 & 0.01600 & 0.01599 , & 0.01601 \\
\hline EU-19555 & $\mathrm{UO}_{2}$ & 107 & 0.8783 & 0.8785 & 0.8784 & 0.8789 \\
\hline EU-19956 & $\mathrm{UO}_{2}$ & 104 & 0.8787 & 0.8787 & 0.8793 & 0.8786 \\
\hline EU-19965 & $\mathrm{UO}_{2}$ & 117 & 0.8782 & 0.8790 & 0.8790 & 0.8783 \\
\hline EU-19687 & $\mathrm{U}-\mathrm{Al}$ & 91 & $\begin{array}{l}0.1461, \\
0.1461\end{array}$ & 0.1461 & 0.1463 & 0.1465 \\
\hline
\end{tabular}

This study indicates clearly that the Titrator can titrate uranium solutions prepared by the NBL method with essentially the same reliability as obtained by a careful analyst carrying out the titration conventionally to a preselected potential provided the quantity of uranium is within certain limits. It also indicates that the Titrator (especially in the gravimetric mode) should be capable of being used in an automated apparatus such as the Automatic Uranium Analyzer (Dichromate). 1 In such a case, the cupped noble metal electrode responsible for the "seeking" action, previously found to be necessary in the Analyzer to slow down the titrant delivery as the end point is approached, ${ }^{1}$ would be unnecessary. This modification would be a distinct advantage because the "seeking" action is difficult to adjust and is the weakest point of the Analyzer. Accordingly, an automatic uranium apparatus based upon the Radiometer Titrator is being constructed for evaluation.

The study also indicates that the possibility of making two modifications in the Titrator should be investigated. In the first place, it would be advantageous to slow down even more the rate of addition of titrant near the end point. Secondly, it would be helpful to be able to use a proportional band of $150 \mathrm{mV}$, a span of potentials in between the $100 \mathrm{mV}$ and $200 \mathrm{mV}$ now on the instrument. These changes should help speed up some analyses and prevent overshooting the actual end point in other cases in which small amounts, $<50 \mathrm{mg}$, of uranium are titrated with either $0.01 \underline{\mathrm{N}}$ or $0.027 \underline{\mathrm{N}} \mathrm{di}-$ chromate. 


\section{REFERENCES}

1. Eberle, A. R., Lerner, M. W., Goldbeck, C. G., and Rodden, C. J., NBL-252 (July 1970).

2. Wenzel, A. W., Simmons, H. N., and Pietri, C. E., NBL-250 (April 1970), p. 41. 


\title{
EVALUATION OF AN AUTOMATIC URANIUM ANALYZER BASED UPON CONSTANT CURRENT COULOMETRY - A PROGRESS REPORT
}

\author{
C. G. Goldbeck, M. W. Lerner and G. E. Peoples
}

In a previous report, 1 an automatic uranium analyzer based upon titration with electrogenerated vanadium(V) was described. preliminary data were given of results obtained shortly after the automation of the entire instrument was completed. The present report is concerned with the continued evaluation that is being made before the instrument is used on a routine basis.

It had been shown that problems with the generating plat inum gauze electrode could arise that lead to high results after a short series of determinations. The specific cause was not determined but it was found that the problem could be avoided by using an electrode with large surface area, by generally limiting the quantity of uranium to be titrated to < $130 \mathrm{mg}$, and by leaving the generating electrode in a reducing solution when not in use.

Another difficulty that appeared was a gradual decrease in sensitivity of the platinum sensing electrode, which could result in positive errors. Although sensitivity would be restored for a short time after the electrode was cleaned and 1 ired, the electrode frequently became increasingly sluggish after a few runs. This lack of sensitivity, which causes overshooting of the end-point potential, could be seen as a gradual climbing of the potential of a sample, after the first cut-olf point, to the end-point potential without the need for any current pulsing. When the usual pulsing technique was used near the end point, the registered potential never caught up with the actual potential and serious errors resulted. Again, this behavior could be observed by stopping the pulsing at some point and watching the potential drift past the end point with no additional current being applied.

In studies ${ }^{2}$ being carried out at the New Brunswick Laboratory (NBL) on the interference of various impurity elements on the manual NBL titrimetric method, it was shown that chloride has a deleterious effect on the platinum sensing electrode. To eliminate the possibility that chloride leakage from the calomel electrode caused this gradually increasing sluggish response of the sensing electrode, a potassium sulfate salt bridge was applied to the calomel electrode. This precaution improved the performance of the platinum electrode. It now holds its sensitivity, and may actually improve after the first few runs of the day.

Another factor affecting the instrumental performance was recognized: the position of the platinum sensing electrode with respect to the generating electrode. This position was found to be critical in obtaining a satisfactory cut-off of the continuous current before the pulsing begins. In certain positions, there 
occurs a large (20 to $25 \mathrm{mV}$ ) jump, up or down, in the potential when the current flow stops. The platinum electrode is normally lined up along side of the reference electrode to maintain a fixed distance between the two. To orient the platinum wire with respect to the generating electrode, both the calomel and platinum wire are rotated. This adjustment is now facilitated by the use of a rigid plastic reference electrode holder with a slot in the outer shell for the wire. This holder is simply rotated to position the platinum wire correctly without disrupting the reference-sensor electrode distance.

It was also shown in the previous report ${ }^{1}$ that a negative bias of 0.2 to $0.3 \%$ seemed to appear frequently. This error was found to be lessened by the use of diluent cooled to $<10^{\circ} \mathrm{C}$. How ever, even after this precaution was incorporated later into the procedure, a slight $(0.1$ to $0.2 \%)$ negative bias presisted.

This 0.1 to $0.2 \%$ negative bias was believed at first to be caused by the presence of vanadium(V) in the diluent as reported in reference (3). However, tests by a spectrophotometric procedure 4 failed to show any significant vanadate in the diluent which is made up fresh every day.

Recent work attempting to resolve this problem centered on removing the electrodes from the influences of the atmosphere above the reacting solution during the oxidation step in which large quantities of oxides of nitrogen are evolved in a fine spray of solution. Some analyses were made by adding the reagents manually away from the electrodes, and then putting the beaker in the instrument and lowering the electrodes for the titration. In 11 runs, 9 were within $0.07 \mathrm{sec}$ of the theoretical 100- to 200-sec results. The other 2 were 0.12 and $0.15 \%$ high, not low.

With these results in mind, another gauze electrode was tried which was narrower than the previous electrode and consequently could be suspended higher above the solution during the reactions. No improvement in the negative bias resulted.

An attempt was then made to add the reagents to a beaker one position before the titrating position. In this situation, a magnetic stirrer was to be used to stir the reacting solution. This approach was temporarily abandoned when it was found that the magnetic stirring, with the stirrer base located beneath the turntable, was too difficult to control for smooth mixing of the solution.

Another approach was then studied that involved blowing a fast stream of nitrogen down on the surface of the reacting solution during the entire operation. In the first trial of this study only 1 of 16 runs exceeded $0.1 \%$ of the theoretical value. More data will be accumulated on this modification. It is hoped that whatever step is eventually necessary to eliminate the negative bias will at the same time make it possible to eliminate the necessity of cooling the diluent. 


\section{REFERENCES}

1. Goldbeck, C. G. and Lerner, M. W. , NBL-265 (October 1972), p. 5.

2. Scarborough, J. M. and Bodnar, L. Z., NBL-267 (September 1973), p. 6 .

3. Eberle, A. R. and Lerner, M. W., NBL-258 (June 1971), p. 14.

4. Kiriyama, T. and Kuroda, R., Anal. Chim. Acta, 42, 464 (1972). 
DETERMINATION OF URANIUM IN URANIUM-THORIUM

SOLUTIONS BY CONTROLLED-POTENTIAL COULOMETRY

AT A MERCURY POOL ELECTRODE

$$
\text { K. Lewis }
$$

Uranium in graphite- and silicon carbide-coated uraniumthorium carbide nuclear fuel bead samples is determined routinely at the New Brunswick Laboratory (NBL) by the NBL titrimetric method. 1 This method generally requires 50 to $250 \mathrm{mg}$ of uranium. It was desirable to have an alternative method available that could determine smaller quantities, about $10 \mathrm{mg}$, with the same reliability of within $0.10 \%$ precision and accuracy.

The controlled-potential coulometric determination of uranium at a mercury pool has been shown to be a reliable method. 2-4 Uranium should be readily determined by this technique in uraniumthorium solutions since thorium is not electroactive at the potential used for the reduction of uranium and thus should not interfere. The method was evaluated by analyzing uranium-thorium mixtures.

\section{EXPER IMENTAL}

Reagents and Apparatus

\section{Sulfamic Acid Solution, saturated.}

Standard Uranium Solution, prepared by weight from NBL dingot uranium meta1, $99.972 \%$ uranium.

Standard Thorium Solution, prepared from reagent-grade thorium nitrate tetrahydrate.

Coulometer, M-T Controlled-Potential Coulometer system, Model 3, with cell as in reference (4).

Working Electrode, mercury, double-distilled.

Reference Electrode, saturated calomel (SCE).

Nitrogen, high-purity, dry .

\section{Procedure}

Place $7 \mathrm{ml}$ of mercury in the cell. Add 5 to $7 \mathrm{ml}$ of $0.5 \mathrm{M}$ or $1.0 \mathrm{M} \mathrm{H}_{2} \mathrm{SO}_{4}, 5$ drops of sulfamic acid solution, and the weighed aliquot of sample solution. Assemble the cell and pass nitrogen over the solution surface for $10 \mathrm{~min}$. Pre-reduce at $+0.085 \mathrm{~V}$ vs SCE until a background current of 5 to 10 Ha is attained. Turn off the coulometer and adjust the potential to $-0.325 \mathrm{~V}$ s SCE. 
Zero the integrator and start the reduction and a timer. Continue the reduction until a steady low background current of about $10 \mu \mathrm{a}$ is attained. At this point begin recording the integrator readout and time at 3 to $5 \mathrm{~min}$ intervals. When the change in readout per unit time, $\Delta Q$, is constant, record a final readout and time.

Multiply $\Delta Q$ by the titration time and subtract the product from the final integrated readout to obtain the readout corrected for the continuous background current. Run a blank without uranium in the same manner. Calculate the uranium quantity from the corrected readout by means of the electrical calibration factor of the instrument and Faraday's law in the usual way.

\section{RESULTS AND DISCUSSION}

The precision and accuracy of determining uranium in the absence of thorium were first established. For 6 determinations of about $10 \mathrm{mg}$ of uranium each, the relative standard deviation (RSD) was $0.02 \%$ and the recovery $100.00 \%$.

Initial coulometric determinations on uranium-thorium mixtures with $U:$ Th ratios of $1: 5$ gave relatively lower initial currents, longer runs and lower recoveries than those without the thorium. The electrolyte, therefore, was changed from $0.5 \mathrm{M}$ to $1.0 \mathrm{M} \mathrm{H}_{2} \mathrm{SO}_{4}$. This change improved the run behavior and the urānium recovery. The results of a series of determinations obtained with the $1 \mathrm{M}$ $\mathrm{H}_{2} \mathrm{SO}_{4}$ are shown in Table I.

TABLE I

ANALYSIS OF A URANIUM-THORIUM SOLUTION ${ }^{\mathrm{a}}$

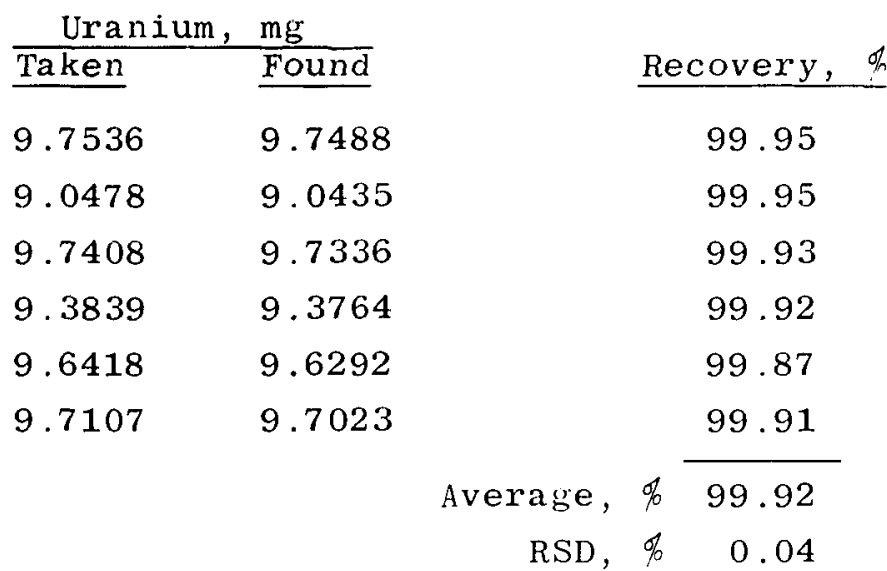

a. U:Th ratio of $1: 5$. 
Although these results are generally satisfactory, they indicate that thorium may in fact affect the determination to a smal1 degree despite the fact that it is not electroactive at these potentials. Accordingly, determinations were made of solutions in which the U:Th ratio was increased, Table II.

TABLE I I

\section{ANALYSIS OF URANIUM-THORIUM SOLUTIONS ${ }^{a}$}

\begin{tabular}{|c|c|c|c|}
\hline U:Th wt. Ratio & $\underline{N}$ & Uranium Recovery, $\%$ & RSD, \% \\
\hline (U a lone) & 7 & 99.97 & 0.06 \\
\hline $1: 5$ & 8 & 99.93 & 0.03 \\
\hline $1: 10$ & 4 & 100.01 & 0.02 \\
\hline $1: 20$ & 4 & 100.13 & 0.09 \\
\hline
\end{tabular}

a. $10 \mathrm{mg}$ U taken.

These results indicated that the method is reliable with $U: T h$ ratios at least as high as $1: 10$.

To determine if the slightly high results obtained with a ratio of $1: 20$ was due to the increased viscosity of the solution, a final series of runs were made with a smaller amount of uranium, $2 \mathrm{mg}$, and a U:Th ratio of $1: 25$. These solutions were less viscous than the previous set. The data, shown in Table III, reveal that the viscosity apparently does cause the slightly high results obtained previously. These meager data, however, are not conclusive.

TABLE I I I

ANALYSIS OF URANIUM-THORIUM SOLUTION (U:Th OF 1:25) CONTAINING LESS URANIUM ${ }^{\mathrm{a}}$

\begin{tabular}{|c|c|c|c|}
\hline U:Th Wt Ratio & $\underline{N}$ & Uranium Recovery, \% & RSD, \% \\
\hline (U a lone) & 7 & 100.07 & 0.06 \\
\hline $1: 25$ & 6 & 100.11 & 0.02 \\
\hline
\end{tabular}

a. $2 \mathrm{mg}$ uranium taken.

\section{REFERENCES}

1. Eberle, A. R., Lerner, M. W., Goldbeck, C. G. and Rodden, C. J., NBL-252 (July 1970).

2. Booman, G. L., Holbrook, W. B. and Rein, J. E., Anal. Chem., $29,219(1957)$.

3. Jones, H. C., Shults, W. D. and Dale, T. M., Anal. Chem., $37,680(1965)$.

4. Waterbury, G. R., Nelson, G. B., Bergstresser, K. S. and Metz, C. F., LA-4537 (1970). 


\section{CONTROLLED-POTENTIAL COULOMETRIC DETERMINATION OF URANIUM WITH A PLATINUM ELECTRODE AFTER REDUCTION WITH IRON(II) IN PHOSPHORIC ACID*}

\section{K. Lewis and M. W. Lerner}

The Davies and Gray ${ }^{1}$ method of determining uranium involves reduction of the uranium to uranium(IV) by iron(II) in strong phosphoric acid solution, oxidation of the excess iron(II) by nitric acid and molybdate catalyst, dilution of the phosphoric acid medium with water, and titration of the uranium(IV) with potassium dichromate.

In the present work, it was found that the uranium(IV) produced by these reactions can be determined by controlled-potential coulometry with a platinum electrode. After the dilution step, the uranium(IV) is allowed to react with the iron(III) present in the solution to produce iron(II) which is then oxidized coulometrically. The volumes of reagents are appropriately scaled down so that all the reactions take place in the conventional coulometric cell.

The results obtained for 5 to $10 \mathrm{mg}$ of uranium have a relative standard deviation of within $0.1 \%$. With an electrical calibration, a negative bias of about $0.2 \%$ exists; therefore, a chemical calibration must be used to obtain accurate results. The reason for the bias is being sought at the present writing.

\section{REFERENCE}

1. Davies, W. and Gray, W., Talanta, 11, 1203 (1964).

\footnotetext{
Accepted for presentation at the Seventeenth Conference on Analytical Chemistry in Nuclear Technology, Gatlinburg, Tenn., October 1973.
} 


\title{
X-RAY SPECTROGRAPHIC DETERMINATION OF URANIUM IN LOW-GRADE SAMPLES BY A LITHIUM TETRABORATE FUSION TECHNIQUE -
}

\author{
A PROGRESS REPORT
}

\author{
A. J. Busch and C. G. Goldbeck
}

$\mathrm{X}$-ray spectrography has the potential to analyze quickly and inexpensively those low-grade residue samples which for reasons of small quantity and inhomogeneity should not be analyzed by the highly precise and accurate New Brunswick Laboratory (NBL) titrimetric method. Moreover, these samples are generally difficult to dissolve, and total dissolution of the fairly large samples required for wet chemical analys is is tedious and slow. In these cases, X-ray spectrographic analyses may be satisfactory if the determination is faster and less tedious than the titrimetric method, and if the accuracy and precision are within $10 \%$.

In the present study the lithium tetraborate fusion ${ }^{1}$ technique was used. Refinements added to the basic fusion procedure involved the addition of lithium carbonate ${ }^{1}$ to ensure better mixing in the melt, the addition of an absorber such as lanthanum oxide ${ }^{2}$ to obtain more uniform matrices, and better casting details such as the use of high fusion temperatures and the use of graphite casting rings and block. These factors plus a more efficient measurement procedure involving a higher voltage on the target tube and a rotating sample holder gave results that appeared to be promising.

\section{EXPERIMENTAL}

Reagents and Apparatus

Lanthanum Oxide, $99.999 \%$ pure.

Lithium Tetraborate, $99.99 \%$ pure.

Lithium Carbonate, analytical reagent.

Graphite Crucibles, $21 / 4$ in. long $\times 1 / / 4$ in. OD and 1 in. ID. Graphite Casting Block and Retaining Rings, 1 1/4 in. OD and 1 in. ID.

Mixer Mi11, Spex Industries. ba 11 .

Plastic Vials, $60 \mathrm{ml}$, with $3 / 8$ in. diameter plastic mixing

Electric Furnaces, one to be used at $1100^{\circ} \mathrm{C}$, one at $600^{\circ} \mathrm{C}$. 
X-ray Spectrograph, Norelco, inverted optics with four-sample chamber, a target tube operated at $50 \mathrm{kV}$ and $20 \mathrm{~mA}$ in an a ir path together with a lithium fluoride analyzing crystal and a scintillation counter with a thallium-activated sodium iodide crystal operated at $0.75 \mathrm{kV}$. A single-channel pulse-height analyzer is adjusted to a base-1ine of $0.50 \mathrm{~V}$ with a window-width of $3.00 \mathrm{~V}$.

Procedure

Fused Disk preparation. Place about $10 \mathrm{~g}$ of sample in a plastic vial with plastic ball, and $\mathrm{mix}$ in a mixer mill for $5 \mathrm{~min}$ to break up any lumps and homogenize the sample. Place the following materials into a fresh plastic vial containing a plastic mixing ba 11: $100.0 \mathrm{mg}$ of sample; $1.00 \mathrm{~g}$ of lanthanum oxide; $0.64 \mathrm{~g}$ of lithium carbonate; and $8.00 \mathrm{~g}$ of lithium tetraborate. Shake the vial for $5 \mathrm{~min}$ in the mixer mill. Transfer the mixture to a graphite crucible and place the crucible in a furnace at $1100^{\circ} \mathrm{C}$. After 5 min remove the crucible, swirl it well, and return it to the furnace. Place the graphite casting block and ring in the $600^{\circ} \mathrm{C}$ furnace. After $10 \mathrm{~min}$, remove the block and $\mathrm{ring}$ and place them on a transite sheet. Remove the crucible from the furnace and pour the melt into the ring resting on the block. Allow to cool to room temperature. Dislodge the ring to obtain the prepared disk.

Measurement. Mount the disk in the rotating specimen holder so that the plane side is measured. Count the uranium $\mathrm{L}_{\alpha}$ peak at a $2 \theta$ of $26.14^{\circ}$, and the background on both sides of the peak at $25.14^{\circ}$ and $30.14^{\circ}$ for $100 \mathrm{sec}$ each. Calculate the net $L_{\alpha}$ count by subtraction of a weighted background equal to $3 / 4$ of the $25.14^{\circ}$ intensity plus $1 / 4$ of the $30.14^{\circ}$ intensity in the usual manner. Determine the uranium concentration from a calibration curve prepared from standards, either previously analyzed by wet chemical analysis or synthetically prepared, counted in an identical manner.

\section{RESULTS AND DISCUSSION}

The recommended procedure is based upon many exploratory tests designed to improve the homogeneity of the prepared disk and to minimize the effects of differences in sample composition. other preliminary tests indicated that reliable measurements could be obtained by using the target tube voltage and the background correction technique proposed.

The calibration curve of net uranium counts/sec vs uranium concentration is essentially linear up to $5 \%$ uranium for the particular type of residues analyzed. These residues consists chiefly of silicates and oxides and may contain calcium, aluminum, niobium, zirconium, iron and other elements in addition to the uranium.

A comparison of the $X$-ray spectrographic results and wet chemical results obtained by two different laboratories including NBL on a group of residue samples is shown in Table $I$. The wet chemical data indicate that the samples may not have been completely homogeneous. With this factor in mind and considering the small samples used here, the average $X$-ray spectrographic data with a few exceptions agree fairly well with the wet chemical values. The agreement between the duplicate $\mathrm{X}$-ray spectrographic results is 
rather poor. This poor precision is due in part to the small net counts obtained in addition to the use of small samples of a somewhat heterogeneous nature. Future work will involve attempts to obtain more homogeneity in the materials to be analyzed, and the use of a polished disk face and longer counting times to improve the reproducibility. The applicability of the standard addition or internal standard techniques to this particular type of sample may also be investigated.

TABLE I

COMPARISON OF X-RAY SPECTROGRAPHIC RESULTS WITH WET-CHEMICAL RESULTS

\begin{tabular}{|c|c|c|c|c|c|}
\hline \multirow{2}{*}{$\begin{array}{c}\text { Sample } \\
\text { No. } \\
\end{array}$} & \multicolumn{3}{|c|}{$x-$ Ray } & \multicolumn{2}{|c|}{$\begin{array}{l}\text { Wet Chemical } \\
\text { (Titrimetric) }\end{array}$} \\
\hline & (1) & (2) & Average & NBL & other \\
\hline 1 & 0.0063 & 0.0072 & 0.0068 & 0.0069 & 0.00813 \\
\hline 2 & 0.0064 & 0.0067 & 0.0066 & 0.0075 & 0.00876 \\
\hline 3 & 0.0072 & 0.0078 & 0.0075 & 0.0079 & 0.00797 \\
\hline 4 & 0.0061 & 0.0069 & 0.0065 & 0.0063 & 0.00710 \\
\hline 5 & 0.0106 & 0.0116 & 0.0111 & 0.0109 & 0.0116 \\
\hline 6 & 0.0131 & 0.0131 & 0.0131 & 0.0130 & 0.01314 \\
\hline 7 & 0.0061 & 0.0061 & 0.0061 & 0.0064 & 0.0075 \\
\hline 8 & 0.0070 & 0.0067 & 0.0069 & 0.0064 & 0.00737 \\
\hline 9 & 0.0034 & 0.0025 & 0.0030 & 0.0053 & 0.0062 \\
\hline 10 & 0.0079 & 0.0085 & 0.0082 & 0.0094 & 0.0092 \\
\hline 11 & 0.0068 & 0.0068 & 0.0068 & 0.0066 & 0.00753 \\
\hline 12 & 0.0062 & 0.0065 & 0.0064 & 0.0070 & 0.0080 \\
\hline 13 & 0.0078 & 0.0082 & 0.0080 & 0.0097 & 0.0103 \\
\hline 14 & 0.0086 & 0.0082 & 0.0084 & 0.0083 & 0.0090 \\
\hline 15 & 0.0068 & 0.0063 & 0.0066 & 0.0063 & 0.0067 \\
\hline 16 & 0.0086 & 0.0078 & 0.0082 & 0.0103 & 0.00995 \\
\hline 17 & 0.0106 & 0.0103 & 0.0105 & 0.0102 & 0.01049 \\
\hline 18 & 0.0070 & -- & 0.0070 & 0.0065 & 0.00765 \\
\hline 19 & 0.0067 & -- & 0.0067 & 0.0070 & 0.00753 \\
\hline 20 & 0.0058 & -- & 0.0058 & 0.0063 & 0.00715 \\
\hline 21 & 0.0069 & -- & 0.0069 & 0.0083 & 0.00954 \\
\hline 22 & 0.0112 & 0.0112 & 0.0112 & 0.0112 & 0.01208 \\
\hline
\end{tabular}




\section{REFERENCES}

1. Stephenson, D. A., Ana 1. Chem., 41, 966 (1969).

2. Rose, H. J., Jr., Adler, I., Flannagan, F. J., "Methods for Emission Spectrochemical Analys is," 5 th Ed., Am. Soc. Testing Mat., Philadelphia, Pa., (1968), pp. 778-782. 
NON-DESTRUCTIVE ANALYSIS OF LOW-GRADE URANIUM SAMPLES BY A PASSIVE GAMMA-RAY TECHNIQUE

R. C. Hagenauer, C. L. Zyskowski and L. C. Nelson, Jr.

The application of reliable non-destructive analysis (NDA) techniques for the determination of uranium-235 is one of the projects currently being undertaken by the New Brunswick Laboratory (NBL). The application of NDA to low-grade uranium samples is one phase of this project. Analysis of these samples by highly precise and accurate wet chemical methods is generally unwarranted for three reasons: they are often not homogeneous, and sampling errors may far outweigh the advantages of accurate measurements; the concentration of uranium in the total quantity of material represented by the sample may be small, thus the intrinsic value of the material may be low; and the dissolution of the sample is generally slow and tedious.

General NDA methods that have been used for the analysis of nuclear fuels include $f$ ission-neutron coincidence counting, 1 and 14-MeV-neutron activation ${ }^{2}$ or thermal-neutron activation with fission-product gamma-ray counting. ${ }^{3}$ These methods either are not applicable to the types of samples mentioned above because of a lack of sensitivity, or they involve variables that significantly decrease the reliability of the analyses.

Gamma-ray spectrometry has been used extensively at NBL for the analysis of low-grade samples in the past. 4,5 Correction for self-absorption, however, has always presented a problem. The decay of uranium-235 to thorium-231 is accompanied by the emission of an intense gamma ray with an energy of $185.7 \mathrm{keV}$. Since this energy is relatively low, attenuation by the typical sample to be analyzed is significant. In the present study, a technique involving ytterbium-1696 has been applied to obtain this correction. In this technique, the attenuation of a pair of gamma rays from ytterbium-169 which bracket the energy of the gamma ray from uranium-235 is observed. The quantitative measurement of the uranium-235 gamma ray and the determination of its attenuation correction are the basic factors in the proposed method.

\section{EXPER IMENTAL}

\section{Apparatus}

Via 1s, polystyrene, $22 \mathrm{~mm}$ OD $x 12 \mathrm{~mm}$ high, and $39 \mathrm{~mm}$ OD $x 12 \mathrm{~mm}$ high. (The larger vial, used for samples of low uranium-235, can accommodate nearly four times as much sample as the smaller vial. The smaller vial is adequate for most samples.)

Counting Equipment. A Ge(Li) detector with a cobalt-60 gammaray efficiency of $4 \%$ relative to a $3 \times 3$ in. NaI detector, and a 
resolution of $1.32 \mathrm{keV}$ at the $185.7 \mathrm{keV}$ gamma ray was used in conjunction with an 8192-channel analog-to-digital converter interfaced to a PDP-15 computer. A block diagram of the electronic configuration is shown in Figure 1 .

Procedure

For a series of measurements on similar samples, proceed as follows :

(1) select a sample with a uranium-235 concentration that gives a count rate approximating the average activity of the series;

(2) adjust the pulser frequency to a value within a factor of five of the $185.7-\mathrm{keV}$ gamma-ray peak activity;

(3) select a ytterbium-169 source so that the intensities of the $177.2-$ and $198.0-\mathrm{keV}$ peaks are also within a factor of five of the intensity of the $185.7-\mathrm{keV}$ peak;

(4) adjust the counting time so that at least 10,000 counts at the uranium-235 peak will be collected;

(5) when the correct pulser frequency has been established, record a spectrum of the pulser only;

(6) with an empty vial in place, take a blank count of both the ytterbium-169 source and the pulser;

(7) with a vial containing a sample in place, collect the spectral data for ytterbium-169, uranium-235 and the pulser; for each series of samples count a standard sample to check the overall counting electronics;

(8) Iinally, determine the height of the sample in the vial with the vial on its side.

Acquire the data and calculate peak areas by means of two computer programs. Use the $\mathrm{PHA}_{4} \mathrm{~K}^{7}$ program to acquire data in 1024 channels of computer memory. Accumulate data from lour spectral areas ( $4 \mathrm{~K}$ data area) and store on magnetic tape. At a later time, retrieve the data, compute and read out the peaks of interest by means of the peak-fitting program GASPAN. ${ }^{8}$

\section{RESULTS AND DISCUSSION}

pulser Correction. The variable frequency pulser shown in Figure 1 is used to correct for detector pile-up. As the count rate increases, the percentage of counts lost increases. The decrease in the pulser count rate is a measure of this loss. The correction can differ by $7 \%$ between standards and samples.

Geometry Correction. The size of the sample is variable. Assuming that all the activity is coming from a point source at the center of the sample, it can be seen that as the sample volume in the vial increases, the distance from the point source to the detector will increase and the solid angle subtended by the detector will decrease. 


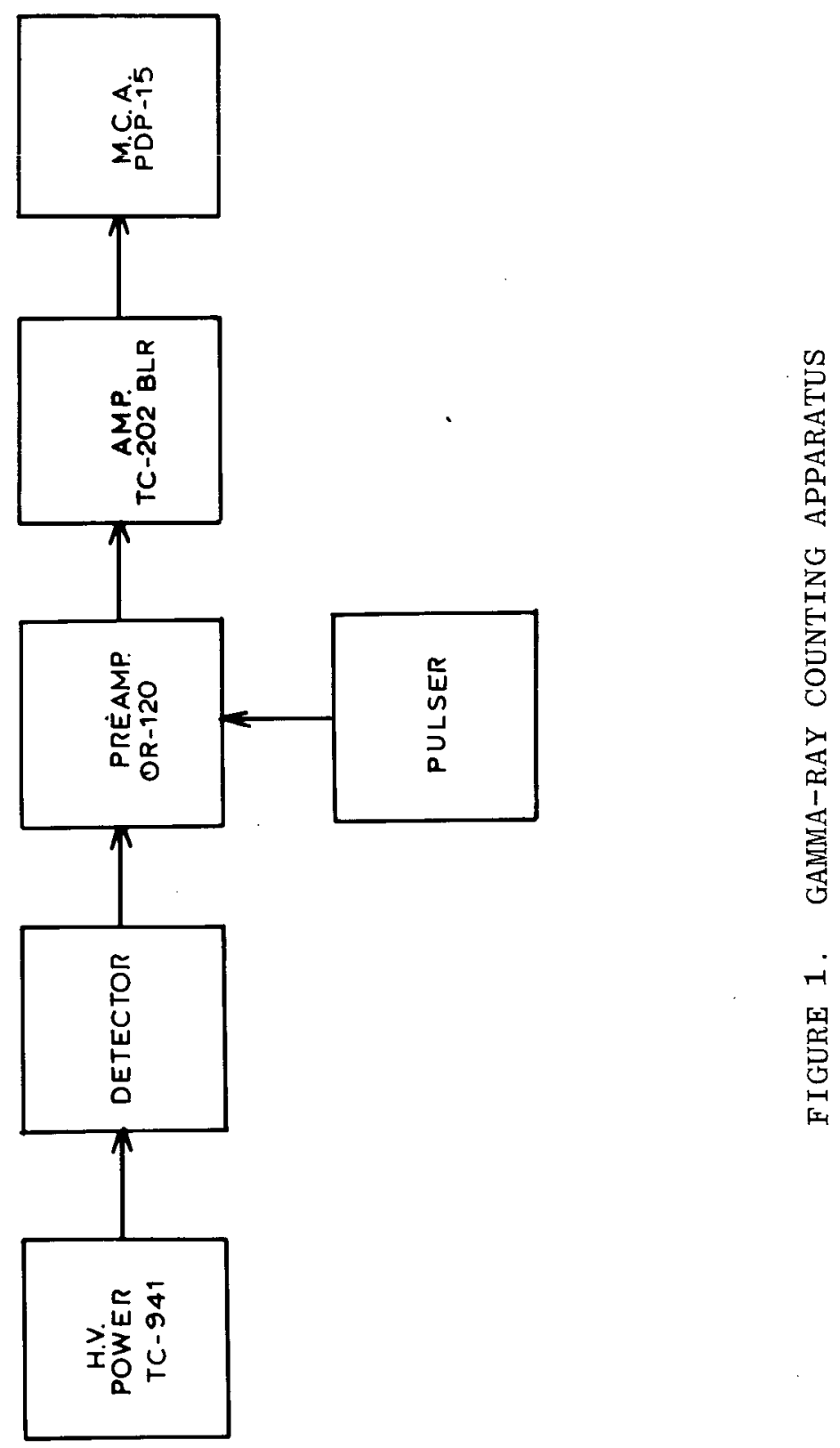


Since the vial is a thin cylinder, it is easier to measure the sample volume by placing the vial on its side and measureing the sample height perpendicular to the plane which is tangent to the vial circumference rather than measuring the sample height along the central axis. In this way small volume differences between samples become more apparent. The height of a sample measured this way is related to the volume by the equation:

$$
\mathrm{V}_{\mathrm{S}}=\mathrm{h}\left[\left(\mathrm{T}-\frac{\mathrm{d}}{2}\right)\left(\mathrm{dT}-\mathrm{T}^{2}\right)^{\frac{1}{2}}+\frac{\mathrm{d}^{2}}{4}\left(\sin ^{-1}(\mathrm{x})+\frac{\pi}{2}\right)\right]
$$

where

$$
\begin{aligned}
& \mathrm{v}_{\mathrm{S}}=\text { sample volume, } \mathrm{mm}^{3} ; \\
& \mathrm{h}=\text { thickness (height) of vial, } \mathrm{mm} ; \\
& \mathrm{d}=\text { diameter of vial, } \mathrm{mm} ; \\
& \mathrm{T}=\text { measured height of sample, } \mathrm{mm} ; \\
& \mathrm{x}=\left[\left(\mathrm{T}-\frac{\mathrm{d}}{2}\right) / \frac{\mathrm{d}}{2}\right]
\end{aligned}
$$

and

The heights can be measured reproducibly to $0.5 \mathrm{~mm}$. A computer program was used to calculate the actual volume at $0.5-\mathrm{mm}$ height intervals. The fraction of the vial capacity occupied by the sample can then be calculated by dividing the sample volume by the total volume of the vial:

$$
\mathrm{Cf}=\mathrm{V}_{\mathrm{S}} / \mathrm{V}_{\mathrm{V}}=\text { capacity fraction }
$$

where

$$
\begin{aligned}
v_{v} & =\text { volume of empty vial, } \mathrm{mm}^{3} ; \\
& =\pi \mathrm{d}^{2} \mathrm{~h} / 4 .
\end{aligned}
$$

A preliminary peak efficiency tor the $185.7-\mathrm{keV}$ gamma ray was estimated. After correcting the observed peak counts for gammaray attenuation, the geometry factor, GF, was determined by the use of standards from the following equation:

$$
\mathrm{GF}=\frac{\mathrm{Pe}}{\mathrm{observed} \mathrm{C} / \mathrm{sec} \cdot \mathrm{mg}^{235} \mathrm{U}}
$$

where

$$
\begin{aligned}
& \mathrm{Pe}=\text { peak efficiency of counting system, in units of } \\
& \frac{\mathrm{C}}{\mathrm{sec} \cdot \mathrm{mg} 235 \mathrm{U}}
\end{aligned}
$$

and $\quad \mathrm{C}=$ counts

The Cf vs GF was then plotted and a linear least squares fit through the points was computed. Since the GF must approach 1 as the sample volume approaches 0 , the slope was forced to go through the origin by correcting the estimated gamma-ray peak efficiency. This corrected peak efficiency thus is a more accurate value for the actual peak efficiency for the counting system. These data are shown in Table 1 and Figure 2. The scatter of the points in Figure 2 is believed to be due to some inhomogeneity of the (synthetic) standard samples. 


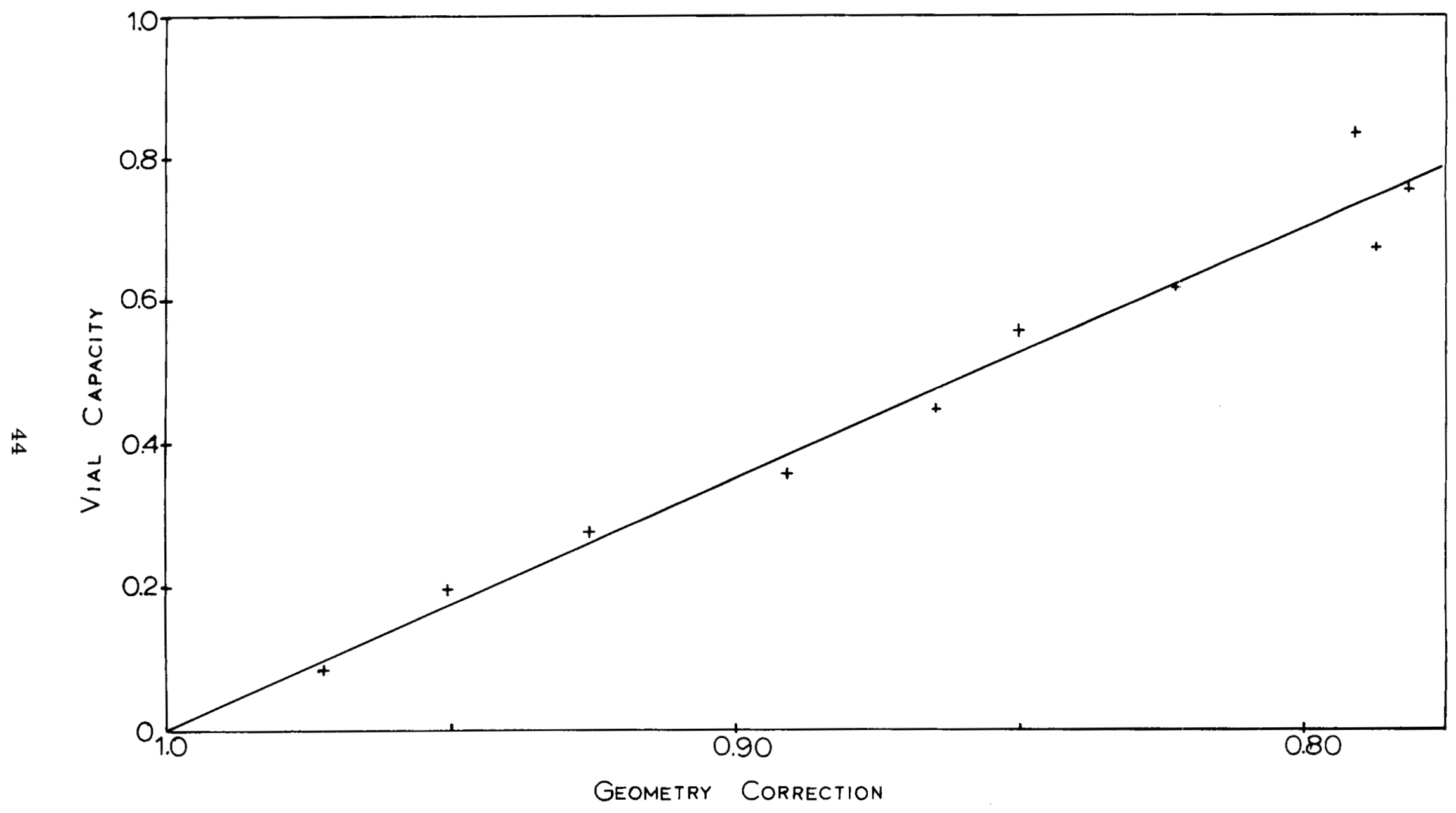

FIGURE 2 . CORRECTION FOR GEOMETRY EFFECTS OF SAMPLE SIZE 
TABLE I

VARIATION OF GEOMETRY CORRECTION WITH CAPACITY FRACTION

\begin{tabular}{ccc} 
Sample Height, mm & Capacity Fraction & Geometry Correction \\
\hline 3.0 & 0.081 & 0.972 \\
5.5 & 0.195 & 0.951 \\
7.0 & 0.273 & 0.926 \\
8.5 & 0.356 & 0.891 \\
10.0 & 0.442 & 0.864 \\
12.0 & 0.557 & 0.850 \\
13.0 & 0.615 & 0.823 \\
14.0 & 0.671 & 0.787 \\
15.5 & 0.753 & 0.782 \\
17.0 & 0.829 & 0.792
\end{tabular}

Self Absorption. Since the 185.7-keV gamma ray is of low energy, it is absorbed significantly within the sample according to the following equation:

$$
A=A_{O} e^{-\mu x}
$$

where

$$
\begin{aligned}
& A=\text { measured activity of the sample, counts; } \\
& A_{0}=\text { true activity (at zero self-absorption), counts; } \\
& \mu=\text { linear absorption coefficient of the sample } \\
& \text { matrix, } \mathrm{mm}^{-1} \text {; } \\
& \text { and } \quad x=\text { distance through the sample which uranium-235 } \\
& \text { gamma rays must travel, } \mathrm{mm} \text {. }
\end{aligned}
$$

The attenuation by the sample was measured by the ytterbium-169source technique. ${ }^{6}$ The ytterbium-169 isotope has $177.2-\mathrm{keV}$ and 198.0-keV gamma rays that bracket in energy the 185.7-keV gamma ray of uranium-235. Consequently, the average ytterbium-169 attenuation is an estimate of the attenuation of the radiation from uranium-235. Since the assumption has been made that the activity of the uranium-235 arises from the center of the material, and since the ytterbium-169 is placed on top of the material in the vial, its gamma rays must pass through twice as much material as the uranium235 gamma rays. Attenuation (Att) of ytterbium-169 can then be represented by the relationship:

$$
\text { Att }=\frac{A_{O}}{A}=e^{2 \mu x}=e^{b}
$$

where $\quad \mathrm{b}=2 \mu \mathrm{x}$. 
The ytterbium-169 attenuation was calculated by counting the ytterbium-169 source through an empty vial previous to counting the standard. Since, on the average, uranium-235 gamma rays travel only half the distance travelled by ytterbium-169 gamma rays, its attenuation can be approximated by the following calculation:

$$
\left.\operatorname{Att}_{(169} \mathrm{Yb}\right)=\mathrm{e}^{\mathrm{b}}
$$

therefore,

$$
\mathrm{b}=\ln \left[\mathrm{Att}\left(\mathbf{1 6 9}_{\mathrm{Yb})}\right]\right.
$$

Let

$$
\mathrm{c}=\mathrm{b} / 2
$$

therefore,

$$
\mathrm{e}^{\mathrm{C}}=\operatorname{Att}(235 \mathrm{U})
$$

Standards of known uranium-235 content were prepared in different matrices of different densities and average atomic number. Pulser and vial capacity corrections were made for each count. Both ytterbium-169 and uranium-235 attentuation factors were determined experimentally. Attenuation factors for the uranium-235 standards were determined by comparing the measured gamma activity to the amount of uranium-235 gamma activity expected after correction for geometry and detector peak efficiency. Table 2 lists the experimentally determined attenuation factors for ytterbium-169 and uranium-235. The attenuation factors for uranium-235 were also calculated using the expressions derived above (equations 4 to 8 ) in combination with the experimental values of Att $(169 \mathrm{Yb})$. The solid line in Figure 3 represents a least squares fit of the relationship between Att $(169 \mathrm{Yb})$ and Att $(235 \mathrm{U})$ for different matrices. Most of the points obtained by counting uranium-235 standards (appearing as points on graph) fall close to the line of the theoretical slope. It is not yet known why the standards containing a natural uranium matrix show greater deviations.

Analysis of Samples. The quantity of uranium-235 is calculated using the detector peak efficiency as follows:

$$
235 \mathrm{U}, \mathrm{mg}=\frac{(\mathrm{P})(\mathrm{PF})(\mathrm{G})}{(\mathrm{H})(\mathrm{Pe})(\mathrm{t})}
$$

where

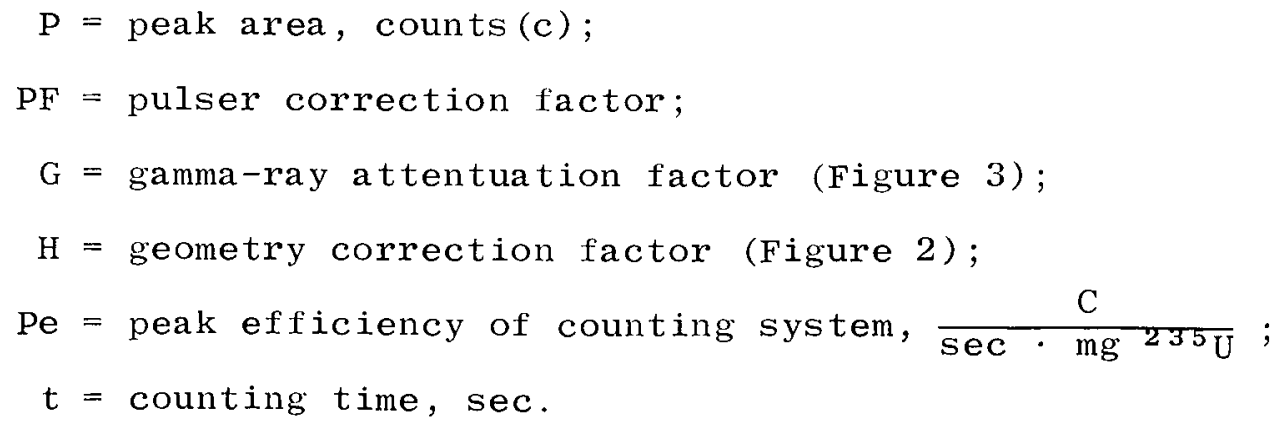




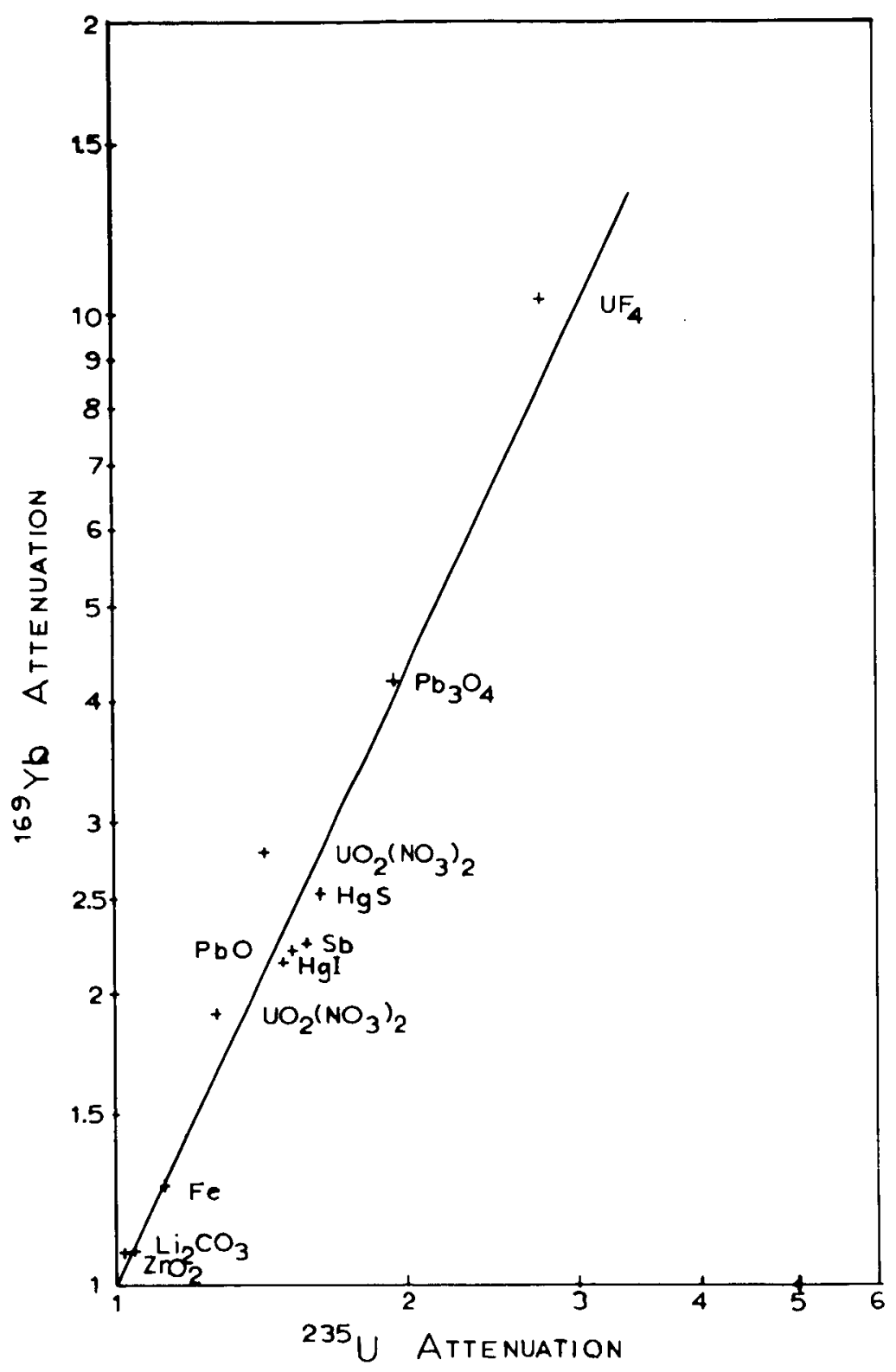

FIGURE 3. CORRECTION FOR GAMMA-RAY ATTENUATION 
URANIUM-235 GAMMA-RAY ATTENUATION WITH VARIOUS MATRICES

Sample Matrix

$\mathrm{UO}_{2}\left(\mathrm{NO}_{3}\right)_{2}$

Hg I

$\mathrm{Fe}$

$\mathrm{Li}_{2} \mathrm{CO}_{3}$

$\mathrm{Sb}$

$\mathrm{UF}_{4}$

$\mathrm{UO}_{2}\left(\mathrm{NO}_{3}\right)_{2}$

$\mathrm{Pb}_{3} \mathrm{O}_{4}$

$\mathrm{HgS}$

$\mathrm{Pb}_{3} \mathrm{O}_{4}$

$\mathrm{PbO}$

$\mathrm{ZrO}_{2}$

\begin{tabular}{|c|c|}
\hline Average $169 \mathrm{Yb}$ & $235 \mathrm{U}$ \\
\hline 1.90 & 1.27 \\
\hline 2.16 & 1.49 \\
\hline 1.26 & 1.12 \\
\hline 1.08 & 1.01 \\
\hline 2.20 & 1.51 \\
\hline 10.35 & 2.76 \\
\hline 2.80 & 1.43 \\
\hline 4.20 & 1.94 \\
\hline $\begin{array}{l}2.53 \\
2.50\end{array}$ & $\begin{array}{l}1.62 \\
1.63\end{array}$ \\
\hline 4.13 & 2.04 \\
\hline 2.25 & 1.58 \\
\hline 1.08 & 1.04 \\
\hline
\end{tabular}

A set of data obtained for actual samples is shown in Table III. The activity range is typical of the usual residue or scrap sample received at NBL for analysis. The attenuation corrections are small because of the small quantities of samples used. The agreement of less than $1 \%$ between duplicate samples indicates the reliability of the attenuation and sample height correction factors and also the homogeneity of the samples. In Table IV, the total uranium results calculated on the basis of the isotopic abundance values are given together with the chemical values obtained by another laboratory. (Chemical values obtained by NBL are not available at the present time.) 
TABLE III

ANALYSIS OF CALCINED ASH RESIDUES ${ }^{a}$

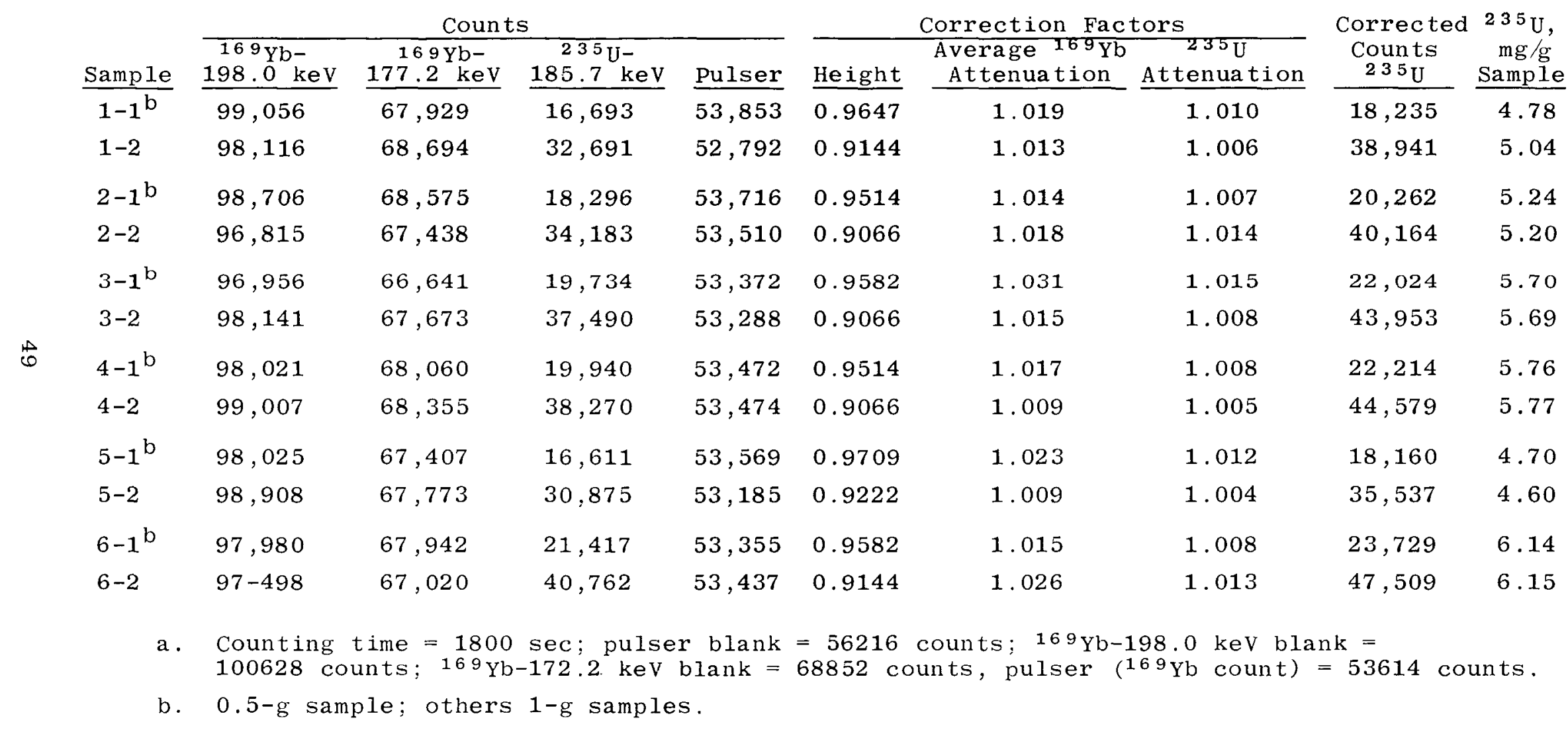


TABLE IV

COMPARISON OF NDA AND CHEMICAL RESULTS IN SAMPLES

\begin{tabular}{|c|c|c|}
\hline \multirow[b]{2}{*}{ Sample } & \multicolumn{2}{|c|}{$\mathrm{U}, \mathrm{mg} / \mathrm{g}$} \\
\hline & $\mathrm{NDA}$ & Chemical \\
\hline $1-1$ & 5.20 & 5.35 \\
\hline $1-2$ & 5.55 & -- \\
\hline $2-1$ & 5.77 & 5.89 \\
\hline $2-2$ & 5.73 & -- \\
\hline $3-1$ & 6.28 & 6.11 \\
\hline $3-2$ & 6.27 & -- \\
\hline $4-1$ & 6.32 & 6.21 \\
\hline $4-2$ & 6.36 & -- \\
\hline $5-1$ & 5.18 & 5.29 \\
\hline $5-2$ & 5.07 & -- \\
\hline $6-1$ & 6.76 & 6.75 \\
\hline $6-2$ & 6.77 & -- \\
\hline
\end{tabular}

\section{REFERENCES}

1. Walton, R. B., LA-4457-MS (1970), p. 26 .

2. Augustson, R. H. and Evans, A. E., LA-4605-MS (1970), p. 7 .

3. Bussel1, H. and Nelson, L. C., Jr., NBL-147 (November 1958), p. 57 .

4. Nelson, L. C., Jr., NBL-159 (May 1960), p. 87 .

5. Nelson, L. C., Jr., Nucleonics, 21, 88 (June 1963).

6. Walton, R. B., Augustson, R. H., East, L. V., Evans, A. E., Foley, J. E., Forster, R. A., Keepin, G. R., Malanify, J. J., Menlove, H. O., Menzel, J. H., Parker, J. L., Reilly, T. D., Smith, D. B., Thorpe, M. M. and Weisbin, C. R., LA-DC-12801, 1972 .

7. "Pulse Height Analyzers Software User's Guide," Digital Equipment Corp., Maynard, Mass.

8. "Gamma SpectraI (GASPAN) and Isotope Identification (ISOID)," Digital Equipment Corp., Maynard, Mass. 


\section{DETERMINATION OF URANIUM-235 BY A DELAYED NEUTRON COUNTING TECHNIQUE}

R. C. Hagenauer, C. L. Zyskowski and L. C. Nelson, Jr.

Determination of the uranium-235 content of samples weighing up to $20 \mathrm{~g}$ has been carried out by bombarding with thermal neutrons and counting the delayed neutrons arising from fission of the uranium-235. Standards containing uranium-235 are treated in the same manner. Because of the high thermal-neutron cross section of uranium-235, self-absorption is an important factor in the analysis, especially in samples such as pyrocarbon- and silicon carbidecoated uranium-thorium carbide nuclear fuel beads which have relatively high local concentrations of uranium-235.

\section{EXPER IMENTAL}

\section{Apparatus}

Vials, polystyrene, $16 \mathrm{~mm}$ OD x $55 \mathrm{~mm}$ high.

Neutron Source. The thermal-neutron source assembly consists of a $250-\mu \mathrm{g}$ californium-252 source placed in the center of a beryllium block 6 in. $x 6$ in. $x 8$ in. surrounded by 10 in. of paraffin. A hole 2 in. in diameter is drilled through the parafitin and beryllium to within 2 in. of the californium-252 source, Figure 1. In this hole is placed a sample vial holder made from a 2-in. diameter lucite rod with a 9/16 in. hole down the center. This combination of beryllium and plastic gives an even tlux distribution along the sample and a fairly high degree of moderation.

Counting Equipment. The neutron counter consists of thirty 20-in. long helium-3 detector tubes placed in 3 concentric circles around a 2-in. diameter well to provide an absolute efficiency of $40 \% .1$ pulses from the detectors are amplitied and counted on NIM scaler equipment. An additional pulse discriminator circuit is used to reject gamma-ray pulses. Ten seconds after the vial is removed from the neutron source, a microswitch located in the assembly automatically initiates the counting by activating a timer. The scaler count and sample identification number are printed and punched on paper tape by an attached teletype for subsequent computer reduction. A block diagram is shown in Figure 2 .

\section{Procedure}

Place a weighed sample in a sample vial, position the vial in the neutron source assembly, and bombard for $2 \mathrm{~min}$. Transfer the vial manually to the neutron detector well and take a $200-\mathrm{sec}$ count $10 \mathrm{sec}$ after removal from the neutron source. 


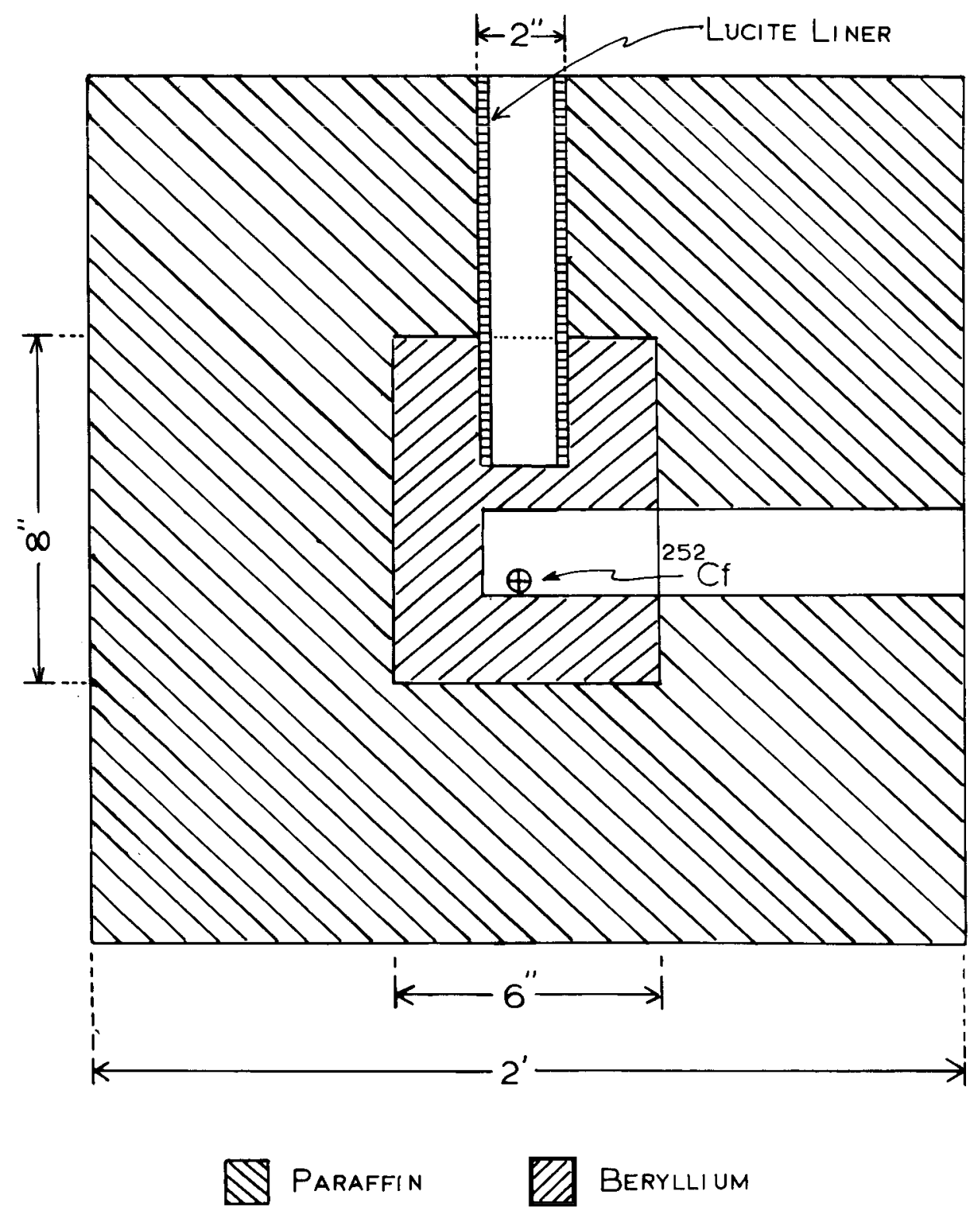

FIGURE 1. CALIFORN I UM-252 BOMBARDMENT CONFIGURATION 


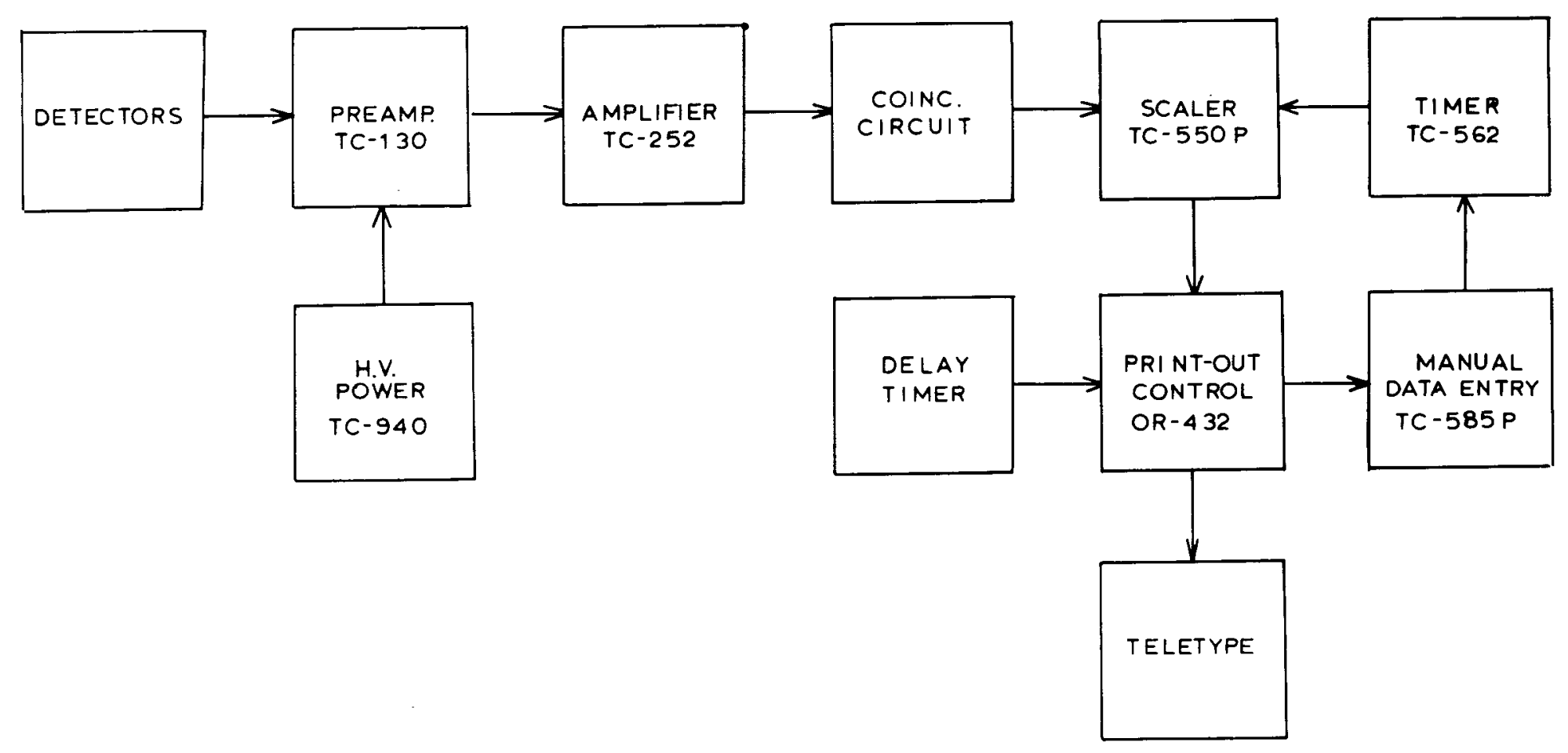

FIGURE 2 . DELAYED NEUTRON COUNTING APPARATUS 
As the uranium-235 quantity in the sample approaches $200 \mathrm{mg}$, significant self-shadowing to the neutron flux occurs as shown in the calibration curve, Figure 3 . At these levels, thorough mixing of the standards and samples to obtain homogeneity is important to ensure uniform self-absorption.

The proposed procedure was used to analyze synthetic uranium dioxide-thorium dioxide mixtures with known uranium concentrations, and samples of pyrocarbon- and silicon carbide-coated uraniumthorium carbide nuclear fuel beads. With the latter samples an estimation of accuracy was obtained by using the average of many wet chemical results obtained by several laboratories as the true value. The NDA results, shown in Table I, were calculated from the determined uranium-235 values on the basis of the known isotopic abundances. A positive bias of about $3 \%$ is in evidence. It is estimated that the lower limit of determination is about $20 \mathrm{mg}$ of uranium-235.

TABLE I

THERMAL NEUTRON ANALYSIS OF URANIUM-THORIUM MIXTURES

\begin{tabular}{|c|c|c|c|c|}
\hline Sample Type & $\begin{array}{l}\text { Approximate } \\
\text { Quantity of U } \\
\text { Determined,mg }\end{array}$ & $\begin{array}{l}\text { Number of } \\
\text { Determi- } \\
\text { nations, } \underline{\underline{N}}\end{array}$ & $\begin{array}{c}\text { Accuracy }{ }^{a} b \\
(\text { Difference) } \\
\% \\
\end{array}$ & $\begin{array}{l}\text { Precision } \\
\text { (RSD), } \% \\
\end{array}$ \\
\hline $\mathrm{UO}_{2}-\mathrm{ThO}_{2}$ & 310 & 30 & +3.12 & 0.65 \\
\hline $\begin{array}{l}\text { Riffled Fuel } \\
\text { Beads }\end{array}$ & 510 & 29 & +2.98 & 0.53 \\
\hline $\begin{array}{l}\text { Unriffled Fuel } \\
\text { Beads }\end{array}$ & 510 & 30 & +2.66 & 1.02 \\
\hline
\end{tabular}

a. Accuracy $=\left(\frac{\text { Determined Value-"True" Value }}{\text { "True" Value }}\right) \cdot 100$

b. "True" value obtained from 17 values in the case of the riffled beads, and 18 values on the unriffled.

Future work designed to reduce the effects of self-absorption will involve modification of the source configuration to increase the flux of neutrons of intermediate energy.

\section{REFERENCE}

1. Fabricated by the Department of Applied Science, Brookhaven National Laboratory, Upton, N. Y. 


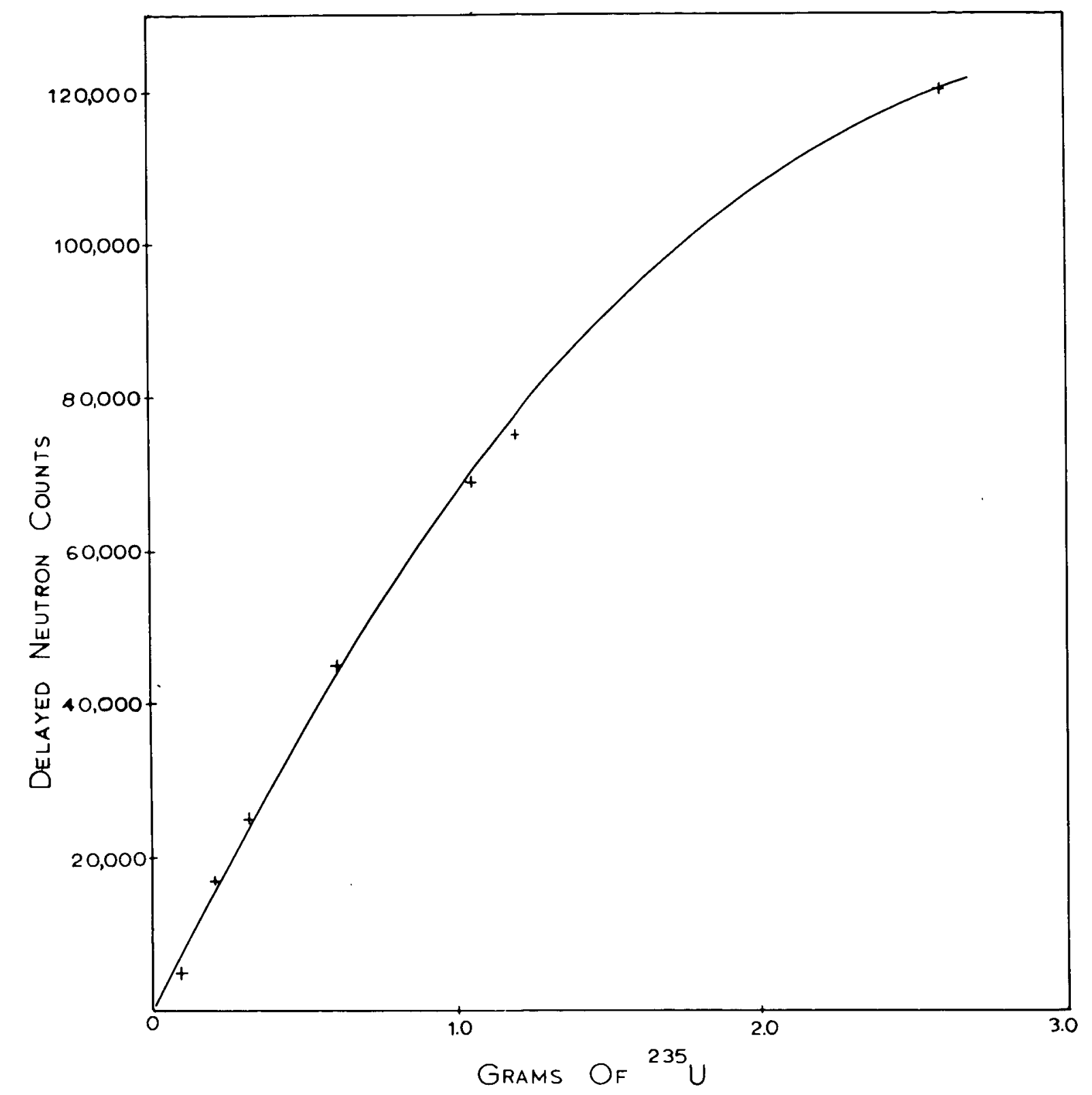

FIGURE 3. DELAYED NEUTRON CALIBRATION CURVE. 
PREPARATION OF TEST MATERIALS FOR AN INTERLABORATORY CALIFORN IUM-252 ACTIVATION ANALYSIS EVALUATION PROGRAM

N. M. Trahey, J. M. Scarborough and L. Z. Bodnar

Investigations designed to evaluate the general applicability of californium-252 as a neutron source for activation analysis have been underway for several years within the Atomic Energy Commission. As part of this continued evaluation, Savannah River Operations office (SROO) was given the responsibility of administering an interlaboratory evaluation program involving the use of californium-252 for activation analysis, and the New Brunswick Laboratory (NBL) was assigned the task of implementing the preparation and distribution of the test materials. The test materials were to consist of one $2 \mathrm{~N}$ nitric acid solution containing 13 elements at various trace levels, and one solid material composed of a $70 \%$ silica, $20 \%$ iron oxide and $10 \%$ calcium carbonate matrix containing the identical trace elements at different concentration levels. The preparation and characterization of these test materials are described in the present report.

\section{Part I. Preparation of Test Materials}

It was requested of NBL that these test materials be prepared with the trace impurities at known concentrations within the definite concentration ranges 1 isted in Table I.

\section{TABLE I}

\section{SPECIFIED CONCENTRATION RANGES FOR TRACE} ELEMENTS IN TEST MATERIALS

\begin{tabular}{|c|c|c|c|}
\hline Element & $\begin{array}{c}\text { Concentration Range, } \\
\mu \mathrm{g} / \mathrm{g}\end{array}$ & Element & $\begin{array}{r}\text { Concentration } \\
\mu \mathrm{g} / \mathrm{g} \\
\end{array}$ \\
\hline $\mathrm{Na}$ & $100-1000$ & As & $20-200$ \\
\hline Al & $50-500$ & $\mathrm{Se}$ & $500-5000$ \\
\hline $\mathrm{V}$ & $10-100$ & Mo & $400-4000$ \\
\hline Mn & $2-20$ & $\mathrm{Cd}$ & $500-5000$ \\
\hline $\mathrm{Co}$ & $100-1000$ & $\mathrm{Eu}$ & $0.2-2.0$ \\
\hline $\mathrm{Cu}$ & $20-200$ & $\mathrm{Hg}$ & $300-3000$ \\
\hline $\mathrm{Zn}$ & $1000-10,000$ & & \\
\hline
\end{tabular}


The test materials were to be essentially a dilute nitric acid solution for the liquid material, and a $70 \%$ silica, $20 \%$ iron oxide, and $10 \%$ calcium carbonate matrix for the solid material. Note that the concentrations were to be prepared and reported on a weight basis, $\mu \mathrm{g} / \mathrm{g}$ of test material.

\section{EXPERIMENTAL}

Reagents and Apparatus

Silica, prepared from certified ACS reagent silicic acid, 325 mesh, by drying at $160^{\circ} \mathrm{C}$ for $48 \mathrm{hr}$ and igniting at $500^{\circ} \mathrm{C}$ for $16 \mathrm{hr}$.

Ferric Oxide, certified ACS reagent.

Calcium Carbonate, certified ACS reagent.

All other reagents were either high-purity or analytical reagent-grade except as otherwise stated.

Water, deionized.

V-Blender, polymethylme thacrylate.

Ball Mill, polyethylene with porcelain balls.

Sieve, 40 mesh, nylon.

\section{Procedure}

\section{Preparation of Stock Solutions}

Prepare all stock solutions so that the concentration is known both by volume and by weight of final solution.

Sodium, $100.0 \mathrm{mg} / \mathrm{ml}$ and $81.71 \mathrm{mg} / \mathrm{g}$. Prepare by dissolving. $\mathrm{NaNO}_{3}$ in water and diluting to volume and weight.

Aluminum, $20.0 \mathrm{mg} / \mathrm{ml}$ and $18.17 \mathrm{mg} / \mathrm{g}$. Prepare by dissolving $\mathrm{Al}\left(\mathrm{NO}_{3}\right)_{3} \cdot 9 \mathrm{H}_{2} \mathrm{O}$ in water and diluting to volume and weight. Determine the final concentration by evaporating an aliquot, and icniting to $\mathrm{Al}_{2} \mathrm{O}_{3}$, and weighing.

Vanadium, $2.0 \mathrm{mg} / \mathrm{ml}$ and $2.00 \mathrm{mg} / \mathrm{g}$. Prepare by dissolving $\mathrm{NH}_{4} \mathrm{VO}_{3}$ in water and diluting to volume and weight. Determine the final concentration by evaporating an aliquot, igniting to $\mathrm{V}_{2} \mathrm{O}_{5}$, and weighing.

Manganese, $10.0 \mathrm{mg} / \mathrm{ml}$ and $9.76 \mathrm{mg} / \mathrm{g}$. Prepare by dissolving Mn metal in dilute $\mathrm{HNO}_{3}$ and diluting to volume and weight.

Coba1t, $50.4 \mathrm{mg} / \mathrm{ml}$ and $44.66 \mathrm{mg} / \mathrm{g}$. Prepare by dissolving Co metal in dilute $\mathrm{HNO}_{3}$ and diluting to volume and weight.

Zinc, $50.0 \mathrm{mg} / \mathrm{ml}$ and $44.85 \mathrm{mg} / \mathrm{g}$. Prepare by dissolving $\mathrm{Zn}$ metal in dilute $\mathrm{HNO}_{3}$ and diluting to volume and weight. 
Arsenic, $10.5 \mathrm{mg} / \mathrm{ml}$ and $10.34 \mathrm{mg} / \mathrm{g}$. Prepare by dissolving $\mathrm{As}_{2} \mathrm{O}_{3}$ in $2 \% \mathrm{HNO}_{3}$ and diluting to volume and weight.

Selenium, $94.8 \mathrm{mg} / \mathrm{ml}$ and $89.65 \mathrm{mg} / \mathrm{g}$. Prepare by dissolving $\mathrm{H}_{2} \mathrm{SeO}_{3}$ in dilute $\mathrm{HNO}_{3}$ and diluting to volume and weight. Determine the final concentration by reducing an aliquot with hydroxylamine hydrochloride and weighing the selenium metal.

Molybdenum, $99.9 \mathrm{mg} / \mathrm{ml}$ and $89.00 \mathrm{mg} / \mathrm{g}$. Prepare by dissolving $\left(\mathrm{NH}_{4}\right) \overline{6}_{6} \mathrm{MO}_{7} \mathrm{O}_{24} \cdot 4 \mathrm{H}_{2} \mathrm{O}$ in dilute $\mathrm{NH}_{4} \mathrm{OH}$ and diluting to volume and weight. Determine the final concentration by evaporating an aliquot, igniting to $\mathrm{MoO}_{3}$, and weighing.

Cadmium, $70.0 \mathrm{mg} / \mathrm{m} 1$ and $62.89 \mathrm{mg} / \mathrm{g}$. Prepare by dissolving Cd metal in dilute $\mathrm{HNO}_{3}$ and diluting to volume and weight.

Mercury, $100.4 \mathrm{mg} / \mathrm{ml}$ and $88.70 \mathrm{mg} / \mathrm{g}$. Prepare by dissolving $\mathrm{Hg}$ metal in dilute $\mathrm{HNO}_{3}$ and diluting to volume and weight.

Copper, $10.2 \mathrm{mg} / \mathrm{ml}$ and $9.40 \mathrm{mg} / \mathrm{g}$. Prepare by dissolving $\mathrm{Cu}$ metal in $\mathrm{HNO}_{3}$ and diluting to volume and weight.

Europium, $1.00 \mathrm{mg} / \mathrm{ml}$ and $0.987 \mathrm{mg} / \mathrm{g}$. Prepare by dissolving $\mathrm{Eu}_{2} \mathrm{O}_{3}$ in $\mathrm{HNO}_{3}$ and diluting to volume and weight. Determine the final concentration by reducing an aliquot on a Jones reductor, adding the reduced aliquot to excess ferric chloride, and titrating the ferrous iron formed with potassium dichromate.

Preparation of Dilute Acid Test Material

Weigh a 9-kg quantity of $2 \mathrm{~N} \mathrm{HNO}_{3}$ into a large carboy. Add weighed aliquots of the appropriate size of each stock solution. Mix thoroughly. Calculate the concentration of additives in $\mu \mathrm{g} / \mathrm{g}$ of final solution. Determine a density value for the solution to obtain the concentrations on a volume basis. Bottle the test material in 1-1. glass bottles with polycone screw caps.

preparation of $\mathrm{SiO}_{2}-\mathrm{Fe}_{2} \mathrm{O}_{3}-\mathrm{CaCO}_{3}$ Matrix Test Material

(NOTE: Perform most of these operations in a hood and wear a surgical mask and eye goggles because the finely divided materials dust bad1y.)

Weigh into a No. 13 porcelain evaporating dish $2800 \mathrm{~g}$ of silica. Weigh out appropriate aliquots of each trace element stock solution and combine all the trace element aliquots in 1.31 . of $2 \mathrm{~N} \mathrm{HNO}_{3}$ contained in a 2-1. separatory funnel except those for mercury, selenium and molybdenum. Add the mixed solution to the silica with constant mixing with a large plexiglass spatula. Rinse the separatory funnel with small amounts of $2 \mathrm{~N} \mathrm{HNO}_{3}$ and add the rinsings to the dish with mixing. Add the mercury, selenium and molybdenum aliquots individually to the silica in the same way. Blend the mixture thoroughly and add water until the mixture changes from a lumpy paste to a smooth slurry. (The total volume of liquid required to obtain this creamy mixture is about $3350 \mathrm{ml}$.) 
Place the dish in a drying oven at $110^{\circ} \mathrm{C}$ for $24 \mathrm{hr}$. Mix the cooled contents thoroughly and repeat the drying for $24 \mathrm{hr}$ until the weight is constant (about $120 \mathrm{hr}$ ). Add $800 \mathrm{~g}$ of iron oxide and $400 \mathrm{~g}$ of calcium carbonate, mixing dry but thoroughly after each addition. place the mixture in a $\mathrm{V}$-blender and mix for $8 \mathrm{hr}$. Transfer the mixture to a ball mill and mill for $36 \mathrm{hr}$. Sieve the material through a 40-mesh nylon screen and return it to the $\mathrm{V}$-blender for an additional $4 \mathrm{hr}$ of blending. Bottle the test material in 2 polyethylene containers.

\section{DISCUSSION OF PREPARATIONS}

The nature of the solid matrix composition precluded the usual preparatory procedure of using standard pools of trace elements added to the premixed matrix because the dilute acid pools would destroy portions of the calcium carbonate and iron oxide. For this reason the pools had to be added to the silica and the acid removed before the calcium carbonate and iron oxide were added.

A single pool could not be made of all the trace element aliquots; mercury, selenium and molybdenum precipitated when added to the other elements. Accordingly, separate pools were made of these elements.

In the addition of the pools to the silica, the usual technique of adding the minimum amount of liquid just to wet the solid could not be used here. When this procedure was applied, the silica proved difficult to wet: large lumps together with dry powder were apparent until sufficient liquid was added to form the creamy slurry. Only this slurry could be blended efficiently.

For the solid test material, the aliquot weights and resulting calculated concentrations are given in Table II. These calculated concentrations will differ from the final concentrations if the "blank" matrix mixture contains traces of the particular element. In the case of manganese, no aliquot was added because analyses of the blank matrix materials indicated that the desired level would be obtained by the "blank" quantities only.

Homogeneity of the solid test material was verified by emission spectrographic analyses of random bottled samples for all elements except selenium, arsenic, sodium and europium.

Of some concern was the stability, that is, freedom from precipitation, of the liquid test material for at least a 6-month period. Already observed was the precipitation of $\mathrm{HgSeO}_{3}$ in a dilute acid mixture. There was also some question about the stability of molybdate in the acid mixture. To select the proper acid concentrations for the test material, a series of solutions was prepared containing the elements in the described concentrations but with different amounts of $\mathrm{HNO}_{3}$. When the trace element solution aliquots were added to water, hydrolysis of some of the elements occurred rapidly. When $1 \mathrm{~N} \mathrm{HNO}_{3}$ (or $\mathrm{H}_{2} \mathrm{SO}_{4}$ ) was used, precipitation in the solution become apparent in a matter of hours. However, when $2 \mathrm{~N}^{-} \mathrm{HNO}_{3}$ was used, the solution appeared to be completely free 
of precipitation for at least 2 weeks. This concentration was used for the final master solution, aliquots of which are still free of any sediment after standing for 6 months.

TABLE II

WEIGHT OF STOCK SOLUTION ALIQUOTS TAKEN AND CALCULATED CONCENTRATION-SOLID TEST MATERIAL

Calculated

Trace Element Aliquot Used, $\mathrm{g}$ Concentration, $\mu \mathrm{g} / \mathrm{g}$

$\mathrm{Na} .19 .532 \quad 376$

Al $\quad 88.717 \quad 380$

$\begin{array}{lll}\mathrm{V} & 158.76 & 75\end{array}$

Mn $--\quad 0$

Co $22.216 \quad 234$

$\mathrm{Cu} \quad 10.893 \quad 24$

$\mathrm{Zn} \quad 266.85 \quad 2820$

As $\quad 15.074 \quad 37$

Se $\quad 54.736 \quad 1156$

Mo $\quad 127.50 \quad 2674$

$\mathrm{Cd} \quad 96.427 \quad 1429$

$\begin{array}{lll}\mathrm{Eu} & 5.0462 & 1.1\end{array}$

$\mathrm{Hg} \quad 27.428 \quad 573$

Weight of Final Mixture $=4244.4 \mathrm{~g}$

The trace element solution aliquot weights and the final calculated concentrations for the liquid test material are given in Table III.

TABLE I I I

WEIGHT OF ALIQUOTS TAKEN AND CALCULATED

CONCENTRATIONS-LIQUID TEST MATERIAL

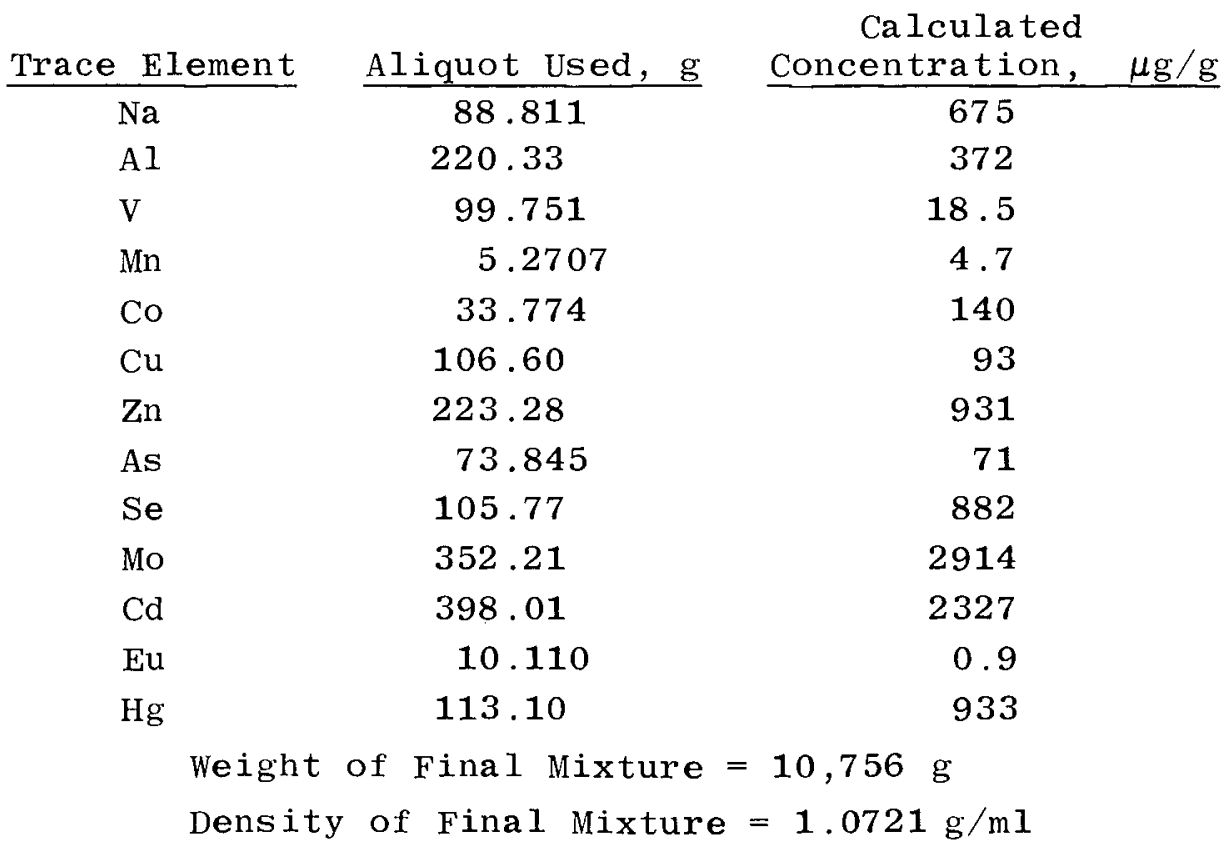


Part II. Analysis of Test Materials

The final silica-iron oxide-calcium carbonate matrix and the $2 \mathrm{~N} \cdot \mathrm{HNO}_{3}$ test materials were analyzed chiefly by spectrophotometric methods for the trace element concentrations. Additional data were provided by atomic absorption and flame emission spectrophotometry, emission spectrometry, spark source mass spectrometry and polarography.

\section{EXPER IMENTAL}

\section{Reagents and Apparatus}

The reagents used for each determination can be found in the reference for the particular method.

Spectrophotometer. Beckman Model DU.

Polarograph, Sargent Model XXI, used with a dropping mercury electrode.

Emission Spectrograph, Jarrell-Ash, 3.4 Ebert, and Jaco Varisource.

Spark Source Mass Spectrometer, Associated Electrical Industries MS-7 instrument modified for electrical detection by the manufacturer.

Atomic Absorption Spectrophotometer, Perkin-Elmer Model 403, with associated hollow-cathode lamps.

\section{Procedure}

Dissolution of Solid Test Material for Analysis

Transfer a 5-g sample of the solid test material to a 250-ml beaker and cover with a watch glass. Carefully add about $40 \mathrm{ml}$ ol $1: 3 \mathrm{HNO}_{3}: \mathrm{HCl}$ into the beaker in small portions. When the reaction stops, rinse down the watch glass and beaker sides with about $5 \mathrm{ml}$ additional acid mixture. Warm the solution on a steam bath for $1 \mathrm{hr}$ and cool. Filter the mixture through whatman No. 42 paper, washing the residue and paper thoroughly with water. Reserve the filtrate.

Transfer the residue and filter paper to a covered platinum dish. Ignite the paper. Dissolve the cooled residue by adding 10 to $15 \mathrm{ml} \mathrm{HF}$ and $1 \mathrm{ml}$ of $\mathrm{HNO}_{3}$. Evaporate the solution to near dryness. Dissolve the salts in 1 to $2 \mathrm{ml}$ of $\mathrm{HCl}$ and a small amount of water and add the solution to the reserved filtrate. Dilute the solution to volume in a $500-\mathrm{ml}$ volumetric flask.

Determination of Individual Trace Elements

Table IV lists the methods used for each trace element. 
TABLE IV

\section{METHODS USED FOR ANALYSES OF TEST MATERIALS}

\section{Trace Element}

$\mathrm{Na}$

A1

V

Mn

Co

As

$\mathrm{Se}$

MO

Cd

$\mathrm{Eu}$

$\mathrm{Hg}$

$\mathrm{Cu}$

\section{Reference}

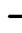

1

-

1

$-$

2

-

1

$-$

3

1

$-$

3

1

4

1

1

-

1

$-$

3

$-$

1

4

5

$-$

3

a. $F=$ flame photometry $\mathrm{SP}=$ spectrophotometry

AAS = atomic absorption spectrophotometry
General Method ${ }^{a}$

$\operatorname{AAS}(+\mathrm{F})$

SP with cupferron and oxine extraction

AAS

SP with oxine extraction

AAS

SP with periodate oxidation

AAS

SP with 1-nitroso-2-naphthol

AAS

P after dithizone separation

SP with dithizone extraction

AAS

P after dithizone separation

SP with distillation and molybdenum blue formation

ES-boiler-cap technique

SP with hydroxylamine and stannous chloride reductions

SP with thiocyanate

AAS

SP with dithizone extraction

AAS

$P$ after dithizone separation

SSMS

SP with dithizone extraction

ES-boiler-cap technique

$S P$ with neocuproine extraction

AAS

P after dithizone extraction

$\mathrm{P}=$ polarography

SSMS $=$ spark source mass spectrometry

$\mathrm{ES}=$ emission spectrometry 
Except for a few modifications made chiefly to eliminate the effect of the large amounts of iron in the prepared solution of the solid test material, the details of each procedure are essentially as described in the particular reference. Briefly, these modifications include (1) extending the detection limits for manganese by decreasing the volume of the final solution to be measured; (2) increasing the cupferron concentration and extraction time for the more complete removal of iron in the aluminum determination;

(3) prior precipitation of selenium with hydroxylamine hydrochloride before the usual procedure is applied with stannous chloride. Other minor modifications were made in several procedures.

All spectrophotometric determinations were made only after the effectiveness of the proposed unmodified or modified procedure was verified by the analysis of standards containing the same ratio of iron(III) to impurity expected in the prepared solution of the solid test material. The same procedures were used to analyze both the solid test material and the liquid test solutions.

Atomic absorption spectrophotometric determinations were also made for most elements in both test materials. Polarography was used to gain additional data for cobalt, copper, zinc and cadmium in the solid mixture. No other elements could be conveniently determined by the technique. Atomic absorption and flame emission spectrophotometry was relied upon exclusively tor the Na values, and spark source mass spectrometry was likewise relied upon for the Eu level in the solid.

To obtain at least an approximate calculated value for the levels in the solid test material it was necessary to determine the blank levels in the silica, iron oxide and calcium carbonate matrix components. These determinations were made by emission spectrometry, and by atomic absorption and tlame emission spectrophotometry with the results shown in Table $V$.

TABLE V

"BLANK" LEVELS IN THE MATRIX COMPONENTS

\begin{tabular}{|c|c|c|c|c|}
\hline \multirow[b]{2}{*}{ Trace Element } & \multicolumn{3}{|c|}{ Concentration, $\mu \mathrm{g} / \mathrm{g}$} & \multirow[b]{2}{*}{$\operatorname{Total}^{a}$} \\
\hline & $\mathrm{SiO}_{2}$ & $\mathrm{Fe}_{2} \mathrm{O}_{3}$ & $\mathrm{CaCO}_{3}$ & \\
\hline $\mathrm{Na}$ & -- & -- & -- & $110^{\mathrm{b}}$ \\
\hline A1 & 70 & 10 & 5 & 85 \\
\hline $\mathrm{Zn}$ & -- & 20 & -- & 20 \\
\hline Mo & $<10$ & 8 & -- & 13 \\
\hline $\mathrm{Cu}$ & $<10$ & $<10$ & -- & 10 \\
\hline $\mathrm{Mn}$ & -- & $100-120$ & -- & 110 \\
\hline
\end{tabular}

a. For a "less-than" value the amount present is arbitrarily assumed to be one-half of the value given.

b. Determined only in the mixture by atomic absorption and flame emission spectrophotometry; all other values determined by emission spectrometry. 
In Table VI are given the concentrations of trace elements added plus the concentration originally present (blank values) together with the levels found by analysis. Also given are the assigned levels for each element. These assigned values are the most reasonable levels to which the activation analyses should be compared, and they were obtained by the following considerations. The spectrophotometric and polarographic determinations are presumed to be accurate within $\pm 5 \%$; the atomic absorption and flame emission spectrophotometric determinations should be within $10 \%$, and the emission spectrographic values should be within $25 \%$. In every case except for selenium, aluminum and copper chiefly in the solid test material, the spectrophotometric results are within $5 \%$ of the "made-up" value. Therefore, for all but these elements (and sodium for which no spectrophotometric determinations were run) the assigned value is a rounded "made-up" value. Most of the analyses thus can be considered to be confirmatory in nature. When the analyses were relied upon, the spectrophotometric results were considered to be the more reliable. The selenium analytical results apparently reflect some losses from volatilization during the preparation of the solid test material. At any rate, for this element the assigned values are based upon the analyses. Likewise, the assigned sodium values are based upon the analyses for two reasons: (1) there are apparently small "blank" quantities added in the reagents; (2) the blending operation for the solid test material undoubtedly added some sodium. It was felt that the ba11milling also added some aluminum, the assigned values for which are also based upon the analysis in the solid test material. For the copper value of the solid test material, the good reliability of the spectrophotometric procedure and the uncertainty of the added "blank" quantity both made the rounded analytical value the most reasonable value.

Table VII gives the added and found quantities for the liquid test material together with the rounded assigned values. 
TABLE VI

TRACE ELEMENT CONCENTRATIONS IN SOLID TEST MATERIAL

Concentration, $\mu \mathrm{g} / \mathrm{g}$

\begin{tabular}{|c|c|c|c|c|c|c|c|c|}
\hline \multirow{3}{*}{ Trace Element } & \multirow{2}{*}{\multicolumn{3}{|c|}{ Calculated }} & \multirow{2}{*}{\multicolumn{4}{|c|}{ Found }} & \multirow[b]{3}{*}{ Assigned } \\
\hline & & & & & & & & \\
\hline & Added & "Blank" & Total & $\mathrm{SP}$ & AAS & $\underline{\mathrm{P}}$ & $\overline{\text { SSMS }}$ & \\
\hline $\mathrm{Na}$ & $\overline{376}$ & 110 & $\overline{486}$ & -- & $570^{\mathrm{a}}$ & - & -- & 570 \\
\hline Al & 380 & 85 & 465 & 494 & 420 & -- & -- & 490 \\
\hline $\mathrm{V}$ & 75 & 5 & 80 & 82 & 78 & -- & -- & 80 \\
\hline Mn & 0 & 110 & 110 & 107 & 83 & -- & -- & 110 \\
\hline $\mathrm{Co}$ & 234 & -- & 234 & 227 & 193 & 250 & -- & 230 \\
\hline $\mathrm{Cu}$ & 24 & 10 & 34 & 31 & 28 & -- & -- & 30 \\
\hline $\mathrm{Zn}$ & 2820 & 20 & 2840 & 2847 & -- & 2897 & -- & 2840 \\
\hline As & 37 & -- & 37 & 34 & $50^{b}$ & -- & -- & 35 \\
\hline $\mathrm{Se}$ & 1156 & -- & 1156 & 1022 & -- & -- & -- & 1020 \\
\hline Mo & 2674 & 13 & 2687 & 2721 & 2850 & -- & -- & 2690 \\
\hline $\mathrm{Cd}$ & 1429 & -- & 1429 & 1411 & 1348 & 1448 & -- & 1430 \\
\hline $\mathrm{Eu}$ & 1.1 & -- & 1.1 & -- & -- & -- & 1 & 1.1 \\
\hline $\mathrm{Hg}$ & 573 & -- & 573 & 558 & $670^{\mathrm{b}}$ & -- & -- & 570 \\
\hline
\end{tabular}

a. By atomic absorption and flame emission spectrophotometry

b. By emission spectrometry. 
TABLE VII

TRACE ELEMENT CONCENTRATIONS IN LIQUID TEST MATERIAL

\begin{tabular}{|c|c|c|c|c|}
\hline \multirow{3}{*}{$\begin{array}{c}\text { Trace } \\
\text { E1ement }\end{array}$} & \multicolumn{4}{|c|}{ Concentration, $\mu \mathrm{g} / \mathrm{g}$} \\
\hline & \multirow[b]{2}{*}{ Added } & \multicolumn{2}{|c|}{ Found } & \multirow[b]{2}{*}{ Assigned } \\
\hline & & $\underline{\mathrm{SP}}$ & AAS & \\
\hline $\mathrm{Na}$ & 675 & -- & $688^{a}$ & 690 \\
\hline Al & 372 & 352 & 364 & 370 \\
\hline $\mathrm{V}$ & 18.5 & 18.7 & 22 & 20 \\
\hline Mn & 4.7 & 4.0 & 4.3 & 5 \\
\hline Co & 140 & 135 & 132 & 140 \\
\hline $\mathrm{Cu}$ & 93 & 92 & 92 & 95 \\
\hline $\mathrm{Zn}$ & 931 & 929 & 895 & 930 \\
\hline As & 71 & 69 & -- & 70 \\
\hline $\mathrm{Se}$ & 882 & 839 & -- & 840 \\
\hline Mo & 2914 & 2892 & 2425 & 2910 \\
\hline $\mathrm{Cd}$ & 2327 & 2276 & 2122 & 2330 \\
\hline $\mathrm{Eu}$ & 0.9 & -- & -- & 0.9 \\
\hline $\mathrm{Hg}$ & 933 & 945 & -- & 930 \\
\hline
\end{tabular}

a. By atomic absorption and flame emission spectrophotometry.

\section{REFERENCES}

1. Sandell, E. B., "Colorimetric Determination of Traces of Meta1s," 3rd Ed., Interscience Publishers, Inc., N. Y. (1959).

2. ASTM Method D350-70, Book of ASTM Standards, Part 32, American Society for Testing and Materials, Philadelphia, Pa., (1970), pp. 833-836.

3. Lerner, M. W., "Analyses of Essential Nuclear Reactor Materials," C. J. Rodden, Ed., U. S. Government Printing Office (1964), p. 790 .

4. Yuster, H. G., NBL-267 (September 1973), p. 109.

5. Gahler, A. R., Anal. Chem., 26, 577 (1954). 
ATOMIC ABSORPTION SPECTROPHOTOMETRIC DETERMINATION OF MERCURY IN TEST MATERIALS FOR THE CALIFORNIUM-252 EVALUATION PROGRAM

$$
\text { R. L. Graff }
$$

The two synthetic test materials prepared at the New Brunswick Laboratory $(\mathrm{NBL})^{1}$ for the interlaboratory californium-252 activation analysis evaluation program consisted of a $2 \mathrm{~N}$ nitric acid solution and a $70 \%$ silica, $20 \%$ iron oxide, $10 \%$ calcium carbonate matrix, both containing $\mathbf{1 3}$ trace elements at various levels. Mercury, at a level of 300 to $3000 \mathrm{ppm}$, was one of these trace elements.

These test materials, after preparation, were analyzed for the trace elements chiefly by spectrophotometric methods. ${ }^{1}$ Mercury was determined by a conventional dithizone procedure, 1 and also by an emission spectrometric procedure. ${ }^{2}$ When atomic absorption spectrophotometry was attempted for mercury, extremely high and erratic results were unexpectedly obtained. It is believed that these anomalous results were caused by differences in the valence state of mercury in the sample and standards.

\section{EXPERIMENTAL}

Reagents and Apparatus

$\mathrm{HNO}_{3}$ and $\mathrm{HCl}$, redistilled from quartz.

$\underline{H F}$, redistilled from platinum.

Mercuric Oxide and Mercuric Chloride, reagent grade.

Atomic Absorption Spectrophotometer, Perkin-Elmer Model 403, equipped with air-acetylene burner head, mercury hollow-cathode lamp, and Deuterium Arc Background Corrector.

\section{Procedure}

Preparation of Standard Solution. Prepare two stock solutions: one from HgO dissolved in $\mathrm{HNO}_{3}$; one from $\mathrm{HgCl}_{2}$ dissolved in water. Dilute both solutions with $2 \mathrm{~N} \mathrm{HNO}_{3}$ to the appropriate volume to obtain solutions containing $5 \mathrm{mg} / \mathrm{ml}$. Dilute these stock solutions with $2 \mathrm{~N}^{-\mathrm{HNO}_{3}}$ to obtain two series of standards containing from 5 to $500 \mu \mathrm{g} 7 \mathrm{ml}$.

Prepare a third and fourth series of standards by spiking solutions of the "blank" matrix material containing iron and calcium salts. Dissolve the blank matrix material as described below under Analysis. 
$2 \mathrm{~N} \mathrm{HNO}_{3}$ Test Material. Dilute this solution with $2 \mathrm{~N} \mathrm{HNO}_{3}$ to various levels to ensure that the measurements fall within the optimum instrumental range: $1: 5$ up to $1: 200$.

Solid Matrix Test Material. After dissolution in HCl, treatment with HF to remove silica, and several evaporations with $\mathrm{HNO}_{3}$ to remove chlorides and fluorides, dilute to $100 \mathrm{ml}$ with $2 \mathrm{~N} \mathrm{HNO}_{3}$. prepare dilutions with $2 \underline{\mathrm{N}} \mathrm{HNO}_{3}$ as above.

Carry out the atomic absorption spectrophotometric measurements using the $\mathrm{Hg}$ line at $2536 \AA$ on standards and samples according to the general procedure outlined in the Perkin-Elmer manual. ${ }^{3}$

\section{RESULTS AND DISCUSSION}

The results obtained on the liquid test solution using standards prepared by dissolving $\mathrm{HgO}$ in $\mathrm{HNO}_{3}$, were much higher than the quantities originally added, and were also higher than those obtained by the dithizone spectrophotometric procedure. The use of the standards prepared from $\mathrm{HgCl}_{2}$ gave essentially the same high results. Determination of mercury in the solid test material by comparison to similar standards also gave higher results than the "added" values. These results were also higher than those obtained both by emission spectrometry ${ }^{2}$ and spectrophotometry after dithizone extraction. ${ }^{1}$ Measurements made with and without the background corrector were essentially identical. The averaged results are shown in Table I.

TABLE I

ATOMIC ABSORPTION SPECTROPHOTOMETRIC RESULTS ON TEST MATERIALS COMPARED TO "ADDED" VALUES AND RESULTS BY OTHER METHODS

Method

Atomic Absorption

Emission Spectrometry

Dithizone Extraction

"Added"

\begin{tabular}{cc}
\multicolumn{2}{c}{ Mercury, $\mu \mathrm{g} / \mathrm{g}$} \\
\hline$\underline{2 \mathrm{~N} \mathrm{HNO}} \mathrm{H}_{3}$ Test Material & $\begin{array}{l}\text { Solid Matrix } \\
\text { Test }\end{array}$ \\
\cline { 2 - 2 } 1870 & 800 \\
-- & 670 \\
945 & 558 \\
933 & 573
\end{tabular}

Since cobalt is present as one of the trace elements in the test materials and is known to interfere with the mercury determination, cobalt was added to standard solutions in the same concentrations as are present in the test materials. No significant effect on the mercury measurements was noted.

Four test solutions were prepared by dissolving mercury metal in $\mathrm{HNO}_{3}$ and diluting to volume with $2 \mathrm{~N} \mathrm{HNO}_{3}$ to serve as "knowns". In dissolving the mercury for these solutions, three were dissolved by the gradual addition of a minimum of $\mathrm{HNO}_{3}$, one was dissolved in a large excess of $\mathrm{HNO}_{3}$ added at one time. Only in the 
case of the latter solution was the correct result obtained; results with the other three solutions were again very high.

In the Perkin-Elmer manual, ${ }^{3}$ the possibility of enhancement of the mercury absorbance by mercury(I) is noted. Qualitative tests for mercury(I) involving precipitation of insoluble mercurous chloride were then made on the various solutions. Mercury(I) was found to be present in appreciable quantity in the $2 \mathrm{~N} \mathrm{HNO}_{3}$ test material and in the three control "knowns" discussed above. A small amount appeared to be present in the solutions prepared from the solid matrix test material. No mercury(I) could be detected in the fourth control "known" which had been found to behave correctly. No mercury(I) was found in the $2 \mathrm{~N} \mathrm{HNO}_{3}$ standard solutions prepared from $\mathrm{HgO}$ and $\mathrm{HgCl}_{2}$.

Apparently, then, the high results obtained in this work are due to the presence of mercury(I) in the sample solutions. In preparing a mercury solution by dissolving the metal in $\mathrm{HNO}_{3}$ some mercury(I) can be formed as shown by its presence in the three control "known" solutions. The mercury that was added to the two californium-252 test materials was prepared in this manner. Moreover, once mercury(I) is present, even in $2 \mathrm{~N} \mathrm{HNO}_{3}$, it appears to remain unchanged for long periods of time. Atomic absorption spectrophotometric measurements made 6 weeks after preparing the $2 \mathrm{~N} \mathrm{HNO}_{3}$ test material still gave the abnormally high results.

Thus, in the determination of mercury by atomic absorption spectrophotometry as in chemical methods, it is essential that the element be converted to a known oxidation state.

\section{REFERENCES}

1. Trahey, N. M., Scarborough, J. M. and Bodnar, L. Z., NBL-267 (September 1973), p. 56.

2. Yuster, H. G., NBL-267 (September 1973), p. 109.

3. Analytical Methods for Atomic Absorption Spectrophotometry, Perkin-Elmer Company, Norwalk, Conn., March, 1973 Revision. 


\section{DETERMINATION OF THORIUM IN URANIUM-THORIUM MIXTURES}

\section{J. M. Scarborough}

Little specific information is available on the determination of thorium in pyrocarbon- and silicon carbide-coated uraniumthorium carbide nuclear fuel beads. Recently, an ethylenediaminetetraacetic (EDTA) titration of the thorium after separation from the uranium on a strongly basic ion-exchange resin column was reported.1 Apparently in many cases the conventional gravimetric procedure involving ammonia, fluoride and oxalate precipitations is being used. This method is lengthy and tedious.

In the present work, a direct EDTA titration was studied. The proposed method was assessed by the analyses of synthetic uranium dioxide-thorium dioxide mixtures. The thorium dioxide used for these mixtures was first carefully characterized for assay by three techniques: EDTA titration, oxalate precipitation and ignition to oxide, and direct ignition plus emission spectrographic determination of impurities for a gravimetric correction. The results obtained by the EDTA titrimetric determination of thorium in the mixed oxides were then compared to those obtained by the conventional gravimetric method.

\section{EXPER IMENTAL}

Reagents and Apparatus

EDTA Titrant, $0.01 \mathrm{M}$, prepared by dissolving $7.4 \mathrm{~g}$ of disodium ethylenediaminetetraacetate in 21 . of water.

Standard Copper Solution, $1.3 \mathrm{mg} / \mathrm{g}$, prepared by dissolving $\mathrm{Cu}$ metal (99.999\% pure) in $\mathrm{HNO}_{3}$ and diluting to weight.

Acetate Buffer, $\mathrm{pH} 6.0$, prepared by adding $28 \mathrm{~g}$. of sodium acetate trihydrate to about 11 . of water and adjusting the $\mathrm{pH}$ to 6.0 with acetic acid.

Potassium Acid Phthalate Buffer, pH 2.5 , prepared by mixing $500 \mathrm{ml}$ of $0.1 \mathrm{M}$ potassium acid phthalate with $388 \mathrm{ml}$ of $0.1 \mathrm{~N}$ HCl.

Xylenol Orange (XO), $0.1 \%$ in ethyl alcohol.

1-(-2 Pyridylazo)-2-Naphthol (PAN), $0.1 \%$ in ethyl alcohol.

Thorium Dioxide, high-purity

Uranium Dioxide, reactor-grade. 
Procedures

Standardization of EDTA

Standardize the EDTA against copper as described in reference (2) noting that the color of the PAN end point appears to be green rather than yellow as reported by the authors.

Preparation of Thorium Solution

Dissolve a $2.5 \mathrm{~g}$ sample of thorium dioxide or an equivalent weight of thorium dioxide-uranium dioxide in $\mathrm{HNO}_{3}$ containing a drop of $\mathrm{HF}$ by warming the mixture until dissolution is complete. Dilute to a known weight of solution.

Titrimetric Determination of Thorium with EDTA

place a weighed aliquot of the solution to contain about $0.1 \mathrm{~g}$ of thorium in a 250-ml beaker and evaporate to dryness on a steam bath. Cool the residue, and add with stirring $75 \mathrm{ml}$ of potassium acid phthalate buffer, pH 2.5. Add 6 drops of XO indicator, and titrate to the disappearance of the pink tint of the Th-XO complex. (Good lighting and a white background are necessary to see the color change.)

Gravimetric Determination of Thorium with Oxalate

Evaporate a weighed aliquot of the nitric acid solution containing about $0.3 \mathrm{~g}$ of thorium on a steam bath. Add 5 to $10 \mathrm{ml}$ of water and again evaporate to dryness. Dissolve the residue in $5 \mathrm{ml}$ of water and add $25 \mathrm{ml}$ of $10 \%$ oxalic acid solution. Heat the mixture to $80^{\circ} \mathrm{C}$ for $1.5 \mathrm{hr}$, and then allow the precipitate to digest overnight at room temperature.

Filter the precipitate through whatman No. 42 paper, washing the paper and precipitate well with $1 \%$ oxalic acid solution. Ignite the paper and precipitate in a platinum crucible at $400^{\circ} \mathrm{C}$ for $1 \mathrm{hr}$, then at $1100^{\circ} \mathrm{C}$ to constant weight (about $3 \mathrm{hr}$ ), and weigh.

Gravimetric Determination of Thorium in Thorium Dioxide by Direct Ignition

Place a weighed $2.5 \mathrm{~g}$ sample in a platinum crucible. Ignite at $1100^{\circ} \mathrm{C}$ to constant weight. Determine the impurities present by emission spectrometry using the carrier distillation technique. Correct the assay value for the concentration of metallic impurities present.

\section{RESULTS AND DISCUSSION}

Ten samples of the same thorium dioxide were analyzed by the EDTA titration and by the gravimetric (oxalate) procedure. Three samples of the thorium dioxide were also analyzed by the direct ignition procedure, Table I. The emission spectrometric values for the impurities are shown in Table II. 
TABLE I

DETERMINATION OF THORIUM IN THORIUM DIOXIDE

Thorium, g Th/g $\mathrm{ThO}_{2}$

\begin{tabular}{|c|c|c|c|}
\hline & EDTA & Oxalate & Direct Ignition \\
\hline & 0.8758 & 0.8762 & 0.8766 \\
\hline $\mathrm{RSD}, \mathrm{a} \%$ & 0.03 & 0.04 & 0.007 \\
\hline
\end{tabular}

a. Relative standard deviation

b. An average value for the impurity elements of $600 \mu \mathrm{g} / \mathrm{g}$ was used.

TABLE I I

IMPURITIES IN ThO $\mathrm{T}_{2}$ OBTAINED BY EMISSION SPECTROMETRY

\begin{tabular}{|c|c|c|c|}
\hline Element & $\begin{array}{c}\text { Concentration, } \\
\mu \mathrm{g} / \mathrm{g} \text { Th } \\
\end{array}$ & Element & $\begin{array}{c}\text { Concentration } \\
\mu \mathrm{g} / \mathrm{g} \mathrm{Th} \\
\end{array}$ \\
\hline $\mathrm{Ag}$ & 50 & $\mathrm{Mg}$ & 0.5 \\
\hline Al & 5 & $\mathrm{Mn}$ & 0.5 \\
\hline $\mathrm{B}$ & 0.2 & Mo & $<1$ \\
\hline $\mathrm{Bi}$ & 0.2 & $\mathrm{Ni}$ & 2 \\
\hline $\mathrm{Ca}$ & 2 & $\mathrm{~Pb}$ & 5 \\
\hline $\mathrm{Cd}$ & $<0.1$ & $\mathrm{Si}$ & 500 \\
\hline $\mathrm{Co}$ & $<1$ & $\mathrm{Sn}$ & $<1$ \\
\hline $\mathrm{Cr}$ & 2 & V & $<10$ \\
\hline $\mathrm{Cu}$ & 0.2 & $\mathrm{Zn}$ & $<10$ \\
\hline $\mathrm{Fe}$ & 15 & Tota 1 & \pm 200 \\
\hline
\end{tabular}

The averages of the results for the three methods of determining the thorium concentration in the thorium dioxide agree fairly well and have an overall average value of $0.8762 \mathrm{~g} \mathrm{Th} / \mathrm{g} \mathrm{ThO}_{2}$ with a weighted standard deviation of $0.0000558 \mathrm{~g} \mathrm{Th} / \mathrm{g} \mathrm{ThO}_{2}(0.015 \%$ relative). These estimates were obtained as follows:

$$
\begin{aligned}
\text { overall average }=\overline{\overline{\mathrm{X}}} & =\frac{\sum \overline{\mathrm{X}}_{\mathrm{i}}}{\text { number of averages }} \\
\operatorname{variance}(\overline{\overline{\mathrm{x}}})=\mathrm{s} \frac{2}{\overline{\mathrm{X}}} & =\frac{1}{\text { (number of averages })_{2}} \cdot \Sigma_{i}\left(\text { variance } \overline{\mathrm{x}}_{1}\right) \\
& =\frac{1}{\text { (number of averages }) 2} \cdot\left(\frac{\mathrm{s}_{1}^{2}}{\mathrm{n}_{1}}+\frac{\mathrm{s}_{2}^{2}}{\mathrm{n}_{2}}+\frac{\mathrm{s}_{3}^{2}}{\mathrm{n}_{3}}\right)
\end{aligned}
$$

The average assay value is calculated to be $99.70 \%$ thorium dioxide. 
The EDTA titration was applied to a series of 10 thorium dioxide-uranium dioxide mixtures containing a fixed Th:U ratio and prepared from the same thorium dioxide as was analyzed above. These results are shown in Table III. Three additional mixtures containing variable Th: U ratios were then analyzed, with 3 determinations being made on 3 aliquots of the solution prepared from each mixture.

\section{TABLE I I I}

\begin{tabular}{|c|c|c|c|}
\hline Th: U Ratio & $\mathrm{N}$ & Thorium, $\mathrm{g} / \mathrm{g} \mathrm{ThO}_{2}$ & $\mathrm{RSD}, \%$ \\
\hline 25 & 10 & 0.8760 & 0.08 \\
\hline 10 & 3 & 0.8769 & 0.02 \\
\hline 16 & 3 & 0.8750 & 0.06 \\
\hline 25 & 3 & 0.8763 & 0.01 \\
\hline
\end{tabular}

These results were then compared to the results obtained ${ }^{3}$ by analyzing in triplicate 6 samples of thorium dioxide-uranium dioxide mixtures by the conventional gravimetric method involving ammonia, fluoride and oxalate precipitation followed by ignition to thorium dioxide, Table IV.

TABLE IV

COMPARISON OF RESULTS OBTAINED BY EDTA TITRATION AND CONVENTIONAL GRAVIMETRIC METHOD

\begin{tabular}{|c|c|c|c|c|}
\hline Average & $(\mathrm{N})$ & EDTA & $(\mathrm{N})$ & Gravimetric \\
\hline Assay, $\mathrm{gTh} / \mathrm{g} \mathrm{ThO}_{2}$ & (19) & 0.8759 & (18) & 0.8754 \\
\hline $\operatorname{RSD}, \%$ & & 0.08 & & 0.44 \\
\hline Bias, $g \mathrm{Th} / g \mathrm{ThO}_{2}{ }^{\mathrm{a}}$ & & -0.0003 & & -0.0008 \\
\hline
\end{tabular}

a. Absolute difterence between assigned value and determined value.

The data in Tables III and IV are expressed as thorium assay values calculated from the known weights of thorium dioxide and uranium dioxide in the mixtures.

It can be seen that the direct EDTA titration appears to be superior to the conventional gravimetric procedure for the analysis of mixtures of thorium and uranium. A future report will be made of the results obtained by using the EDTA titration and the conventional gravimetric procedure for the analysis of graphite- and silicon carbide-coated uranium-thorium carbide nuclear fuel beads.

\section{REFERENCES}

1. Bildstein, H. "Analytical Chemistry of Nuclear Fuels," International Atomic Energy Agency, Vienna, 1972, pp. 67-70. 
2. Iwamoto, T. and Kanamori, K., Anal. Chim. Acta, 26, 167-171 (1962).

3. Zibulsky, H. and Paller, J. S., New Brunswick Laboratory unpublished data, 1973 . 


\title{
DISSOLUTION OF PYROCARBON- AND SILICON CARBIDE-COATED URANIUM-THORIUM CARBIDE FUEL BEADS - CHLORINATION AND FUSION DISSOLUTIONS
}

\author{
C. E. Hedrick
}

Pyrocarbon- and silicon carbide-coated uranium-thorium carbide nuclear fuel beads are difficult to dissolve for chemical analysis because of the refractory nature of the coatings. At the New Brunswick Laboratory (NBL), the beads are routinely dissolved by tedious and time-consuming fusions, first with sodium carbonate and then with sodium bisulfate. ${ }^{1}$

Previous work $\mathrm{k}^{2}$ at NBL has been directed at speeding up the fusion dissolution of the beads. Fusions with many salts and salt mixtures were tested in a variety of crucibles. On the basis of speed of dissolution, absence of reactivity towards platinum and other crucibles, freedom from reaction gassing, ease of work-up alter fusion, and compatibility of the final solution with the NBL titrimetric method for determining uranium, the best mixture found at that time was $(10+1)$ sodium carbonate plus sodium chromate mixture. Yet this technique has shortcomings: in the work-up of the melt, a large amount of insoluble chromium sulfate is obtained unless perchloric acid is used as the solubilizing acid. Moreover, the large quantity of chromium present in the final solution causes difficulties in the titrimetric method.

In the present work, the fusion studies were continued. The tests involved the use of only small quantities of sodium chromate or sodium vanadate added to the sodium carbonate. In addition, the high-temperature chlorination method reported by Robertson ${ }^{3}$ was investigated. Certain modifications in this technique were found to be necessary.

\section{Fusion Studies}

\section{EXPERIMENTAL} stated.

All reagents are analytical reagent-grade unless otherwise Quartz Tubing, $25 \mathrm{~cm}$ long by $7 \mathrm{~mm}$ OD.

\section{Blast Burner}

Tank Oxygen, USP. 
$\underline{\text { Procedure }}$

Weigh a 5-g sample of fuel beads into a 125-ml platinum dish. Cover the dish loosely and ignite for $1 \mathrm{hr}$ with a blast burner while directing a stream of oxygen into the dish with the quartz tubing. Cool the dish, add $5 \mathrm{~g}$ of sodium carbonate and $50 \mathrm{mg}$ of sodium vanadate or sodium chromate. Again ignite as above for $1 \mathrm{hr}$. Cool the dish, add $10 \mathrm{~g}$ additional sodium carbonate, and ignite for $2 \mathrm{hr}$ as before. Cool the dish.

Add in small quantities, washing the cover and dish sides down when necessary, about $40 \mathrm{ml}$ of $8 \mathrm{M} \mathrm{H}_{2} \mathrm{SO}_{4}$ and $40 \mathrm{ml} \mathrm{HF}$. Replace the cover and digest for $1 \mathrm{hr}$ at low heat on a hot plate. Remove the cover, wash it down with water, increase the temperature of the hot plate and evaporate the solution to fumes. Add $\mathrm{H}_{2} \mathrm{SO}_{4}$, if necessary, to complete the removal of fluoride. Fume at high heat until the mass nearly solidifies. Add $20 \mathrm{~g}$ of sodium bisulfate and fuse strongly until the melt is clear. Cool the melt and dissolve the cake in water. If a small residue remains, filter the solution through whatman No. 41 paper reserving the filtrate. Dry the paper in a platinum crucible, ignite, and fuse the residue with $100 \mathrm{mg}$ of sodium nitrate plus $3 \mathrm{~g}$ of sodium carbonate. Dissolve the fusion cake in $20 \mathrm{ml}$ of $(1+1) \mathrm{HNO}_{3}$ and add the solution to the reserved filtrate.

\section{RESULTS AND DISCUSSION}

Small amounts of sodium vanadate or sodium chromate appear to accelerate the fusion attack of the sodium carbonate to a significant extent. In addition, these quantities of vanadium or chromium in the final solution do not affect the NBL titrimetric method of determining uranium. With a sample-to-fusion mixture of $(1: 3)$, the silicon carbide coating in a $5-\mathrm{g}$ sample is removed and about $80 \%$ of the core material is dissolved within $3 \mathrm{hr}$. The remaining core material is dissolved in the subsequent steps.

Unfortunately the vanadate or chromate accelerators in the carbonate fusion cause increased erosion of the platinum dishes. About $20 \mathrm{mg}$ of platinum is lost with the vanadate mixture, about $9 \mathrm{mg}$ with the chromate. Furnace fusions, or the use of sodium metaphosphate, which was also found to be a good activator, causes even greater losses of platinum. These platinum losses make the procedure somewhat more expensive and may necessitate an additional separation step in the titrimetric procedure in which platinum can interfere. The studies are continuing.

High-Temperature Chlorination

EXPER IMENTAL

Reagents and Apparatus

All reagents are reagent grade unless otherwise stated.

Chlorine, high-purity, with monel valve.

Activated Charcoal, 6 to 14 mesh. 
Teflon Tubing, $6 \mathrm{~mm}$ OD with $1 \mathrm{~mm}$ wall thickness, for attachment to the chlorine tank valve.

Tygon Tubing. $1 \mathrm{~cm}$ ID with $2 \mathrm{~mm}$ wall thickness.

Quartz Wool, coarse.

Quartz Combustion Tube, $1 \mathrm{~cm}$ OD, $1 \mathrm{~mm}$ wall thickness, $77 \mathrm{~mm}$ long with constriction to $3 \mathrm{~mm}$ ID at $52 \mathrm{~cm}$. The "short" end of the tube is the exit end.

Tube Furnace, horizontal, high temperature, with quartz liners, $36 \mathrm{~mm}$ OD, $2-\mathrm{mm}$ wall thickness, and $60 \mathrm{~cm}$ long.

Procedure

Fit a loose plug of quartz wool in the longer end of the constricted quartz tube so that it $\mathrm{fits}$ snugly against the constriction. Add a weighed $15-\mathrm{g}$ sample of beads to the tube held vertically and then fit another loose quartz plug about $1 \mathrm{~cm}$ above the sample charge so that the beads are held but are not tightly packed. Place the tube in the tube furnace at 900 to $1000^{\circ} \mathrm{C}$ and pass a stream of air at a flow rate of about $300 \mathrm{ml} / \mathrm{min}$ for $2 \mathrm{hr}$ through the tube by means of tygon tubing fitted onto the "long" end of the tube. Cool the furnace to $600^{\circ} \mathrm{C}$, remove the tube, and cool it to room temperature.

Pack the exit end of the tube with a $15-\mathrm{cm}$ length of activated charcoal held in place again with quartz wool plugs. Insert the tube into the furnace, and while readjusting the furnace temperature to $1000^{\circ} \mathrm{C}$, begin passing the chlorine, by means of a fresh piece of tubing fitted over the entrance end of the quartz tube, through the sample at a flow rate of 300 to $500 \mathrm{ml} / \mathrm{min}$. When a temperature of $1000^{\circ} \mathrm{C}$ is reached, continue the chlorination for $45 \mathrm{~min}$. Turn off the furnace, and when the temperature reaches $800^{\circ} \mathrm{C}$, stop the chlorine flow. Remove the quartz tube and cool it to room temperature.

Remove the exit end quartz wool plug and place it in a $125-\mathrm{ml}$ platinum dish. Pour the charcoal into the dish. Remove the second wool plug and add it to the dish. Hold the tube vertically over the dish (inlet end downward) and pour a small amount of methanol into the exit end to wet the sample charge. Now holding the tube near horizontal with the inlet end over the dish, transfer the charge plugs and residue to the dish by means of methanol. Dry the tube, and draw by suction about $25 \mathrm{ml}$ of $1: 1 \mathrm{HNO}_{3}$ in to the exit end to remove U/Th chlorides, reserving the acid to be added to the solution of the oxidized cores.

Evaporate the methanol from the dish, apply a loose platinum cover, and ignite overnight in a muffle furnace at $900^{\circ} \mathrm{C}$. To the cooled dish add $20 \mathrm{ml}$ of $\mathrm{HNO}_{3}$ and $20 \mathrm{ml}$ of $\mathrm{HF}$. Evaporate the mixture to dryness. Add $50 \mathrm{~g}$ of sodium bisulfate and fuse the oxides. Dissolve the cooled melt in water. If a small amount of residue remains, treat it by the sodium carbonate-sodium nitrate fusion described above under Fusion procedure. Combine the 1:1 $\mathrm{HNO}_{3}$ from the combustion tube wash and the residue solution with the solution of the oxides. 


\section{RESULTS AND DISCUSSION}

Robertson ${ }^{3}$ found that the most effective chlorination was obtained with a vertical tube containing the beads resting on a frit. Los Alamos Scientific Laboratory (LASL) has reported ${ }^{4}$ a similar procedure. In the present work, the more convenient horizontal tube position was found to be effective for the oxidation and chlorination step provided that the beads are loosely packed and the gas flow rate is ample but low enough to prevent tight packing of the beads.

Robertson makes no mention of uranium losses during chlorination. In preliminary evaluation tests of the chlorination, it was found that appreciable amounts, 0.1 to $0.2 \%$, of uranium (and quantities of thorium) volatilized from the charge material along with the silicon chloride and were lost. Initially, 2 U-tube traps in series immersed in ice-water were used to condense the silicon chloride and uranium/thorium; water traps were inconvenient because of the formation of silica gel. The cold U-tube traps hold all the uranium as shown by the absence of uranium in a third trap. When the charcoal column is used, no uranium is found in these two traps. Therefore, the U-tubes were eliminated. In Table I are given the results of three determinations of the uranium content of the identical sample of fuel beads as was used in an interlaboratory evaluation program ${ }^{5}$ involving both chemical and non-destructive assays. The solutions prepared from each vial by the dissolution procedure were analyzed in triplicate. These values are comparable to those obtained in the interlaboratory study and indicate that the uranium recovery was complete.

TABLE I

RESULTS OBTAINED BY HIGH-TEMPERATURE CHLORINATION DISSOLUTION

\begin{tabular}{ccccc} 
Vial No. & Uranium, g/Vial & $\begin{array}{c}\text { Average, } \\
\mathrm{g} / \text { Vial }\end{array}$ & $\begin{array}{c}\text { Average, } \\
\mathrm{g} / \mathrm{g}\end{array}$ \\
\hline 1 & $0.50326,0.50304,0.50355$ & 0.50328 & 0.03331 \\
2 & $0.50283,0.50339,0.50321$ & 0.50314 & 0.03316 \\
3 & $0.50880,0.50880,0.50862$ & 0.50874 & 0.03328
\end{tabular}

Repeated attempts to completely dissolve the core material remaining after the chlorination by $\mathrm{HNO}_{3}-\mathrm{HF}$ mixtures were invariably unsuccessful. Accordingly, the bisulfate fusion had to be used. The chlorination studies are continuing. 


\section{REFERENCES}

1. Zibulsky, H., Paller, J. S. and Siddons, T. J., NBL-265 (October 1972), p. 32 .

2. Hedrick, C. E., NBL-265 (October 1972), p. 28.

3. Robertson, D. M., BNWL-B-196 (July 1972).

4. Unpublished data, 1973 .

5. Bingham, C. D. and Whichard, J., in preparation, 1973. 


\title{
SUMMARY OF AN INTERLABORATORY COMPARISON PROGRAM ON THE ANALYSIS OF PYROCARBON- AND SILICON CARBIDE-COATED URANIUM-THORIUM CARBIDE BEADS
}

\author{
C. D. Bingham and $\mathrm{J}$. Whichard
}

In response to a request from a licensee and concurred in by the Directorate of Regulatoratory Standards, the New Brunswick Laboratory (NBL) sponsored an interlaboratory comparison program on the analysis of pyrocarbon- and silicon carbide-coated uraniumthorium carbide nuclear fuel beads. This material is manufactured during the production of High Temperature Gas-Cooled Reactor (HTGR) fuel.

A series of mixtures of urania $\left(\mathrm{UO}_{2}\right)$ and thoria $\left(\mathrm{ThO}_{2}\right)$ was prepared from characterized starting materials to serve as "knowns" by which to measure the accuracy of uranium and thorium determinations by each participating laboratory. Samples of beads from a single production lot were prepared in sealed glass vials. A11 of the (90) samples were assayed for uranium by non-destructive assay (NDA) techniques by each of three participating laboratories. Three oxide samples and $\mathrm{six}$ bead samples were sent to each of seven participating laboratories for destructive chemical assay of uranium and thorium.

A detailed description of the program, of the results and conclusions is contained in a separate report ${ }^{1}$. NDA data from the oxide samples reveal an apparent strong matrix effect in relating the responses of the oxide samples to those of standards prepared in each NDA laboratory. Two of the three NDA laboratories exceeded the prepared value by more than $2 \%$ (relative). With the exception of one laboratory, whose uranium data were consistently higher than those from other laboratories, the data from the chemical analysis of the oxide samples for uranium revealed a spread of $\pm 0.2 \%$

(relative) about the prepared value. Uranium results on the bead samples from the same chemistry laboratories exhibited a spread of $\pm 0.9 \%$ (relative) about the interlaboratory average. This increased spread could be attributed to variations within the uranium content of the bead population but more likely it reflects differences due to the effect of methods by which the participants solubilized the sample prior to analysis. Results from two of the three NDA laboratories fell within the range of the chemical data for the bead samples.

A Phase II program is being planned to define more clearly the state-of-the-art of the chemical analysis of these coated beads, and those parameters which adversely affect the overall reliability of the uranium measurement.

\section{REFERENCE}

1. Bingham, C. D. and Whichard, J., in preparation, 1973. 


\section{MASS SPECTROMETRIC ISOTOPE DILUTION DETERMINATION OF URANIUM AND PLUTONIUM - VOLUMETRIC VS GRAVIMETRIC TECHNIQUES FOR PREPARING THE ISOTOPE MIXTURES}

A. W. Wenzel, P. C. Puleio, R. J. Greer, G. E. Peoples, $J$. R. Weiss and C. E. Pietri

Mass spectrometric isotope dilution is used frequently at the New Brunswick Laboratory (NBL) for the determination of low levels of uranium and plutonium. In previous reports, 1,2 the procedures were described and precisions and accuracies were evaluated based upon volume additions of tracer and standard solutions. In the present work, both plutonium and uranium tracer solutions were assayed, and the precisions of the results obtained both by volumetric and gravimetric techniques for preparing the standardtracer mixtures were compared.

\section{EXPERIMENTAL}

\section{Reagents and Apparatus}

The reagents and apparatus are as described previously 1,2 with the following exceptions:

plutonium-242 Tracer Solution. Suflicient plutonium-242 as oxide is weighed and dissolved, and the resulting solution diluted to give solutions with a plutonium-242 concentration of about 6.1 $\mu \mathrm{g} / \mathrm{ml}(4.5 \mu \mathrm{g} / \mathrm{g})$ and $10.8 \mu \mathrm{g} / \mathrm{ml}(7.9 \mu \mathrm{g} / \mathrm{g})$.

Total plutonium standard solutions. Two solutions were prepared From National Bureau of Standards (NBS) SRM 949C plutonium metal to contain $11.06 \mu \mathrm{g} / \mathrm{ml}(8.07 \mu \mathrm{g} / \mathrm{g})$ and $9.95 \mu \mathrm{g} / \mathrm{ml}(7.26 \mu \mathrm{g} / \mathrm{g})$ of total plutonium.

Uranium-233 Tracer Solution. A solution containing about $0.94 \mathrm{mg} / \mathrm{ml}$ $(0.75 \mathrm{mg} / \mathrm{g})$ of uranium-233 was prepared from $\mathrm{U}_{3} \mathrm{O}_{8}$ made from uranium233 .

Total Uranium Standard Solution. A solution containing $0.74 \mathrm{mg} / \mathrm{ml}$ (0.72 $\mathrm{mg} / \mathrm{g})$ total uranium was prepared from NBS SRM 960 (NBL C8583) norma 1 uranium metal.

Micropipets. Conventional micropipets consisting of syringe and removal tip were identified by number and calibrated, and were used only for one particular solution to prevent cross-contamination.

Procedure

Determine the concentration of plutonium and uranium in the tracers in separate analyses. Prepare the tracer-standard mixtures 
by pipetting volume aliquots. Weigh the volumes used on a semimicrobalance to obtain the weights of the aliquots. Obtain the mass spectrometric measurements in the usual manner. ${ }^{1,2}$ Repeat the assays over a period of months.

\section{RESULTS AND DISCUSSION}

The tracer solutions could not be prepared to accurately known concentrations because the tracer oxides used could not be sufficiently characterized for purity and stoichiometry. Estimations of accuracy, therefore, could not be obtained from the determined assay values.

The tracer was assayed by obtaining the mass spectrometric measurements, over a period of time, on a single standard-tracer mixture and calculating the tracer concentration on the bas is of either the volumes or weights involved in the mixture. This procedure eliminated any difference in the results associated with the mass spectrometric measurements and allowed a strict comparison of the precision of each technique to be made. The data accumulated over a 9-month period are shown in Table I for plutonium-242 and in Table II for uranium-233. Although the weight aliquot technique appears to be slightly more precise, the relative standard deviations (RSD) in each case are not statistically different. Moreover, the precisions do not appear to be affected by the tracer concentration involved.

This study indicates that the preparation of tracer-standard mixtures for isotopic dilution assay by the use of volumes delivered by calibrated micropipets is essentially as precise as that by weight delivery .

TABLE I

PRECISION OBTAINED USING WEIGHT AND VOLUME ALIQUOTS: PLUTONIUM Plutonium-242

\begin{tabular}{|c|c|c|c|c|c|c|c|}
\hline & \multicolumn{3}{|l|}{$\mu \mathrm{g} / \mathrm{g}$} & \multicolumn{4}{|c|}{$\mu \mathrm{g} / \mathrm{ml}$} \\
\hline & & & $242 \mathrm{Pu}$ & & & & $\overline{242 \mathrm{Pu}}$ \\
\hline Standard & Tracer & $\underline{\mathrm{N}}$ & $\begin{array}{l}\text { Assay, } \\
\text { RSD, \% }\end{array}$ & Standard & Tracer & $\mathrm{N}$ & $\begin{array}{l}\text { Assay } \\
\text { RSD, \% }\end{array}$ \\
\hline 8.065 & 4.486 & 4 & 0.41 & 11.057 & 6.150 & 4 & 0.43 \\
\hline 7.257 & 4.470 & 3 & 0.15 & 9.947 & 6.124 & 3 & 0.17 \\
\hline 8.065 & 7.885 & 10 & 0.15 & 11.057 & 10.802 & 10 & 0.16 \\
\hline 8.065 & 7.898 & 5 & 0.33 & 11.057 & 10.812 & 5 & 0.30 \\
\hline
\end{tabular}

TABLE I I

PRECISION OBTAINED USING WEIGHT AND VOLUME ALIQUOTS: URANIUM

\begin{tabular}{|c|c|c|c|c|c|c|c|}
\hline \multicolumn{8}{|c|}{ Uranium-233 } \\
\hline & \multicolumn{3}{|l|}{$\mathrm{mg} / \mathrm{g}$} & \multicolumn{4}{|c|}{$\mathrm{mg} / \mathrm{ml}$} \\
\hline & & & $233 \mathrm{U}$ & & & & $233 \mathrm{U}$ \\
\hline Standard & Tracer & $\underline{N}$ & $\begin{array}{l}\text { Assay, } \\
\text { RSD, }\end{array}$ & Standard & Tracer & $\underline{N}$ & $\begin{array}{l}\text { Assay, } \\
\text { RSD, \% } \\
\end{array}$ \\
\hline 0.7157 & 0.7525 & 6 & 0.32 & 0.7445 & 0.9441 & 6 & 0.34 \\
\hline
\end{tabular}




\section{REFERENCES}

1. Pietri, C. E., Wenzel, A. W., Jasper, L. J., Finley, H. O. and Nelson, L. C., NBL-238 (May 1967).

2. Puleio, P. C., Pietri, C. E., Wenze1, A. W., Greer, R. J., Peoples, G. E. and Summers, A. W. NBL-265 (October 1972), p. 44 . 


\title{
A FOCAL PROGRAMMING SYSTEM FOR AN ISOTOPE RATIO MASS SPECTROMETER LABORATORY*
}

\author{
L. C. Nelson, Jr.
}

The mass spectrometer installation at the New Brunswick Laboratory (NBL) has been operated under the control of a $4 \mathrm{~K}$ PDP-8 computer for several years.1,2 The application program, as written in assembly language, together with the floating point program, occupied 22 pages of core, was inefficiently written and was cumbersome to modify. Conversion to a FOCAL operating system was adopted in order to provide more efficient and flexible use of the computer system and hands-on operation by the mass spectrometer operators. To facilitate this change, special external functions for the operation of the analog-digital converter (ADC), the buffer-relay driver, and the real-time clock were written, and suitable functions to permit storing variables and chaining programs to and from a DF-32 disk were incorporated as additional FOCAL functions in the operating system. ${ }^{3}$

The ADC function (FADC) is written to process two arguments: one to specify the multiplexor channel; and one to determine the number of $\mathrm{A} / \mathrm{D}$ conversions to be performed. All conversions resulting from a given command are summed and added to the floating accumulator for further processing. The real-time clock function (FCLK) is utilized to "slow down" the data-taking and to provide smoothed data since the mass spectrometer amplifiers, from which the signals are received, are comparatively sluggish in operation. The clock function also is used to provide settling time for the mass spectrometer magnet supply and the amplifier from which the data are derived. The relay-driver function (FRLY), used to set the mass spectrometer magnet control unit and the amplifier gain switch, is very simple, requiring but two instructions. The argument code determines the relay configuration.

The FOCAL operating programs are written to perform the data acquisition and control with suitable variations for the several instruments, type of sample and its enrichment, and for the precision that is desired. The calculations are performed as usual and include statistical evaluations.

The FADC, the FRLY, and the FCLK routines occupy 55 words in memory. With the elimination of the trigonometric extended-functions, and the overlaying of the space used for the disk monitorhead by the disk swapping routines, 3 there are 1010 locations available for applications programming and in-core storage of variables.

* Presented to and published in the proceedings of the DECUS Fall 1972 Symposium, Royal Inn, Anaheim, California, November 29December 2, 1972, p. 77 . 


\section{REFERENCES}

1. Nelson, L. C., Jr., NBL-258 (June 1971), p. 73.

2. Nelson, L. C., Jr. and Hemmer, R. J., "A Computer Controlled Isotope Ratio Mass Spectrometer Using Dry Reed Relays," DECUS Proceedings, Spring 1969.

3. Kelly, M. T., "A Simple Monitor for Disk Storage of FOCAL programs with Flexible Subroutines Linking," DECUS Proceedings, Spring 1971, p. 53. 
DETERMINATION OF SENSITIVITY FACTORS FOR THE SPARK SOURCE MASS SPECTROMETER

\author{
E. L. Callis
}

In broad-range survey-type analyses by spark source mass spectrometry, it is usually assumed that all elements have equal sensitivity. This assumption is probably valid if one is only interested in an accuracy within a factor of 3 . For more reliable work, however, one must either use an external standard material of approximately the same composition as the sample being analyzed, or one must determine sensitivity factors for the elements of interest relative to an element which is either present in the sample or is added in a known concentration as an internal standard. At the New Brunswick Laboratory (NBL) a versatile method applicable to various powder samples as well as liquids was desired. Hence, the internal standard method was chosen. The sensitivity factors were measured for an essentially pure graphite matrix with the hope that dilution of a sample with graphite would produce an approximately common matrix. Although yttrium was used as the reference element in the determination of the relative sensitivity factors (RSF), any one of the elements studied can later be used as an internal standard.

\title{
EXPER IMENTAL
}

Instrumentation. The instrument used is an MS-7 (AEI Scientific Apparatus) fitted with electrical detection by the manufacturer. Sparking parameters were: accelerating voltage, $15 \mathrm{kV}$; pulse repetition rate, $300 \mathrm{p} / \mathrm{sec}$; pulse duration, $200 \mu \mathrm{sec}$; spark voltage, $35 \mathrm{kV}$. The spark gap was manually adjusted by operating the Autospark in the manual mode. The electrodes were not vibrated.

For this work the instrument was operated in the log-ratio scanning mode. In this mode of operation the magnetic field is scanned while the ratio of the electron-multiplier output to the total beam monitor signal is continuously displayed on a ultraviolet beam (UV) recorder. Relative ion intensities are read from the chart paper using a logarithmic scale. The scanning rate was such that the mass range from 240 AMU (atomic mass units) to 9 AMU was covered in about $25 \mathrm{~min}$.

\section{Procedure}

Prepare a mixture containing 71 elements at equal concentrations, mostly as the oxides, from Spex Mixes (Spex Industries, Inc., Metuchen, N. J.). Add a sufficient amount of this mixture to high purity graphite powder (U1tra Carbon UCP-1-M) to produce electrodes containing approximately $1000 \mathrm{ppm}$ of each element. Grind this mixture thoroughly and mix in a plastic vial. 


\section{RESULTS AND DISCUSSION}

The relative sensitivity factors (RSF) are determined by measuring the ratio of the intensity of the major isotope of the unknown element to the reference element, which in this work is monoisotopic yttrium. The general expression relating the various quantities for the unknown and reference elements is

$$
\left.(R S F)_{u n k}=R_{(j / i}\right) \cdot \frac{C_{\text {ref }}}{C_{u n k}} \cdot \frac{\left(I_{i} / M\right)_{\text {ref }}}{\left(I_{j} / M\right)_{u n k}} \cdot(R S F)_{r e f}
$$

where

$$
\begin{aligned}
& i \text { and } j \text { refer to the particular isotopes } i \text { and } j \text { of the } \\
& \text { reference and unknown elements, respectively; }
\end{aligned}
$$

$$
\begin{aligned}
R_{(j / i)} & =\text { ratio of intensities, unknown to reference; } \\
C & =\text { weight concentration; } \\
I & =\text { isotopic abundance; } \\
M & =\text { atomic weight of the respective elements. }
\end{aligned}
$$

It should be noted that no corrections are made for the mass response of the detector or peak width. Hence, the RSF as defined is an overall correction factor.

In Table I are presented the measured sensitivity factors. Each value is the result of 5 determinations corresponding to 5 sample loadings. The reference peak was scanned 6 times for each complete scan of the spectrum.

TABLE I

RELATIVE SENSITIVITY FACTORS DETERMINED IN A GRAPHITE MATRIX

\begin{tabular}{cc} 
Element & Isotope Used \\
\cline { 2 - 2 } $\mathrm{U}$ & 238 \\
$\mathrm{Th}$ & 232 \\
$\mathrm{Bi}$ & 209 \\
$\mathrm{~Pb}$ & 208 \\
$\mathrm{~T} 1$ & 205 \\
$\mathrm{Hg}$ & 202 \\
$\mathrm{Au}$ & 197 \\
$\mathrm{Pt}$ & 195 \\
$\mathrm{Ir}$ & 193 \\
$\mathrm{Re}$ & 187 \\
$\mathrm{~W}$ & 186 \\
$\mathrm{Ta}$ & 181 \\
$\mathrm{Hf}$ & 180
\end{tabular}

$\begin{array}{ll}\underline{R S F}^{\mathrm{a}} & \underline{\text { RSD, } \%} \\ 1.8 & \pm 43 \\ 1.9 & \pm 38 \\ 2.1 & \pm 43 \\ 4.0 & \pm 33 \\ 4.3 & \pm 15 \\ 0.5 & \pm 106 \\ 1.8 & \pm 100 \\ 2.1 & \pm 110 \\ 1.1 & \pm 61 \\ 0.4 & \pm 48 \\ 3.3 & \pm 56 \\ 1.7 & \pm 56 \\ 1.3 & \pm 24\end{array}$

('Table I continued) 


\section{TABLE I (Continued)}

RELATIVE SENSITIVITY FACTORS DETERMINED IN A GRAPHITE MATRIX

\begin{tabular}{|c|c|c|c|}
\hline Element & Isotope Used & $\underline{\mathrm{RSF}}^{\mathrm{a}}$ & RSD, \\
\hline $\mathbf{L u}$ & 175 & 1.0 & \pm 14 \\
\hline $\mathrm{Yb}$ & 174 & 1.7 & \pm 29 \\
\hline $\operatorname{Tm}$ & 169 & 1.1 & \pm 43 \\
\hline $\operatorname{Er}$ & 166 & 1.2 & \pm 32 \\
\hline Ho & 165 & 0.93 & \pm 41 \\
\hline Dy & 162 & 1.2 & $\pm \quad 41$ \\
\hline $\mathrm{Tb}$ & 159 & 0.88 & \pm 43 \\
\hline $\mathrm{Gd}$ & 158 & 0.86 & \pm 20 \\
\hline $\mathrm{Eu}$ & 153 & 0.96 & \pm 13 \\
\hline $\mathrm{Sm}$ & 152 & 1.1 & \pm 34 \\
\hline $\mathrm{Nd}$ & 146 & 0.83 & \pm 18 \\
\hline $\operatorname{Pr}$ & 141 & 0.84 & \pm 20 \\
\hline $\mathrm{Ce}$ & 140 & 0.71 & \pm 29 \\
\hline $\mathrm{La}$ & 139 & 0.78 & \pm 24 \\
\hline $\mathrm{Ba}$ & 138 & 0.97 & \pm 16 \\
\hline $\mathrm{Cs}$ & 133 & 3.6 & \pm 30 \\
\hline $\mathrm{Te}$ & 130 & 1.3 & 39 \\
\hline I & 127 & 1.3 & 13 \\
\hline $\mathrm{Sb}$ & 121 & 1.3 & $\pm \quad 32$ \\
\hline $\mathrm{Sn}$ & 120 & 2.3 & \pm 44 \\
\hline In & 115 & 2.0 & \pm 21 \\
\hline $\mathrm{Cd}$ & 114 & 0.78 & \pm \\
\hline $\mathrm{Ag}$ & 107 & 2.7 & \pm 23 \\
\hline $\mathrm{Pd}$ & 106 & 1.5 & 28 \\
\hline $\mathrm{Rh}$ & 103 & 0.7 & \pm 105 \\
\hline $\mathrm{Ru}$ & 102 & 0.94 & \pm 31 \\
\hline Mo & 98 & 1.6 & 26 \\
\hline $\mathrm{Nb}$ & 93 & 0.98 & 22 \\
\hline $\mathrm{Zr}$ & 90 & 1.4 & 33 \\
\hline $\mathrm{Sr}$ & 88 & 1.3 & 22 \\
\hline $\mathrm{Rb}$ & 85 & 4.2 & 30 \\
\hline $\mathrm{Br}$ & 81 & 1.2 & 33 \\
\hline $\mathrm{Se}$ & 80 & 1.8 & 37 \\
\hline As & 75 & 1.8 & \pm 27 \\
\hline
\end{tabular}


TABLE I (continued)

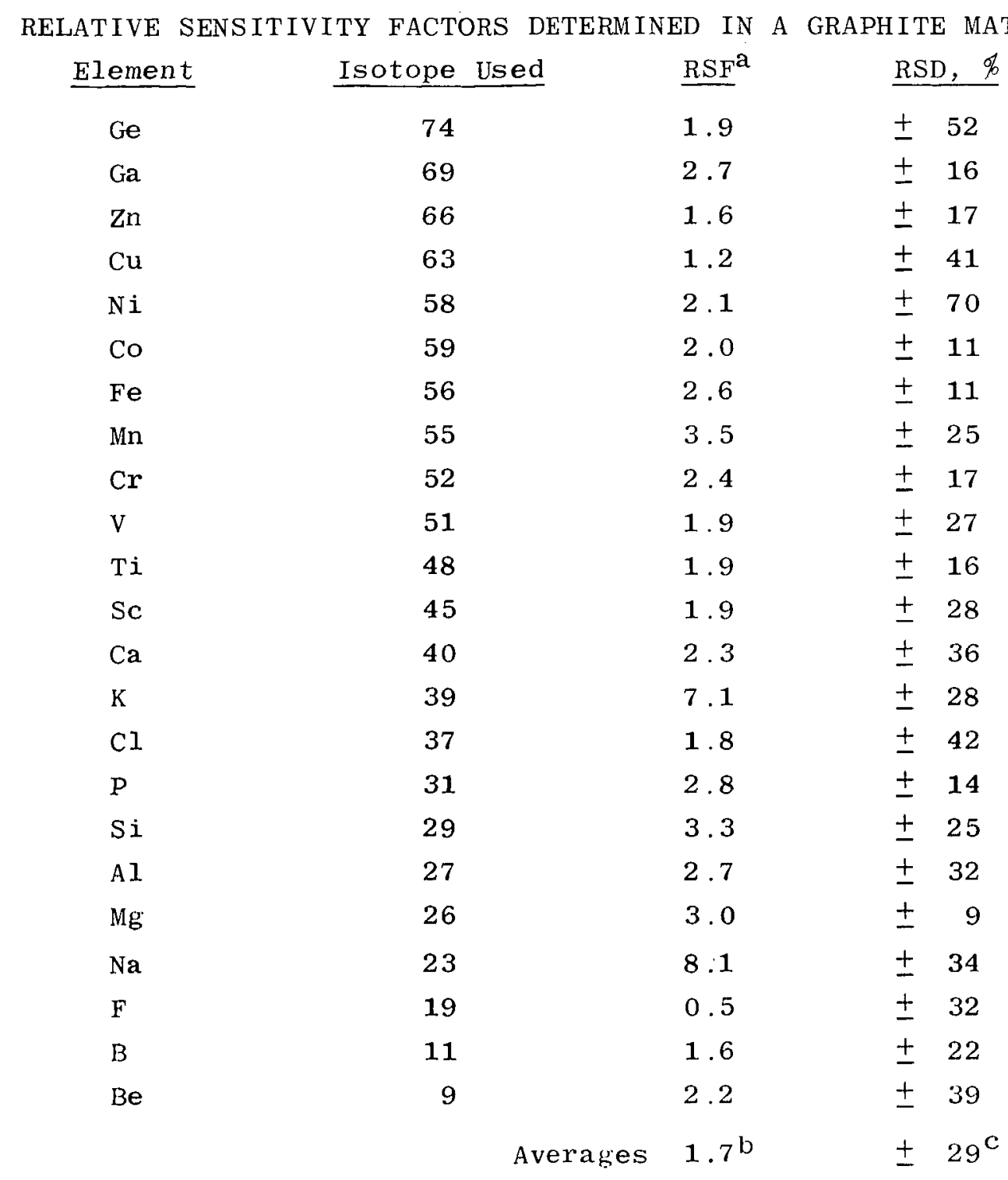

a. Relative to 1.00 for yttrium

b. Values for $\mathrm{Na}$ and $\mathrm{K}$ excluded

c. Values for $\mathrm{Hg}, \mathrm{Au}, \mathrm{Pt}, \mathrm{Ir}, \mathrm{Rh}, \mathrm{Ni}$ excluded in the determination of the average precision due to apparent inhomogeneity.

The large relative standard deviations (RSD) of the values for mercury, gold, platinum, iridium, rhodium and nickel indicate that these elements were probably inhomogeneously distributed. The average RSD of $29 \%$ for an individual determination is consistant with that reported by other workersi using the scanning technique. 
In Table II are shown the results of an analysis, using the sensitivity factors in Table $\mathrm{I}$, of $\mathrm{U}_{3} \mathrm{O}_{8}$ to which impurities had been added. TABLE II

ANALYSIS OF $\mathrm{U}_{3} \mathrm{O}_{8}$ SPIKED WITH IMPURITIES

\begin{tabular}{|c|c|c|}
\hline \multirow[b]{2}{*}{ Element } & \multicolumn{2}{|c|}{ Concentration, $\mathrm{ppm}$} \\
\hline & Added & Determined \\
\hline $\mathrm{Bi}$ & 50 & 70 \\
\hline $\mathrm{Pb}$ & 50 & 70 \\
\hline $\mathrm{Hg}$ & 50 & 40 \\
\hline $\mathrm{Ba}$ & 500 & 410 \\
\hline $\mathrm{Te}$ & 50 & $\leq 100$ \\
\hline $\mathrm{Sb}$ & 50 & 120 \\
\hline $\mathrm{Sn}$ & 50 & 160 \\
\hline In & 50 & 80 \\
\hline $\mathrm{Cd}$ & 10 & $\leq 25$ \\
\hline $\mathrm{Ag}$ & 10 & 14 \\
\hline Mo & 500 & 570 \\
\hline $\mathrm{Nb}$ & 50 & 100 \\
\hline $\mathrm{Sr}$ & 500 & 520 \\
\hline $\mathrm{Rb}$ & 500 & 425 \\
\hline $\mathrm{Ge}$ & 50 & 40 \\
\hline $\mathrm{Zn}$ & 500 & 450 \\
\hline $\mathrm{Cu}$ & 50 & 70 \\
\hline $\mathrm{Ni}$ & 100 & 100 \\
\hline $\mathrm{Co}$ & 50 & 35 \\
\hline $\mathrm{Fe}$ & 500 & 480 \\
\hline Mn & 50 & 40 \\
\hline $\mathrm{Cr}$ & 100 & 95 \\
\hline $\mathrm{V}$ & 500 & 330 \\
\hline $\mathrm{Ti}$ & 50 & 250 \\
\hline $\mathrm{Ca}$ & 50 & 75 \\
\hline $\mathrm{K}$ & 630 & 570 \\
\hline $\mathrm{P}$ & 500 & 425 \\
\hline $\mathrm{Si}$ & 500 & 1050 \\
\hline Al & 500 & 850 \\
\hline $\mathrm{Mg}$ & 50 & 130 \\
\hline $\mathrm{Na}$ & 820 & 940 \\
\hline $\mathrm{B}$ & 10 & 14 \\
\hline
\end{tabular}


Gallium at a concentration of $3200 \mathrm{ppm}$ was added as the internal standard. The agreement between the measured and added values for impurities at the $100 \mathrm{ppm}$ and above level appears to be good, the average deviation being less than $14 \%$ if the values for silicon and aluminum are excluded. The large discrepancies in the cases of titanium, aluminum and silicon are not understood. The relatively poorer agreement for the 50-and $10-\mathrm{ppm}$ levels may be due to the peak intensities being measured at gain settings too low for reliable results.

In Table III are shown the results of an analysis of a synthetic mineral sample. The matrix of $70 \%$ silica, $20 \%$ iron oxide, and $10 \%$ calcium carbonate was spiked with oxide impurities, and $500 \mathrm{ppm}$ gallium was added as the internal standard.

TABLE I I I

ANALYSIS OF A SYNTHETIC MINERAL SAMPLE

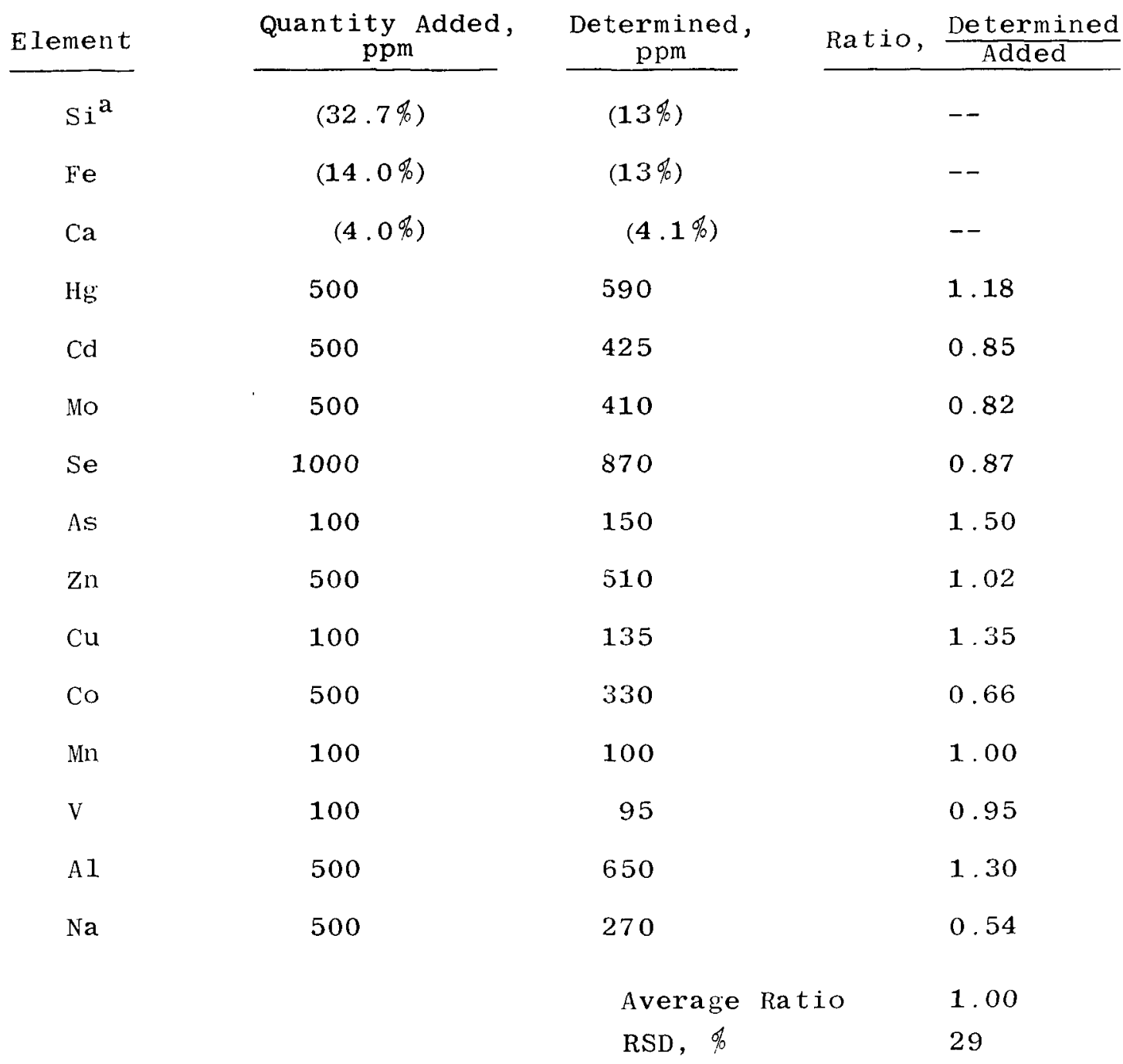

a. Matrix elements $\mathrm{Si}, \mathrm{Fe}$ and $\mathrm{Ca}$ included for information only. 
It is interesting to note the low value for the matrix element Si. Low values for silicon have been cbserved at NBL in other analyses of this matrix using the internal standard technique. The low results are believed to be due to a significant broadening of the ion energy distributions at matrix level concentrations causing a smaller fraction of the ions of a given element to be transmitted by the monitor into the magnetic analyzer.

For the added impurity elements, the ratic of the determined to the added value has been calculated. The average value of 1.00 for this quantity is reassuring and the RSD of $29 \%$ is consistant with the precisions observed in the determinations of the sensitivity factors.

Based on the limited analyses presented in this report it would appear that relative sensitivity factors determined for a graphite matrix are, in most cases, valid also for $1: 1$ samplegraphite electrodes. The relationships probably break down, however, at concentrations approaching matrix levels.

\section{REFERENCE}

1. Bingham, R. A. and Elliott, R. M., Anal. Chem., 43, 44 (1971). 


\title{
SPARK SOURCE MASS SPECTROGRAPHIC DETERMINATION OF IMPURITIES IN URANIUM HEXAFLUORIDE - A PROGRESS REPORT
}

\author{
E. L. Callis
}

Development of a spark source mass spectrographic technique for the determination of volatile impurities in uranium hexafluoride $\left(\mathrm{UF}_{6}\right)$ is currently underway at the New Brunswick Laboratory (NBL). The technique involves the introduction of gaseous uranium hexafluoride into a spark gap where it is ionized. The primary advantage of this method of analysis is the fact that no chemical separations or conversions are required.

In a previous report ${ }^{1}$ the preliminary work on this project was described. Recently, an improved inlet system has been constructed which allows a small quantity of uranium hexafluoride to be heated to a maximum of $300^{\circ} \mathrm{C}$ and admitted into the ion source. Since the inlet system is "floated" at the accelerating potential of $15 \mathrm{kV}$, an isolated power unit was built to supply power to the heating tapes which are used to heat the system. The only serious problem encountered so far is the radiation of spark noise by the system. It is felt that this can be overcome by proper shielding.

Another improvement has been the fabrication of various source parts of nickel and Monel to replace the conventional tantalum parts. This permits the determination of tantalum as an impurity.

Work on a Uranium Hexafluoride Impurity standard. To obtain quantitative results using this direct ionization technique, uranium hexafluoride containing known amounts of impurities is needed. An attempt was made to produce such a material by adding impurities in the elemental form to the uranium hexafluoride and heating in a fluorination tube to $300^{\circ} \mathrm{C}$. Several of the elements were detected in the mass spectrum and appeared to have converted quantitatively while others were detected at much lower concentrations than were added or were not detected at all.

Future work will be directed toward devising a method for the production of a reliable reference material and, in general, the development of an overall analysis technique which will permit routine analysis.

A complete report of this work will be issued at a later date.

\section{REFERENCE}

1. Cal1is, E. L., NBL-265 (October 1972), p. 53 . 


\title{
EVALUATION OF THE FABRY-PEROT INTERFERENCE SPECTROMETER FOR URANIUM ISOTOPIC ANALYSIS - A STATUS REPORT
}

\author{
H. G. Yuster
}

In a previous report ${ }^{1}$ a commercial Fabry-Perot interference spectrometer manufactured by Jobin-Yvon Company in France was evaluated for the determination of uranium isotopic abundance. The results obtained at that time can be briefly summarized as follows. The speed of analys is is relatively slow because a single hollow cathode excitation source is used which requires prior conditioning before the measurements. In addition the technique of pressure scanning is an inherently slow process when adiabatic conditions must be met. This latter factor, which leads to long time intervals between peak measurements and necessitates taking the average of many peak ratios, is responsible, at least in part, for the poor precision obtained despite the fact that the hollow cathode source is relatively stable.

Three modifications to the basic instrumentation are in progress. First, a 6-unit hollow cathode cluster of the turret type as shown in Figure 1 and 2 has been constructed to replace the single unit presently used. With this system, one hollow cathode can be in the measurement mode while the remaining five are being. conditioned at reduced amperage. The unit is powered by a regulated $550 \mathrm{VDC}$ and $500 \mathrm{~mA}$ supply with controls for the amperage and individual ammeter monitoring of each cathode. The maximum amperage on one hollow cathode is about $80 \mathrm{~mA}$. Ball-bearing detents allow the cluster to be rotated so that each hollow cathode can be placed in the optical path. Second, a piezo-electric unit with a special ramp generator has been ordered for the rapid scanning of the etalon plate. Third, a digital voltmeter with printer is being obtained. These latter two items will materially speed up the scanning and measurements and hopefully will improve the precision of the data.

\section{REFERENCE}

1. Yuster, H. G., NBL-265 (October 1972), p. 74 . 


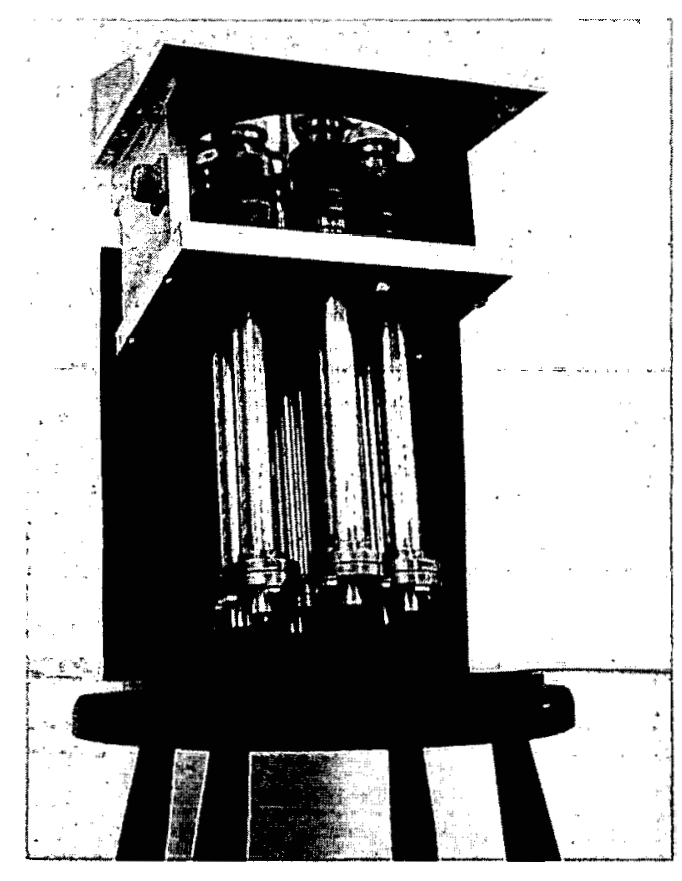

FIGURE 1. PHOTOGRAPH OF HOLLOW CATHODE CLUSTER SIDE VIEW.

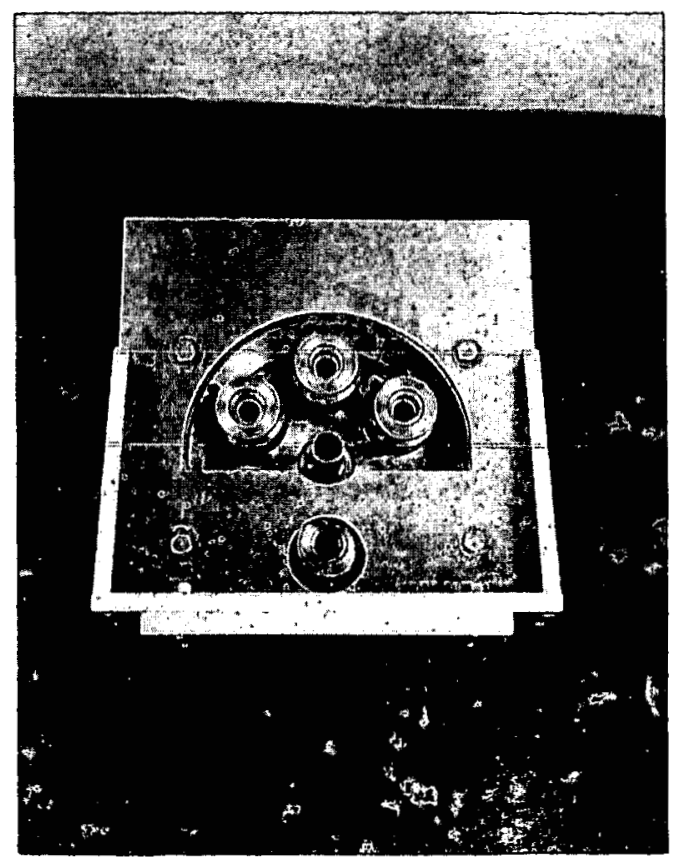




\section{A CENTRAL ANNUNCIATOR PANEL FOR THE NEW BRUNSWICK LABORATORY - A PROGRESS REPORT}

\section{R. J. Hemmer}

Under the previous alarm system at the New Brunswick Laboratory (NBL), abnormal instrumental readings or malfunctions would set off the following audio or visual alarms: Fire, Smoke, Stack Monitor, Waste Tank, Differential Pressure, Gamma Monitor, Air Monitor, Stack Flow, Air Pressure and Freeze. Some of these alarms were laboratory-wide, others were only local. The various alarms of this system, added piece-meal as the need arose, were confusing and, in some cases, ineffective because of problems associated with the fact that the laboratory consists of two separate buildings.

The present report describes the planned consolidation of all these alarms into one master panel located in the main laboratory with a repeater panel located in the second building. The various alarms are given one of three different priorities indicated by the color of the lighted display on the panels and by a distinct audio signal. The completed system will be generally more efficient and less confusing than the original one.

\section{General Design and Operation}

The master panel is located in the lobby of the main building directly behind the telephone switchboard and public address system. This location is optimum for alerting the operator or guard on duty who will have quick access to the internal or external communication lines. With the NBL-designed panel, only the floor plan of the laboratory and the motor status display are shown under a noalarm condition. The repeater panel is located in the entrance way of the second building behind the main building.

The master panel is shown in Figure 1 . When an alarm is tripped, the type of alarm, Smoke, Fire, etc., is indicated by lighted displays on the left side of the panel, and the location of the condition is lighted on the floor plan, Figure 2. An audio signal sounds. Both visual and audio alarms continue until manually shut off.

One of three priorities are assigned to an alarm to indicate the seriousness of the emergency. Level 1 denotes a criticality incident shown by a Gamma Monitor pair. The audio alarm is a wavering siren and the panel lighting color for this level is green. Under level 1 , all personnel evacuate immediately.

A laboratory-wide alert is assigned level 2. The audio alarm is a claxon horn and the panel lighting is red. Under level 2, all personnel make preparation to evacuate and wait instruction. These instructions to personnel are given over the public address 


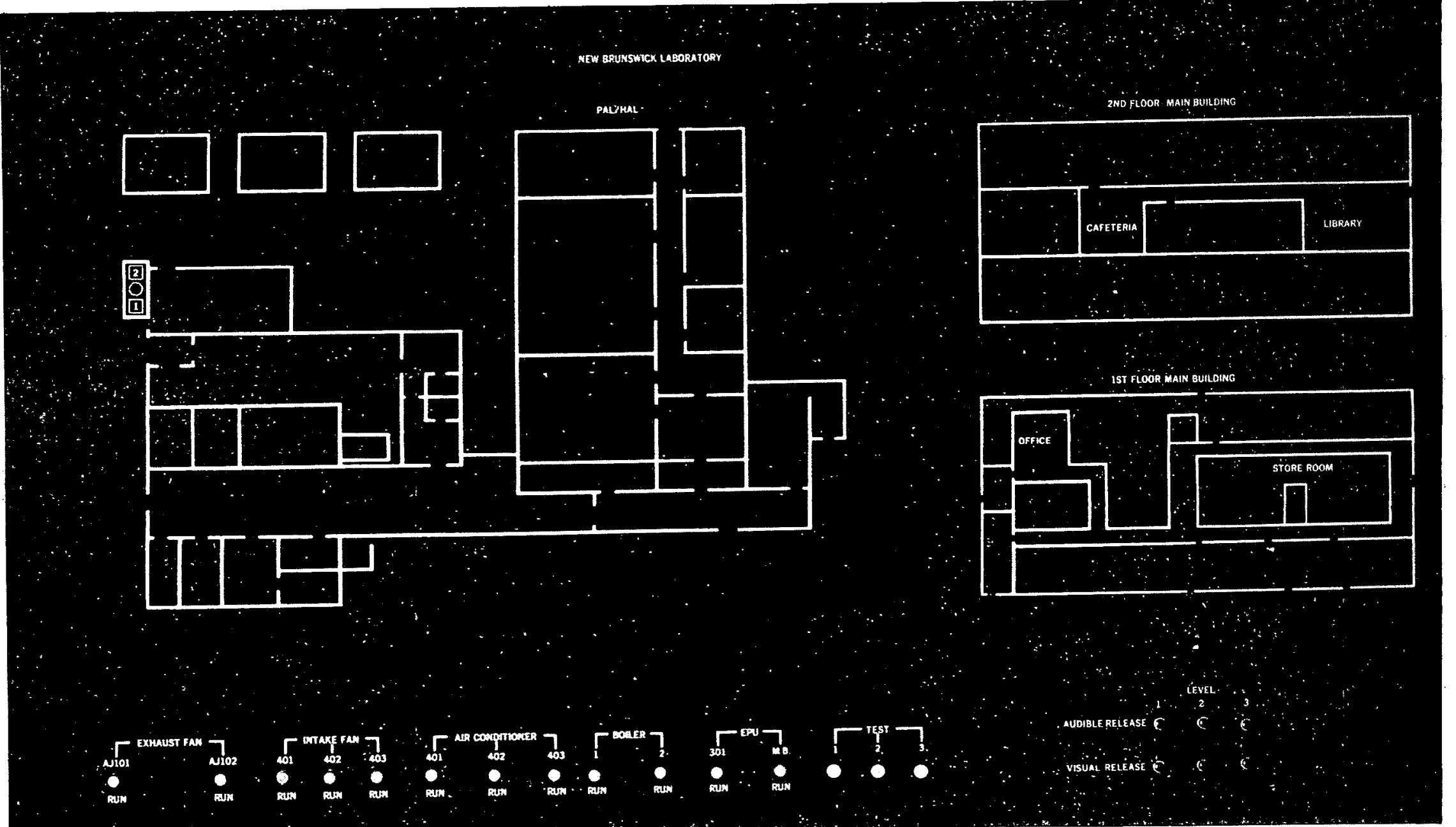

FIGURE 1. PANEL UNDER NO ALARM CONDITION. 


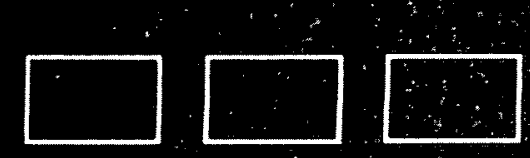

घ)

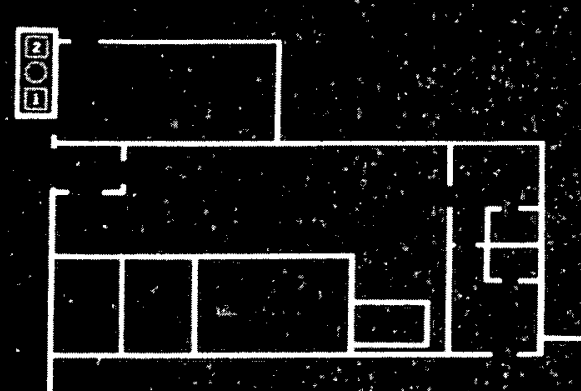
ए广

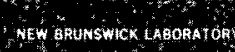

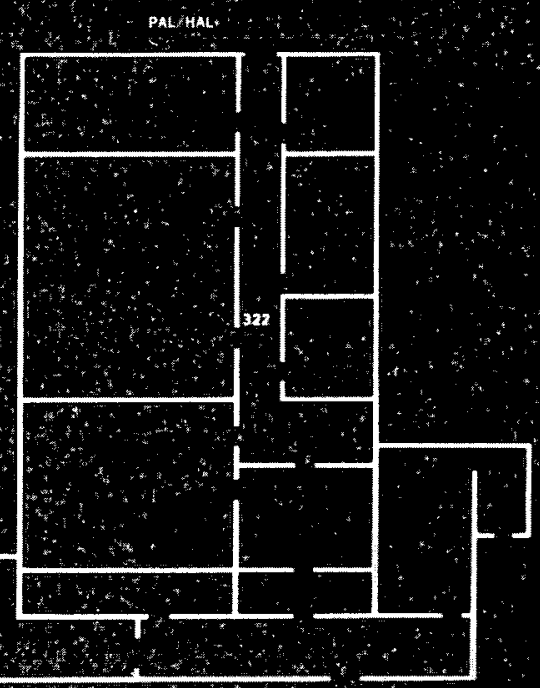

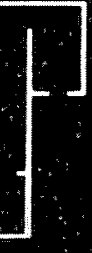

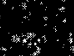

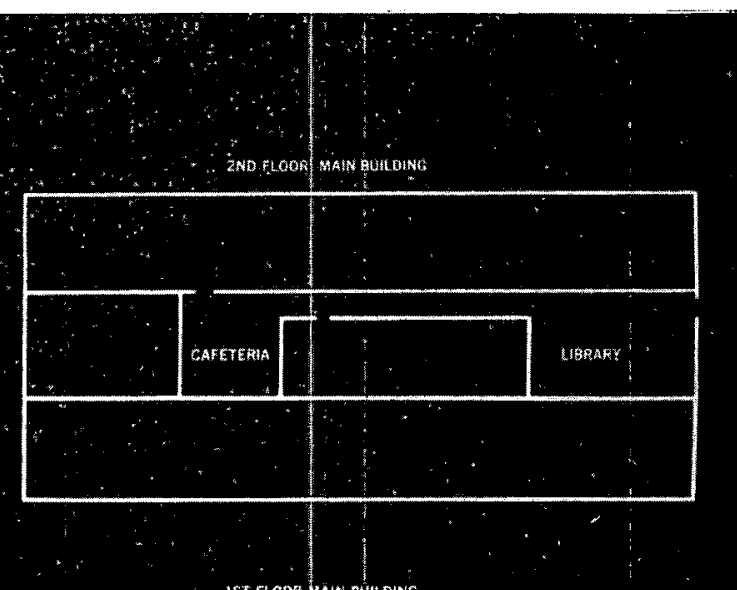

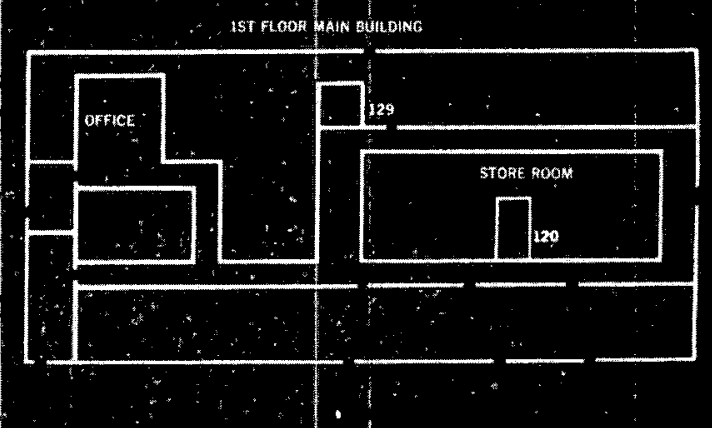

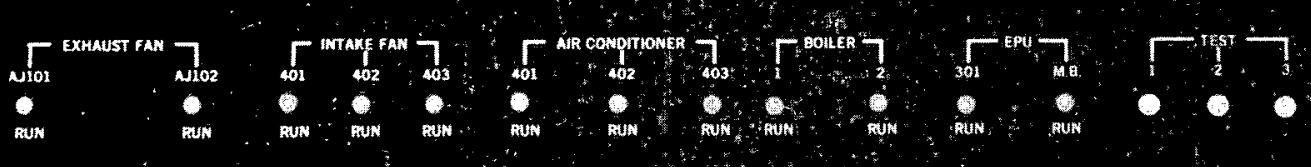

FIGURE 2. PANEL WITH ROOMS 120, 129 AND 322 GIVING A GAMMA MONITOR ALARM. 
system. The alarms assigned priority level 2 are the stack Monitor (High-level), Fire, Air Monitor, and single Gamma Monitor.

Level 3 indicates a non-emergency condition requiring action by certain laboratory personnel. Information and instructions, as required, are again given over the public address system. The alarm is a continuously ringing bell and the lighting color is orange. These alarms include the stack Flow, Differential pressure, Waste Tank, Smoke, Stack Monitor (low-level), Gamma Monitor, Freeze, Air, and Air Monitor.

The master panel contains all the circuitry necessary for the alarm operation, for the testing of the 3 levels individually, for silencing the audible alarms, and for resetting the visual indicators. The repeater panel merely repeats the lighting on the master panel.

Figure 3 indicates how a FIRE alarm originating in Room 308 activates the master panel: Switch 51 closes and energizes relay K1 which causes the visual and audio alarms to be activated. Relay $\mathrm{K}_{2}$ is much faster than relay $\mathrm{K} 1$, thus allowing it to operate. Relay $K_{2}$ operates the horn; Switch $S 2$ deactivates the horn for testing, while lamp I1 indicates proper operation of relay K3. The red room number 308 is used by three different level-2 alarms; therefore, diodes are used to isolate the three systems.

Status. The panels have been in operation for the past three months with the Fire and Gamma Monitor (Criticality) alarms connected. Operation has been satisfactory even during a temporary power failure. The other functions will be added as quickly as time permits. 


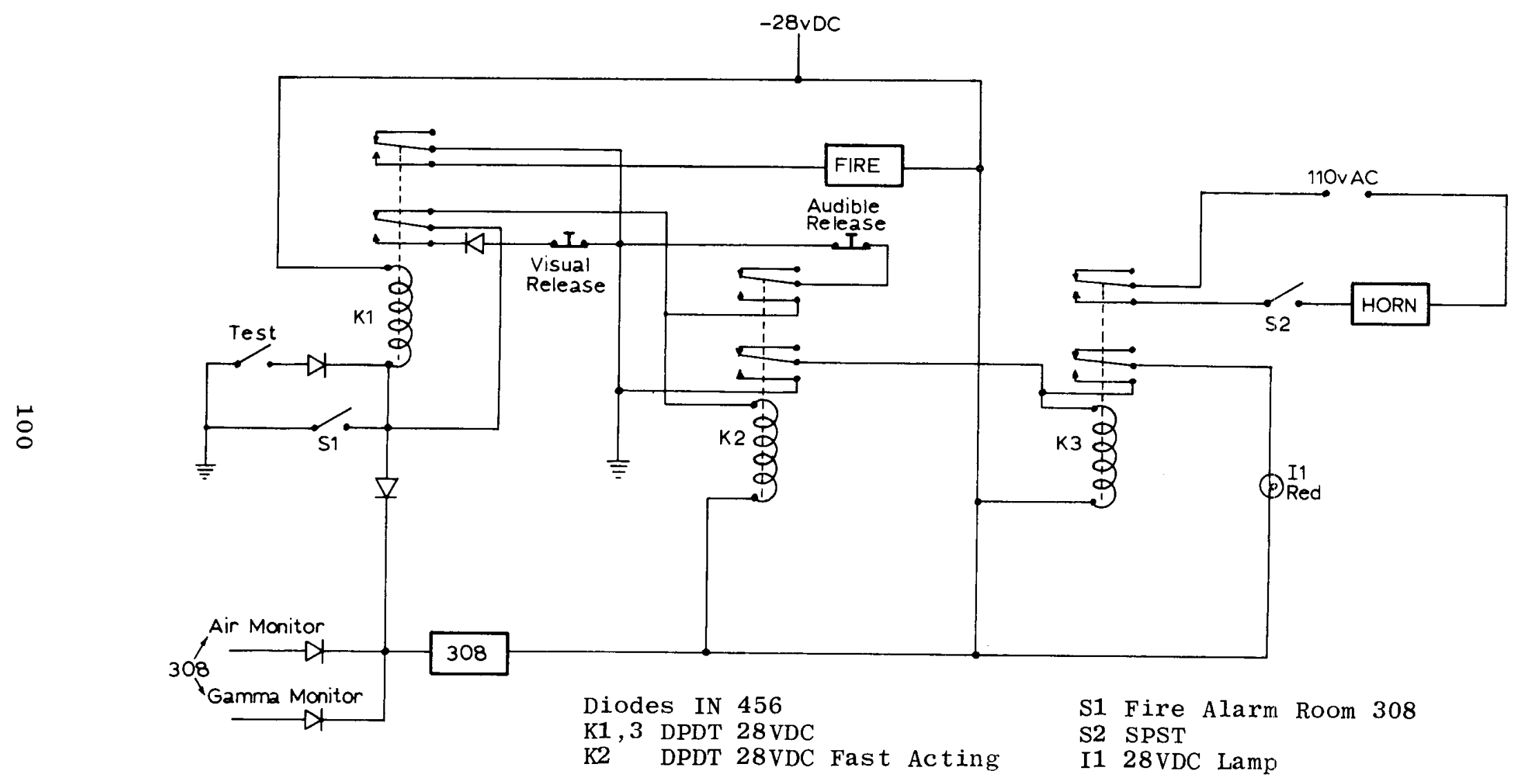

FIGURE 3. TYPICAL ALARM TRIP CIRCUIT. 


\title{
AN AUTOMATED MINI ION-EXCHANGE AND COULOMETRY SYSTEM - A PROGRESS REPORT
}

\author{
J. R. Weiss, A. W. Wenzel and C. E. Pietri
}

Although controlled-potential coulometry is adversely affected by few elements, many plutonium samples are not readily analyzed by this method because of their high salt and impurity content. separation of plutonium from impurities is considered necessary for reliable results.1,2

A large increase in the number of plutonium samples analyzed in the nuclear field is anticipated in the next few years. To meet these demands with a minimum increase in operating costs and no loss in quality, the New Brunswick Laboratory (NBL) is developing two related automated systems.

The first system (Autosep) automates the mini ion-exchange separation of plutonium from interferences. The second system (Autocoulometry) automates the controlled-potential coulometric determination of plutonium in the separated samples. These two systems are based on procedures previously described. ${ }^{1}$

The present report, preliminary in nature, describes the project and gives the status of the fabrication.

\section{Autosep System}

The Autosep system is designed as a batch-type operation in which 10 sample aliquots are simultaneously passed through ionexchange columns. Weighed aliquots of dissolved sample, each containing 5-10 $\mathrm{mg}$ of plutonium, are added to each of 10 reservoirs in the mini-ion exchange separator. The volume of liquid in each reservoir is brought to $10 \mathrm{ml}$ by addition of a reagent and all subsequent steps in the separation are done automatically. The system incorporates a means of programming adjustment to the plutonium(IV) oxidation state, reagent delivery, column loading and washing, and stripping of the mini-ion exchange columns. The reagents are delivered by gravity from a module whose only moving parts are solenoid valves. The eluted plutonium solutions are collected in glass coulometer cells held in stainless steel trays.

The Autosep system consists of 3 modules, an Agastat programmex, a reagent delivery module, and a mini ion-exchange separator, Figure 1. Only the mini-ion exchange separator must be inside a glove box.

\section{Autocoulometry System}

The Autocoulometry system has a sample-handling apparatus capable of 100 samples per loading. Samples are loaded on to the 


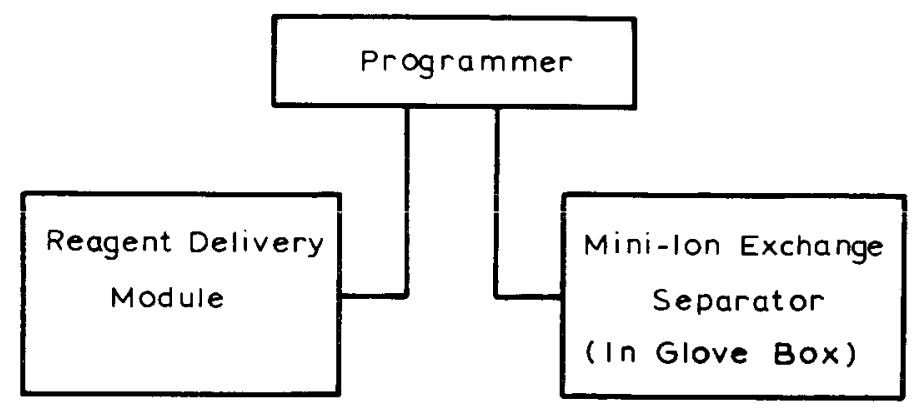

\section{AUTOCOULOMETRY SYSTEM}

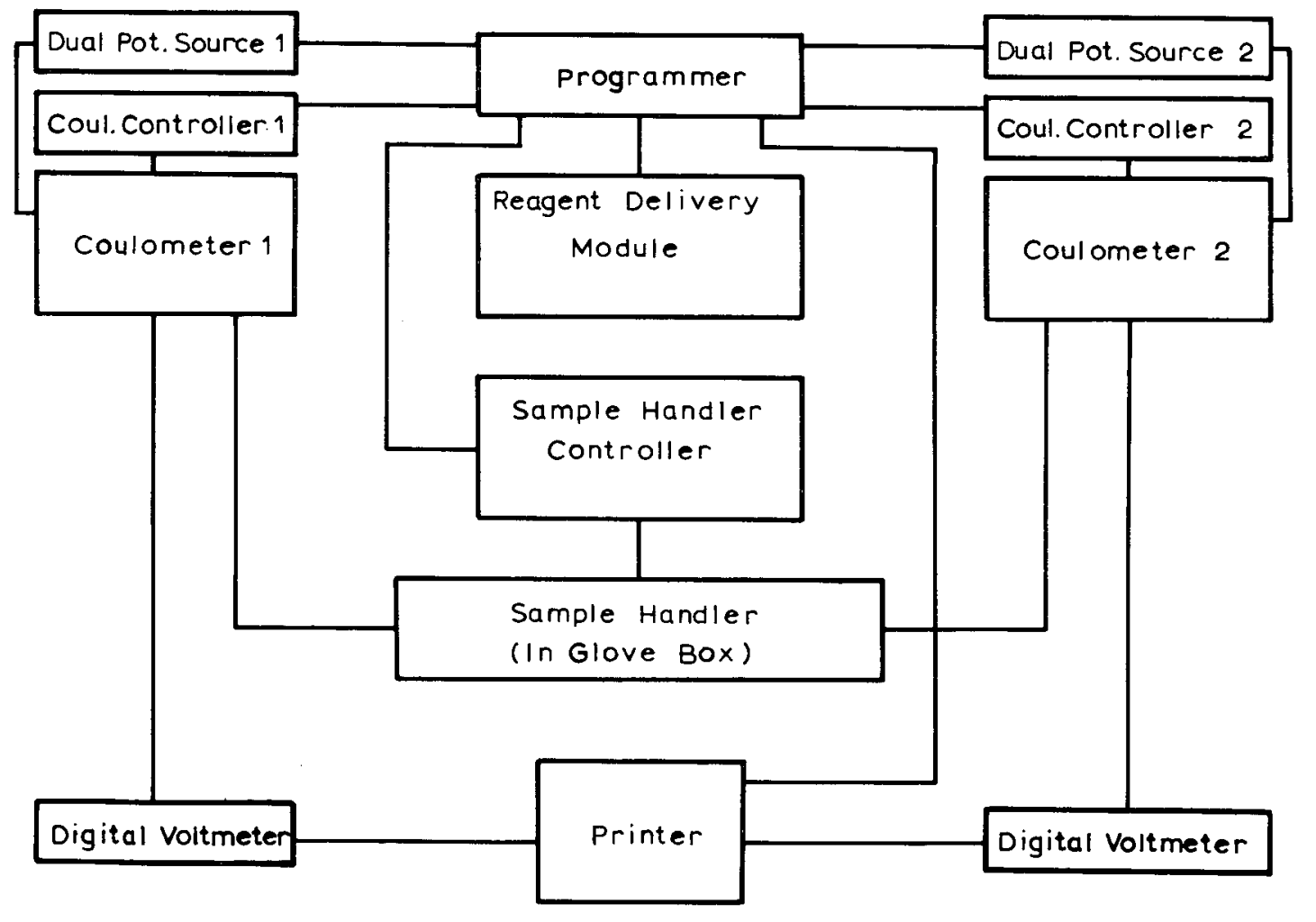

FIGURE 1.

BLOCK DIAGRAM OF AUTOSEP AND AUTOCOULOMETRY SYSTEMS 
unit in stainless steel trays, each tray containing 5 glass coulometer cells with each cell holding a plutonium sample. The unit has dual cell heads which operate simultaneously, and a controlled potential coulometer for each head. The sample handler, by means of conveyor systems, moves the trays such that cells are sequentially placed under the cell heads, the cell heads are lowered into place, and the programmer is advanced to the next operation. Ten trays are run by each head per loading. The system has provisions for automatically determining separate blanks for each sample, controlling the coulometric determination, combining analyzed samples for recovery of plutonium, cleaning all coulometer cells for re-use, and printing data.

The Autocoulometry system consists of 13 modules including an Agastat programmer, a reagent delivery module, a sample handler, a sample-handler controller, 2 dual-potential source units, 2 coulometer controllers, 2 controlled-potential coulometers, 2 digital voltmeters, and a printer, Figure 1 . Only the sample handler must be inside a glove box.

\section{DISCUSSION}

Maintenance was considered in designing the systems, and standard commercially available parts were used where possible. An effort was made to select materials for the units in the glove boxes which would be most resistant to an acid environment. This factor led to the use of sealed switches and plastic or stainless steel parts where teasible.

The Autosep and Autocoulometry systems, although in a preliminary stage, show much promise in meeting our goal of increased high-quality output without the need for more glove box space or additional personnel. It is estimated that a 3 to 5 fold increase in productivity, with the same size staft, will result with less glove-box space requirement than that needed for the existing operations. The Autocoulometry system has the capability of operating 24 hours a day. The increased sample capacity using the two systems should allow several determinations on each sample to be made and allow a calculation of the precision of the results.

\section{$\underline{\text { Status }}$}

At present, the modules composing the two systems are in various stages of construction. The parts for the reagentdelivery modules for both systems are on hand and await assembly. The sample-handlex controller for Autocoulometry is designed but is not yet assembled since the sample handler itself is still under construction. Delivery of the dual-potential source units and the coulometer controllers for Autocoulometry, designed and built at Lawrence Livermore Laboratory, is expected in the near future. The mini-ion exchange separator for Autosep is almost completed. The remaining modules are on hand and operational. 


\section{REFERENCES}

1. Weiss, J. R., Pietri, C. E., Wenzel, A. W. and Nelson, L. C., Jr., NBL-265 (October 1972), p. 94.

2. Pietri, C. E., Wenzel, A. W. and Simmons, H. N., NBL-258 (June 1971), p. 47 . 


\section{CALCULATION OF HYDROGEN GENERATION FROM PLUTONIUM-INDUCED RADIOLYSIS OF NITRIC, SULFURIC AND PERCHLORIC ACIDS}

\section{J. R. Weiss and C. E. Pietri}

The products of radiolysis in an aqueous system vary with the type of radiation and the particular solutes present in the solution. Plutonium in aqueous solution causes radiolytic generation of several gases including hydrogen which in stored solutions presents an explosion hazard. To evaluate the magnitude of such a hazard, it is necessary to predict the rate of hydrogen generation. In a previous report, 1 these calculations were made for a dilute sulfuric acid solution of plutonium held in a storage assembly with several different venting configurations. In the present study, an existing equation ${ }^{2}$ was modified to permit calculation of the hydrogen generation in various concentrations of nitric, sulfuric and perchloric acid and various concentrations and isotopic compositions of plutonium.

The modified equation to calculate the hydrogen generation is as follows:

$$
\mathrm{H}_{2}(\mathrm{moles} / \mathrm{day})=\left(1.675 \times 10^{-5}\right)(\mathrm{Pu})(\mathrm{G})(\mathrm{C})
$$

where $\mathrm{Pu}=$ quantity of plutonium in the solution, $\mathrm{g}$;

$\mathrm{G}=$ hydrogen evolved per 100 electron volts of energy absorbed by the system, molecules;

and

$$
\begin{aligned}
\mathrm{C}= & 0.01(302.0[238 \mathrm{Pu}(\%)]+1.000[239 \mathrm{Pu}(\%)]+ \\
& 3.696[240 \mathrm{Pu}(\%)]+0.0417[241 \mathrm{Pu}(\%)]+ \\
& 0.0604[242 \mathrm{Pu}(\%)])
\end{aligned}
$$

with the isotopic compositions expressed as weight per cent.

The data indicate that plutonium in nitric or perchloric acid generates considerably less hydrogen than in sulfuric acid. For example, $50 \mathrm{~g}$ of plutonium consisting of $0.7 \%$ plutonium-238, $41 \%$ plutonium-239, 43\% plutonium-240, $10.4 \%$ plutonium-241 and $4.9 \%$ plutonium-242 produces $16 \mathrm{ml} /$ day (STP) of hydrogen in $1 \mathrm{M}$ nitric acid, $29 \mathrm{ml} /$ day in $1 \mathrm{M}$ perchloric acid, and $124 \mathrm{ml} /$ day in $0.1 \mathrm{M}$ sulfuric acid. A calculation for $1 \mathrm{M}$ sulfuric acid could not be carried out because of the lack of pertinent data, but it is estimated that the hydrogen generation at this concentration would be only slightly lower than $124 \mathrm{ml} /$ day.

This same $50 \mathrm{~g}$ of plutonium in $10 \mathrm{M}$ nitric acid produces only $1.4 \mathrm{ml} /$ day of hydrogen. Thus it is clear that there is a considerable advantage in storing plutonium in solutions of high nitric acid concentration in order to avoid high hydrogen generation rates and thereby minimize the explosion hazard. 
A detailed account of this study has been accepted for publication in Radiation Effects.

\section{REFERENCES}

1. Weiss, J. R. and Pietrí, C. E., NBL-265 (October 1972) p. 104.

2. Sheppard, J. C., BNWL-751, May 1968. 
A GENERAL ANALYTICAL EVALUATION (GAE)

PROGRAM FOR URANIUM HEXAFLUORIDE

\section{D. Bingham}

A program has been planned and placed into operation to demonstrate whether a consistent level of performance exists in the chemical assay and measurement of isotopic abundance of uranium in uranium hexafluoride $\left(\mathrm{UF}_{6}\right)$. Some of those organizations presently involved or likely to become involved in toll-enrichment transactions as well as fuel reprocessing or conversion facilities have been invited to participate.

Phase I of the program involves measuring the uranium content and isotopic abundance each month in each of three samples ranging from near-normal to approximately $2 \%$ enrichment in uranium-235. Phase I sample distribution began in June 1973 and will continue for 14 months. Nine domestic and 11 foreign laboratories are currently participating in phase $I$.

Phase I samples for uranium assay are being distributed in tluorothene ("P-10") tubes, Figure 1. Samples for uranium isotopic abundance measurements are being distributed in heat-sealed polyethylene ("pig tail") tubes.

Phase II will consist of similar measurements made upon material taken as sub-samples from $1 \mathrm{~S}$ containers to assess the contribution of sampling to the overall variance of measurement. A Phase III will involve measurement of impurity element content in samples of uranium hexafluoride. A firm time schedule for phases II and III has not been established, pending experiences observed in phase I. 


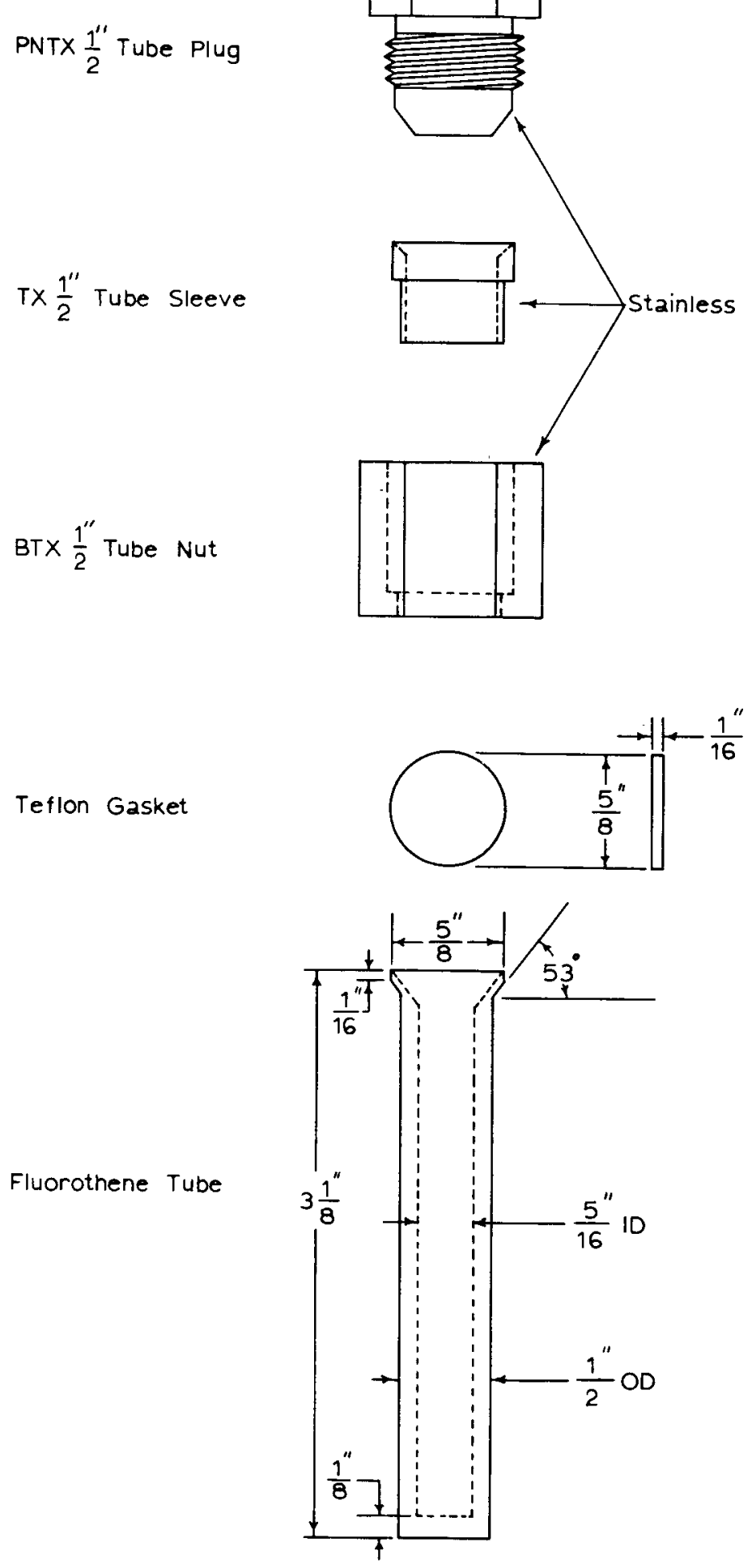

PNTX, TX, BTX-Parker,

Hannifin Parts Code

FIGURE 1. FLUOROTHENE (P-10) TUBE. 


\title{
A TENTATIVE METHOD FOR THE SPECTROCHEMICAL DETERMINATION OF MERCURY AND ARSENIC IN A SYNTHETIC ENVIRONMENTAL TEST MATERIAL
}

\author{
H. G. Yuster.
}

An environmental test material consisting of $70 \%$ silica, $20 \%$ ferric oxide, and $10 \%$ calcium carbonate containing various impurities at known levels was prepared at the New Brunswick Laboratory (NBL). This material was one of two test samples to be used in an interlaboratory evaluation program designed to test the reliability of activation procedures utilizing californium-252. To confirm the levels of the various impurities obtained by addition to the base material, a variety of methods was used to analyze the final mixture.

For the spectrochemical determination of mercury and arsenic, no standards were available. Attempts to prepare standards from the matrix material indicated that the mixing after the addition of mercury, arsenic and the proposed internal standard tellurium would be very tedious. The spiked powder balled up and tended to stick to the mortar tenaciously. Therefore, the standards were prepared in $\mathrm{U}_{3} \mathrm{O}_{8}$ which can be very smoothly homogenized after spiking. The final procedure involved the addition of the test material to $\mathrm{U}_{3} \mathrm{O}_{8}$ and comparing the data obtained with this mixture to that obtained with $\mathrm{U}_{3} \mathrm{O}_{8}$ standards, containing mercury, arsenic and tellurium, mixed with the blank matrix material. The boilercap technique was used for the spectral excitation.

\section{EXPER IMENTAL}

Reagents and Apparatus

All reagents are reagent-grade.

$\mathrm{U}_{3} \mathrm{O}_{8}$, high-purity

Vials, plexiglass, $1 / 2$ in. diameter by 1 in. long, with $3 / 8$ in. plastic bal1.

Mixer Mill, Wiggle-Bug, Spex Industries.

Spectrograph, Jarrell-Ash, $3.4 \mathrm{~m}$ Ebert, with a reciprocal. linear dispersion of $5 \AA / \mathrm{mm}$.

Densitometer. Jarrel-Ash Microphotometer.

Standards preparation. Prepare a solution of the internal standard tellurium by dissolving the metal in $1: 1 \mathrm{HCl}$ to obtain a concentration of $10 \mathrm{mg} / \mathrm{ml}$. Add $1.00 \mathrm{ml}$ of this solution to $10 \mathrm{~g}$ of $\mathrm{U}_{3} \mathrm{O}_{8}$ 
to give a $1000 \mathrm{ppm}$ concentration. Dry the mixture at $110^{\circ} \mathrm{C}$ for $1 \mathrm{hr}$. Grind and scrape down in an agate mortar in the usual way to obtain a well-homogenized mixture. To this mixture add appropriate aliquots of solutions of mercuric chloride and arsenious oxide, basing the calculation on the use of $20 \mathrm{mg}$ of base material to $980 \mathrm{~g}$ of the $\mathrm{U}_{3} \mathrm{O}_{8}$ to obtain the following concentrations in the final mixture:

\begin{tabular}{|c|c|c|}
\hline$\underline{\mathrm{Hg}}$ & As & $\mathrm{Te}$ \\
\hline 900 & 200 & 1000 \\
\hline 450 & 100 & 1000 \\
\hline 225 & 50 & 1000 \\
\hline 113 & 25 & 1000 \\
\hline 0 & 0 & 1000 \\
\hline
\end{tabular}

Dry and homogenize the $\mathrm{U}_{3} \mathrm{O}_{8}$ mixture in the usual way.

Sample preparation. Add $20 \mathrm{mg}$ of sample to $980 \mathrm{~g}$ of $\mathrm{U}_{3} \mathrm{O}_{8}$ in a plastic vial containing a plastic ball and mix in a Wiggle-Bug for $60 \mathrm{sec}$.

Analytical Conditions

$$
\begin{aligned}
\frac{\text { Source }}{\text { Gap }} & -4 \mathrm{~mm} \\
\frac{\text { Charge }}{\text { Electrodes }} & -200 \mathrm{mg} \text {, punched with venting tool } \\
& - \text { Lower ASTM S-2 } \\
& - \text { Pedestal ASTM S-1 } \\
& - \text { Boiler Cap UCC } \\
\text { Elexposure } & -30 \text { sec (no prearc) } \\
\frac{\text { Elates }}{\text { Explength }}- & -2200-3400 \AA \\
\frac{\text { Wavelen }}{\text { Processing }} & - \text { According to ASTM E115 recommendations } \\
\text { Analytica1 Lines } & - \text { Hg }-2536.52 \AA \\
& - \text { As }-2780.22 \AA \\
& - \text { Te }-2385.76 \AA \text { (Internal Standard for Hg) }
\end{aligned}
$$

\section{RESULTS AND DISCUSSION}

The results obtained with 3 replicate analyses on the test material as compared with the chemical analytical results and the quantities added are shown in Table I. Only the mercury line was densitometered. 
TABLE I

RESULTS OBTAINED ON THE PREPARED SOLID TEST MATERIAL
$\begin{array}{cccc}\text { Element } & \frac{4}{\text { Cound }} \begin{array}{c}\text { Concentration, ppm } \\ \text { (Average) }\end{array} & \text { (Chemica 1) }^{1} & \text { Added } \\ \text { Hg } & 670 & 560 & 573 \\ \text { As } & 50^{\mathrm{a}} & 35 & 37\end{array}$

a. Visual estimation.

The range of results on the mercury determination was about $5 \%$. These values are satisfactory considering the fact that the spectrochemical results were obtained chiefly to confirm the quantities of mercury and arsenic added. For routine use, additional work would probably be necessary to make the procedure more precise and accurate.

\section{REFERENCE}

1. Trahey, N. M., Scarborough, J. M. and Bodnar, L. Z., NBL-267 (September 1973), p. 56 . 


\section{BACKGROUND CORRECTION IN EMISSION SPECTROSCOPY}

H. G. Yuster

The correction of line intensity for background effects when photographic plates are used is often difficult. Slavin ${ }^{1}$ states that an exact correction is impossible. However, it is generally agreed that some form of background correction is desirable even when samples and standards are of similar composition.

Comprehensive discussions of background correction have been given by Ahrens, ${ }^{2}$ and by the American Society for Testing and Materials (ASTM) ${ }^{3}$ One method described involves taking the average of the corrections on both sides of the line. This method requires that readings be taken at equidistant points from the analytical line. Also, the assumption must be made that the monochromatic and continuous radiation, if both are present, have equal photographic response.

In the following mathematical treatment of background correction, densitometric measurements on both sides of the analytical line are considered. The basic equation in densitometry relates transmission $T$ to line density $D$ by the equation:

$$
\mathrm{D}=\log _{10} 100-\log _{10} \mathrm{~T}
$$

The density of an analytical line corrected for the average background density of both the right and left side can thus be expressed as :

$$
\mathrm{D}_{\mathrm{C}}=\mathrm{D}_{\mathrm{M}}-\left(\frac{\mathrm{D}_{\mathrm{R}}+\mathrm{D}_{\mathrm{L}}}{2}\right)
$$

where subscript $\mathrm{C}=$ corrected,

and $M=$ measured.

Combining equations (1) and (2) one obtains the relationship in terms of $\mathrm{T}$, the measurement obtained by a densitometer:

$$
\mathrm{T}_{\mathrm{C}}=\frac{100 \mathrm{~T}_{M}}{\left(\mathrm{~T}_{\mathrm{R}} \mathrm{T}_{\mathrm{L}}\right)^{1 / 2}}
$$

With the use of equation (3), per cent transmission measurements can be used to obtain easily a corrected $\mathrm{T}_{C}$ value for the determination of log relative intensity values in the plot of analytical curves. Previously, background and line per cent transmission values were converted to densities so that the correction could be made, and then the corrected density was converted back to $\mathrm{T}_{\mathrm{C}}$. 
To obtain more valid corrections it is desirable to use a step sector and choose transmission readings between 30 and 70 . A11 readings should be made in the same step.

\section{REFERENCES}

1. Slavin, M., "Emission Spectrochemical Analys is," Vol. 36 , Wiley-Interscience, New York, N.Y., (1971), pp. 196-197.

2. Ahrens, L. H. and Taylor, S. R., "Spectrochemical Analysis," 2nd Ed., Addison-Wesley Publishing Co., Inc., Reading, Mass., (1961), pp. 164-169.

3. "Methods of Emission Spectrochemical Analysis," 5 th Ed., Am. Soc. Testing Mat., Philadelphia, Pa., (1968), pp. 159-163. 


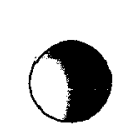

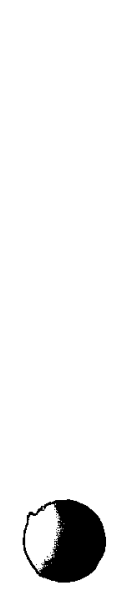

